University of Louisville

ThinkIR: The University of Louisville's Institutional Repository

Electronic Theses and Dissertations

$12-2009$

\title{
The leadership styles of social work educators.
}

Patricia Louise Desrosiers 1969-

University of Louisville

Follow this and additional works at: https://ir.library.louisville.edu/etd

\section{Recommended Citation}

Desrosiers, Patricia Louise 1969-, "The leadership styles of social work educators." (2009). Electronic Theses and Dissertations. Paper 339.

https://doi.org/10.18297/etd/339

This Doctoral Dissertation is brought to you for free and open access by ThinkIR: The University of Louisville's Institutional Repository. It has been accepted for inclusion in Electronic Theses and Dissertations by an authorized administrator of ThinkIR: The University of Louisville's Institutional Repository. This title appears here courtesy of the author, who has retained all other copyrights. For more information, please contact thinkir@louisville.edu. 
THE LEADERSHIP STYLES OF SOCIAL WORK EDUCATORS

\author{
by
}

Patricia Louise Desrosiers

B.A., Psychology, Kentucky Wesleyan College, 1991

M.S. W., University of Southern Indiana, 2001

\author{
A Dissertation \\ Submitted to the Faculty of the \\ Graduate School of the University of Louisville \\ in Partial Fulfillment of the Requirements \\ for the Degree of \\ Doctor of Philosophy \\ Kent School of Social Work \\ University of Louisville \\ Louisville, Kentucky \\ and \\ College of Social Work \\ University of Kentucky \\ Lexington, Kentucky
}

December 2009 
Copyright 2009 by Patricia L. Desrosiers

All rights reserved 
THE LEADERSHIP STYLES OF SOCIAL WORK EDUCATORS

by

Patricia Louise Desrosiers

B.A., Psychology, Kentucky Wesleyan College, 1991

M.S.W., University of Southern Indiana, 2001

A Dissertation Approved on

November 17,2009

By the followiag Dissertation Committee:

Thomas Lawson, Ph.D., Chair

Pamela Yankeelov, Ph.D.

Anlifa Barbee, Ph.D.

Jbseph Brown, Ph.D.

James Clark, Ph.D. 


\section{DEDICATION}

This dissertation is dedicated to God, my family, and my friends. God is always with me, and she has been instrumental in both beginning and completing this degree. It was God who allowed me to go forward with this course of education and gave me strength to continue along when life got difficult.

Most influential and helpful in my doctoral pursuits has been my mother, Sarah Stelmach. Throughout my life she has always been nurturing and supportive constantly telling and showing me that I could complete any goal I put my mind toward achieving. Without her my life would be drudgery; she reminds me to have fun. This dissertation is dedicated to her and to my children Jonathen and Naomi who patiently allowed "Mommy's research" to take place on days when they would rather have been enjoying a life balanced more toward their own wants and desires.

Finally, this dissertation is dedicated to my wonderfully supportive friends who never wavered for a moment in their belief that I would complete this monumental task. They were always there to offer support, advice, and a listening ear when needed. I hope they all feel as loved by me as I do by them. 


\section{ACKNOWLEDGMENTS}

The author wishes to acknowledge the support and patience of Tom Lawson, Ph.D., who through slow progress, life stress, and many concept papers saw this project through to the end. There were times when his dedication to my project must have waivered, but he never showed anything but support. Dr. Lawson's dedication to international social work is a true benefit to the field.

The author wishes to acknowledge all of the committee members: Anita Barbee, Ph.D.; Joseph Brown, Ph.D.; Pam Yankeelov, Ph.D.; and James Clark, Ph.D. for their substantial guidance and support during the production of this research. Without their critical insights, this work would not be as focused as it has become.

Acknowledgement must be made to Amy Cappiccie, Ph.D, and Elaine Wright, Ph.D., for passing along their wisdom and the wisdom of others as needed; to Ruth Huber, Ph.D., for her gentle strength and guidance toward the completion of this dissertation project; and to Molly Beth Kerby, Ph.D., for her extremely helpful insights into Feminist Theory which added a definite richness to this dissertation project. 


\section{ABSTRACT \\ THE LEADERSHIP STYLES OF SOCIAL WORK EDUCATORS}

Patricia L. Desrosiers

November 17, 2009

The purposes of this study are twofold: (1) to describe the leadership styles of social workers in educational administration and (2) to explain possible differences in leadership style by determining if context or gender or a combination of both factors influences style. This study will explore and describe the leadership styles of social work education administrators in the United States.

The research design was a cross-sectional survey design and utilized multiple methods, both qualitative and quantitative, to achieve its purposes. Leadership styles were explored primarily through the collection of quantitative data in the form of a scale: the MLQ 5x-Short (Avolio \& Bass, 2004). Specific qualitative data regarding personal views of the impact of context and gender on leadership style were gathered as well as quantitative scale data on the type of organization within which the respondent leads (Pawar \& Eastman, 1997) and demographic data. This research design utilized web based survey methods, specifically the Dillman Tailored Design Method for survey design (2007). Question Pro was the web survey host and software used in the data collection process. Data analysis was completed using univariate, bivariate, and multivariate statistical tests and SPSS data analysis software. 


\section{TABLE OF CONTENTS}

PAGE

DEDICATION

ACKNOWLEDGMENTS

ABSTRACT

LIST OF TABLES

LIST OF FIGURES

iii

iv

v

ix

$x$

PROBLEM STATEMENT

Historical View of Social Work Leadership 3

$\begin{array}{ll}\text { Gender Differences in Leadership Participation } & 7\end{array}$

Comparison with Academe in General $\quad 12$

$\begin{array}{ll}\text { Leadership Style Types } & 14\end{array}$

$\begin{array}{ll}\text { Gender Differences in Leadership Style } & 16\end{array}$

$\begin{array}{ll}\text { Effectiveness of Various Leadership Styles } & 16\end{array}$

$\begin{array}{ll}\text { Relevance of Topic to the Profession } & 17\end{array}$

$\begin{array}{lr}\text { Research Questions } & 18\end{array}$

$\begin{array}{ll}\text { REVIEW OF THE LITERATURE } & 20\end{array}$

$\begin{array}{ll}\text { Concepts } & 20\end{array}$

$\begin{array}{lr}\text { Leadership } & 20\end{array}$

$\begin{array}{ll}\text { Leader } & 22\end{array}$

$\begin{array}{ll}\text { Context } & 23\end{array}$

Development of Leadership Theory $\quad 25$

“Great Man" Leadership Theory 25

Behavioral/Transactional Leadership Theory $\quad 26$

$\begin{array}{ll}\text { Situational and Contingency Theories } & 26\end{array}$

$\begin{array}{ll}\text { Transforming versus Transformational Leadership Theory } & 27\end{array}$

$\begin{array}{ll}\text { Feminist Leadership Theory Overview } & 28\end{array}$ 
Leadership Style Types

Lassiez Faire

Transactional

Transformational

Gender Differences in Leadership Style

In Other Professions

In Social Work

Effectiveness of Leadership Styles

Conclusion

METHODOLOGY

Research Design

Sampling and Data Collection Procedures

Sampling Design

Internet Based Research

Tailored Design Method

Data Collection

Subject Recruitment

Data Collection Tools

Protection of Human Subjects

Institutional Review Board

Variables Operationalized

Leadership Style and the MLQ 5x-Short

Validity of the MLQ 5x-Short

Test Retest Reliability

Gender

Organizational Culture

Statistical Analyses 
Study Hypotheses $\quad 59$

$\begin{array}{ll}\text { Conclusion } & 60\end{array}$

DATA COLLECTION AND ANALYSIS

$\begin{array}{ll}\text { Difficulties Obtaining Data } & 61\end{array}$

Methodological Changes $\quad 62$

Respondent Demographics $\quad 62$

$\begin{array}{lr}\text { College/University Demographics } & 67\end{array}$

MLQ 5x-Short Findings

Analyses of MLQ 5x-Short Data

$\begin{array}{ll}\text { Comparison of Group Views on Leadership Styles } & 83\end{array}$

$\begin{array}{ll}\text { Hypothesis } 1 & 84\end{array}$

Hypothesis $2 \quad 86$

$\begin{array}{lc}\text { Context } & 88\end{array}$

$\begin{array}{lr}\text { College/University Factors } & \mathbf{8 8}\end{array}$

$\begin{array}{lr}\text { Individual Program Factors } & 90\end{array}$

$\begin{array}{lc}\text { ROLE Instrument } & 93\end{array}$

$\begin{array}{lc}\text { Hypothesis } 3 & 93\end{array}$

Hypothesis 4

$\begin{array}{lr}\text { Hypothesis } 5 & 96\end{array}$

$\begin{array}{ll}\text { DISCUSSION } & 97\end{array}$

Review of the Issues Under Study $\quad 97$

Research Question 1: Styles of Social Work Leadership 97

Research Question 2: Gender and Social Work Leadership $\quad 100$

Research Question 3: Context and Social Work Leadership Style 101

Research Question 4: Effectiveness and Social Work Leadership 103

$\begin{array}{ll}\text { Implications for Social Work Practice } & 104\end{array}$

$\begin{array}{ll}\text { Practice Recommendations } & 104\end{array}$ 
$\begin{array}{ll}\text { Training Recommendations } & 106\end{array}$

$\begin{array}{ll}\text { Recommendations for Future Research } & 109\end{array}$

Increase knowledge about social work leadership best practices $\quad 109$

Explore how social work equalizes gender $\quad 110$

$\begin{array}{ll}\text { Need BSW level research } & 111\end{array}$

Need for contextual exploration $\quad 111$

$\begin{array}{ll}\text { Summary } & 112\end{array}$

$\begin{array}{ll}\text { REFERENCES } & 115\end{array}$

APPENDIX A: Introductory Leader Subject Recruitment Letter \#1 125

APPENDIX B: Leader Subject Recruitment Letter \#2 126

APPENDIX C: Leader Subject Recruitment Letter \#3 127

APPENDIX D: Leader Subject Recruitment Letter \#4 128

APPENDIX E: Leader Subject Recruitment Letter \#5 129

APPENDIX F: President Alberto Godenzi Support Letter 130

APPENDIX G: Dean Terry Singer Support Letter $\quad 131$

APPENDIX H: Rater Subject Recruitment Letter \#1 132

APPENDIX I: Rater Subject Recruitment Letter \#2

APPENDIX J: Rater Subject Recruitment Letter \#3

APPENDIX K: Rater Subject Recruitment Letter \#4

APPENDIX L: Rater Subject Recruitment Letter \#5

APPENDIX M: Leader and Rater Preambles $\quad 137$

APPENDIX N: Demographic and Open-ended Questions for Leaders 140

APPENDIX O: MLQ 5X - Short Leader Form Sample Items 142

APPENDIX P: MLQ 5X - Short Rater Form Sample Items 143

APPENDIX Q: Demographic and Open-ended Questions for Raters 144

APPENDIX R: ROLE Scale Sample Items $\quad 145$

APPENDIX S: IRB APPROVAL EMAIL $\quad 146$

APPENDIX T: Permission to Use MLQ 5x-Short 147 


\section{LIST OF TABLES}

TABLE

PAGE

1. Social Work Elements of Leadership and 'Transformational Factors 35

$\begin{array}{lll}\text { 2. Research Purposes and Methods to Achieve Objectives } & 48\end{array}$

3. Dillman's Methods for Obtaining Improved Survey Response 51

$\begin{array}{lll}\text { 4. Analysis of Research Questions } & 63\end{array}$

$\begin{array}{lll}\text { 5. } & \text { Missing Data for the MLQ-5x short scales } & 68\end{array}$

$\begin{array}{ll}\text { 6. MLQ 5x-Short form scale scores with means and SDs. } & 71\end{array}$

7. Passive Avoidant Groups by Transformational Groups Crosstabulation 85

8. Gender and Transformational Leadership ANOVAs from the Combined Group 86 Perspective

9. Gender and Transformational Leadership ANOVAs from the Leader Only $\quad 87$ Perspective

10. Gender and Transformational Leadership ANOVAs from the Employee Only Perspective

12. Impact on leadership style response rate by frequency and percentage 90

13. Correlations between organizational context variables and transformational 94 leadership $(n=15)$

14. Two-way ANOVA summary table 


\section{LIST OF FIGURES}

FIGURE

PAGE

1. Disciplines of deans, directors, and chairs by percentage 64

$\begin{array}{lll}2 . & \text { Deans, directors, and chairs by age } & 65\end{array}$

3. Employees by age $\quad 66$

4. Transformational leadership (combined) scales comparing social work leader $\quad 69$ scores to national norms

5. Individualized influence (attributed) scale comparing social work leader scores 70 and national norms

6. Individualized influence (behavior) scale comparing social work leaders to national norms

7. Inspirational motivation scale comparing social work leader scores to national norms.

8. Intellectual stimulation scale comparing social work leader scores with national norms

9. Individual consideration scale comparing social work leaders to national norms

10. Transactional leadership scale comparing social work leader scores to national norms

11. Contingent reward scale comparing social work leader scores to national norms

12. Management by Exception (Active) scale comparing social work leader scores to national norms

13. Passive/Avoidant leadership scale comparing social work leader scores to national norms

14. Management-by-exception (passive) subscale comparing social work leader scores to national norms

15. Laissez-faire scale comparing social work leader scores to national norms

16. Extra effort scale comparing social work leader scores to national norms

17. Effectiveness scale comparing social work leader scores to national norms

18. Satisfaction scale comparing social work leader scores to national norms 
19. Comparison of group views on leadership styles.

20. Transformational leadership scores by gender differentiated by raters and leaders 


\section{CHAPTER I \\ PROBLEM STATEMENT}

Social workers come from a variety of backgrounds and practice in a variety of settings. Professionally, it has become evident that these disparate contexts can and do lead to differing levels of personal growth and development. Social work is a profession devoted to furthering social justice by decreasing oppression. It would be logical to conclude that leadership with the goals of encouraging individuals to reach their highest potentials and creating less oppressive organizations and societies would be the primary type practiced. Democratic leadership would also be a focus in order to empower others and to make sure that all voices are at the planning table.

Social work education takes place within college and university systems that while proclaiming to be democratic in their leadership practices are often far from that ideal in actual practice. Discrimination is widespread in these institutions as evidenced by the lack of female leaders and administrators (Alpert, 1989; Austin, 1995; Scanlon, 1997), unequal pay for the same work (Alpert, 1989; Young \& Brown, 1996), and fewer female than male professors at all levels (Alpert, 1989; DiPalma, 2005; Glazer-Raymo, 1999) indicating the ineffectiveness of affirmative action policies put in place over 30 years ago to protect and empower women and minorities in the higher education systems (Glazer-Raymo, 1999).

While many colleges and universities have developed their own commissions or diversity officers to make sure diversity goals are met, these commissions have not served their purpose (Glazer-Raymo, 1999). Even when the commissions have successfully documented problems and suggested solutions, higher education has been unable or unwilling to support and implement changes that would improve the outlook for women and minorities. For example, despite specific recommended changes made by the President's Commission on Women in 1971 and again in 1977 that would have made Ohio State University's environment less discriminatory 
against women, a 1991 report found that little had changed. The 1991 report characterized the campus climate as hostile towards women (particularly minority women) with little accountability for ineffective affirmative action policies, sexist attitudes and harassment, and other institutionally condoned behaviors that minimized women's participation in university life (Glazer-Raymo, 1999).

In fact, the Equal Employment Opportunity Commission (EEOC) has continued to be inundated with thousands of reports charging higher education systems with sex, race and ethnic, and religious discrimination each year (Glazer-Raymo, 1999). Many of these reports have gone uninvestigated or been poorly investigated due to the sheer number of complaints relative to an inadequate number of investigators. In addition, the legal system has been unable or unwilling to support federal equal opportunity legislation with a hands-off approach to cases involving academic tenure, hiring, and admission decisions (Glazer-Raymo, 1999).

\section{Social work education and leadership style}

So how do social work educators provide effective leadership in a higher education environment where subtle forms of discrimination are continuing to oppress women, minorities, and other specific groups of people? Social work is a profession dedicated to improving the situation of oppressed populations, so it would be important for social work to begin with their own profession. Austin (1995) called gender and ethnic diversity in management (including educational management) a "particularly serious issue for social work because of the organized profession's strong commitment to the principles of nondiscrimination and equal access to opportunity." (p.1653). Social work departments are often considered "lower status" than other professional departments in higher education (Videka-Sherman, Allen-Meares, Yegidis, \& Yu, 1995) which may be a direct correlate to the diversity of social work departments, however, it is important to determine what leadership styles are predominate as a starting point to self examination of the profession.

A transformational leadership style is more conducive to empowerment of individuals and groups (Bass \& Riggio, 2006). The father of transformational leadership, James Burns (1978), called his new type of leadership "Transforming Leadership" because of its result "a relationship of mutual stimulation and elevation that converts followers into leaders" (p.4). With an emphasis 
on empowering individuals to reach their full potential while at the same time meeting corporate objectives (Kark, Shamir, \& Chen, 2003), transformational leadership is a powerful leadership style that, when used in an ethical manner, can lead to collective empowerment, as well (Jung \& Sosik, 2002).

What types of leadership styles have social work educators implemented in the higher education environment? While leadership style is an important part of the leadership literature, there is very little research on the leadership styles of social workers, in general (Gellis, 2001; Mary, 2005; Mizrahi \& Berger, 2001). This study seeks to expand that literature. Leadership style will be examined as one way to assess the nature of social work educational leadership being practiced in United States higher education at the current time.

\section{Historical View of Social Work Leadership}

Austin (1995) describes the early history of social work as influenced heavily by wealthy businesspeople particularly wealthy college educated women who created, organized, and successfully administrated charity agencies and settlement houses with a "highly personalized" leadership style (p.1643). The success of these early organizations influenced the development of governmental and political programs and social services agencies with leaders such as Jane Addams and Julia Lathrop from the Hull House earning presidential support including federal administrative positions "with responsibility for social welfare issues".(Austin, 1995, p.1643).

The early $20^{\text {th }}$ century led to the development of larger organizational responsibilities for professional social workers (Austin, 1995). Social workers became increasingly managerial in their leadership focus and created many national associations at this time which were disbanded in the 1950 s. Social workers were more likely to manage by transactional methods, such as the social casework method with employees given expectations to meet in order to continue employment with little emphasis on personal growth, while boards of directors struggled with the authority of the board versus the authority of the executives. Growth of social services programs through increased federal funding occurred throughout the early and mid $20^{\text {th }}$ century, however, in the 1960 s and throughout the late $20^{\text {th }}$ century there was an increase in "community-based" programs that were intended to be led with a less bureaucratic structure involving consumers in 
decision making procedures very similar to transformational leadership practices described later in this section (Austin, 1995).

Despite ongoing questions regarding the appropriateness of administration as a field of practice for social workers, there has been continued participation in administration in human services organizations, higher education, and governmental programs and organizations (Austin, 1995). Developed in the late 1940 s as a secondary practice method for social work, administration (in addition to research) has been viewed as supplemental to the basic skills of caseworker, group facilitator, or community organizer (Morales \& Sheafor, 1998).

This study focuses on higher education administration where social work leadership is taking place. The literature indeed has focused on the examination of deans as a way to assess the nature of leadership in social work. Even as Rank and Hutchinson (2000) surveyed social work leaders in a more general way, they chose deans who were members of the Council on Social Work Education (CSWE) and presidents and executive directors who were members of the National Association of Social Workers (NASW) leaving out all other leaders that may exist in the social work profession (leaders in community organizing and in fields outside of social work such as Domestic violence, child welfare, etc.). Since the literature focuses on dean research, so will this next section.

\section{Deans as social work leaders}

As early as 1979 , Gandy, Randolph, and Raymond identified that fully one-third of social work deans reported practicing democratic leadership with authority shared among many, onefourth reporting authority was spread among the faculty, and slightly more than one-third reporting that authority rested with the dean. In their study, $98 \%$ of the deans felt that the faculties were loyal to the dean indicating great teamwork was ongoing. Deans also reported allowing or encouraging faculty conflict as healthy to the development of their programs, however, these same deans ( $29 \%$ of them) felt that faculty problems such as rivalry, dissension, resistance to change, and incompetent faculty were the second largest problem they faced as deans, second only to financial/budgetary difficulties (Gandy et al., 1979). 
At the time of Gandy et al.'s (1979) research short terms for deanships were the norm, and a management focus was evident. In fact, organizing, staffing, and financial management were three 'management areas' that were troublesome for their social work deans (Gandy et al., 1979). Many deans mentioned the importance of leadership; they also reported being ill prepared to deal with the day to day relationships with faculty that could sometimes be unpleasant. Their college's relationship to the larger university was often viewed as oppressive. The lack of leadership preparation and the lack of opportunity for external professional activities (which could have been satisfying enough to make up for a lack of personal fulfillment derived from their post as a dean) were cited as definite downsides to the deanship. Many deans reported feeling as if they were given power in name only often having to deal with 'invisible' leaders or leadership groups operating beneath the radar in opposition to the dean or other groups (Gandy et al., 1979). These are all examples of the subtle forms of discrimination that are ongoing in the higher education systems (Glazer-Raymo, 1999).

Of course, it is important to remember that only $17 \%$ of the Gandy et al. sample was female (1979). The same study completed today with about $36 \%$ female deans will possibly describe a different set of problems. Videka-Sherman, Allen-Meares, Yegidis, and Yu (1995) did base their 1993 survey instrument on the Gandy et al. (1979) study instrument with extensive modification. Describing current academic institutions as "unlike other large organizations in that they are governed by faculty in a collegial model rather than by administrative program heads in a bureaucratic fashion" (p.12), Videka-Sherman et al. (1995) implies shared or democratic leadership practice which is partially confirmed by the distribution of authority within programs table (Table 1.11, p.13). However, two areas: a) faculty salary increases and b) budgets are primarily controlled by the dean in $55 \%$ and $90 \%$ of schools respectively. This implies that the money is still primarily controlled by the deans and is further demonstrated in an increased emphasis on fundraising through external research grants and alumni organizations (external relations) as a growing role for deans. This research also uncovered significant changes in the titles of social work department heads due to organizational restructuring. Many social work colleges are being subsumed under other graduate program groupings (ie. "Colleges of Human 
Services", or "Colleges of Public Policy") leading to title changes from dean to director or chair and a subsequent pay reduction of approximately $\$ 30,000$ per year (Videka-Sherman et al., 1995).

These changes will have a significant impact on the social work profession as its stature within the university dwindles and resources are diverted to other higher-status professions such as medicine and law (Videka-Sherman etal., 1995). Moses Newsome, Jr., (1995) president of the Council on Social Work Education (CSWE) at the time, named developing effective leaders within the profession as a top priority. Without effective social work leaders coming to the "bargaining table where research and training priorities are identified and social policies are developed", social work outcomes would likely be absent (Newsome, 1995). Newsome also proposed increased training and increased professional leadership development with students through mentoring and professional socialization as one way to achieve this aim. This imperative is particularly poignant in respect to the prior Videka-Sherman et al. findings that the status of social work departments within higher education is dwindling. Videka-Sherman et al. believe that this can be overcome with strong leadership in professional social work schools.

The recently conceived Social Work Reinvestment Initiative (NASW, 2007) is one effort instituted by social work leaders to promote and to prioritize social work practice by increasing governmental funding and legislative support of the profession (NASW, 2008). The introduction of the "Dorothy Height/Whitney Young Social Work Reinvestment Act" in 2008 will serve several purposes, for example increasing awareness of social work workforce shortages and the concordant negative impacts on communities. This act will also attempt to demonstrate statistically to overwhelming need for reinvestment in the social work profession and garner government funding for education and research specific to the social work profession (NASW, 2008). This type of action oriented coalition utilizing multiple social work networks and organizations can only take place with firm coordinated leadership efforts.

Fagin (1997) writes of deanship roles such as building a network of support in the community at large and in the university community, developing and implementing departmental 
strategies as a group, and 'being the person in the middle'. In fact, Fagin (1997) clearly demonstrates the perception of a female dean stating:

I have defined my role as providing leadership to the members of the school so that the mission of the school can be accomplished. I see my major function as developing leadership in others... This function can only be done when leadership is democratic rather than autocratic and where those involved in carrying out the decisions are part of the decision-making process (p.99).

This quote demonstrates the changing role of dean from a female perspective, and is consistent with Rank and Hutchinson's predictions for the future needs of social work leadership (2000). Rank and Hutchinson (2000) point to a future where strong leadership in social work would include roles such as proactively using collaborative skills to engage social workers and policy makers from diverse backgrounds to advance social work values. These views on leadership are very consistent with the transformational leadership style which will be discussed later.

Historically, social work leadership studies have focused on deans, however, there is a growing awareness within the profession that others can and do provide leadership. Rank and Hutchinson (2000) developed a definition of social work leadership based on dean members of CSWE and presidents of NASW. Mary (2005) examined the leadership styles of social workers in a variety of organizational settings including but not limited to educational settings. Gellis (2003) surveyed 234 social workers in urban hospital settings, both academic teaching and community hospitals. Mizrahi and Berger (2001) surveyed social work directors in hospital settings about the challenges and progress due to their leadership in their particular workplaces. With a growing awareness of the importance of leadership styles of all social workers, this study will examine the leadership style of social work educators in a variety of leadership positions and contexts.

\section{Gender Differences in Social Work Leadership Participation}

Articles and books related to the historical significance of women leaders in social work were found. In fact, Rank and Hutchinson's (2000) research determined that one hundred fifty social work leaders declared four females out of five leaders (Jane Addams, Mary Richmond, Jeanette Rankin, Bertha C. Reynolds, and Whitney Young) to be the most influential past leaders 
of the social work profession. Austin (1995) depicts an early social work history replete with female leaders receiving recognition on multiple levels in response to their successful social initiatives and programs. Austin (1997) calls social work "distinctive among major professions in that the majority of practitioners are women and the majority of leadership positions in the profession are increasingly being held by women while there continues to be substantial participation by men" (p.404). Brilliant (1986) lists at least five female social work leaders as influential in the development of the social work profession. Bentley, Hutchison, and Green (1994) reported that 26 females and 19 males were cited as influential to the social work professionals (identified as the top $5 \%$ in scholarly productivity) of their study.

As these articles demonstrate a very competent and influential group of women has existed in the social work profession in all areas. These past female social work role models may still be instrumental today in the promotion of women to leadership positions, however, according to the facts and figures, women continue to be passed over for leadership positions on all levels.

The Council on Social Work Education (CSWE) surveyed all the social work schools in the United States, and the results are compiled in their document Statistics on Social Work Education in the United States: 2002 (Lennon, 2004). According to this document, between 1998 and 2002 women accounted for between 70 to $74 \%$ of the total doctoral degrees awarded (Lennon, 2002). In fact, women received around $88.3 \%$ of the Baccalaureate degrees and $86.6 \%$ of the Master's degrees awarded in 2001-2002, a figure 17\% higher than that of the doctoral programs (Lennon, 2004). This means that along the educational path women get lost.

Even as women are earning continually more Ph.D.s they continue to be disproportionately over represented in non-tenure track positions (Benjamin, 1999). Progress for women social work faculty has occurred with women earning full professorships and tenured associate professorships at increasing rates during a time frame of 1974 to 2000 (DiPalma, 2005). Despite women's lower representation at the rank of full professor (an increase from $10 \%$ in 1974 to $20 \%$ in 1998) and in research intensive universities (an increase from $9 \%$ in 1989 to $15 \%$ of full professors in 1998), the numbers are increasing with women currently holding $45 \%$ of all full professorships in social work in 2002 (Lennon, 2004). Comparatively, men who hold $25 \%$ 
of all social work professorships hold $55 \%$ of all full professorships in social work education (Lennon, 2002).

Some possible explanations for the success of women in social work faculty (relative to other university departments such as medicine and engineering) include the critical mass of women in leadership positions, the values base of the profession making it easier to promote women, the low status of the profession, and CSWE's creation of a monitoring board called the Commission on the Role and Status of Women (DiPalma, 2005). York, Henley, and Gamble's (1988) study of social work students found support for some strategies to increase the female student's career interest in social work administration. These included consciousness-raising activities designed to make explicit the relationship between sex role stereotypes/socialization and career choice, encouragement by mentors, and training on women in social work administration (York et al., 1988). Leadership training and practice were not mentioned in this group of activities, but would most likely be helpful. Perhaps these study results have influenced the choices of females to enter social work administration.

As early as 1976, multiple factors impeding women's progress into social work administration were identified (Fanshel, 1976) including lack of mentoring, lack of support at home, and lack of role models (although lack of female role models has previously here been shown to be only a mild problem). This list could also include lack of institutional support (Marshall, 1993). This list is not that different from the list of impediments to all women academics that includes (1) role conflict, (2) insecurity of position, (3) lack of self confidence, (4) unwritten rules including double standards for men and women, (5) "maleness" of the environment (6) disproportionately more teaching responsibilities, (7) more family related responsibilities, (8) less money, (9) less prestige (Caplan, 1995).

Marshall (1993) reports that women educational administrators "learned to downplay isolation and sexism" in order to fit in to their school cultures and often "keep quiet to avoid embarrassing confrontations and situations that emanate from being different" (p. 173). According to Marshall, these same women are affected in that they have to do extra work to increase the comfort levels of those around them and prove they deserve to be there when for men this is just 
assumed to be an appropriate place. This fits with Bentley et al.'s (1994) finding that a group of successful women social work scholars reported less support from colleagues than a comparable group of successful male social work scholars.

Following congressional passage of Title IX of the Education Amendments of 1972 outlawing sex discrimination in colleges and universities receiving federal funds, a plethora of sexual harassment and sexual discrimination lawsuits against colleges and universities in the past 30 years has demonstrated the pervasive nature of discrimination (Petchers, 1996). Despite wide use to force equality (with judicial support) in the number of women's sports programs in colleges and universities, there has been little judicial support for female educators that have been discriminated against (Glazer-Raymo, 1999).

It wasn't until 1990 with the U.S. Supreme Court's decision in University of Pennsy/vania v. Equal Employment Opportunity Commission that university peer-review decisions and files regarding tenure were forced open for inspection by regulatory agencies and the courts in order to assess charges of discrimination (Petchers, 1996). Prior to that decision, colleges and universities had been able to suppress evidence of sex discrimination in tenure decisions by invoking the right to academic freedom leaving little recourse for women who had been actively discriminated against in the tenure process (Glazer-Raymo, 1999). According to Lanou and Lee (1987) as cited in Glazer-Raymo (1999), of 300 cases of academic litigation only about 20 percent of cases were decided on academic merit, with the rest of the decisions being based on procedural or jurisdictional grounds. Women won only 9 of 116 cases that were decided on merit. Interestingly, whether plaintiffs' win or lose discrimination lawsuits against universities, they often face retaliation at their current and future jobs. Just bringing a lawsuit is usually the end of the plaintiff's career in addition to negatively impacting finances and personal and family relationships (Glazer-Raymo, 1999). This type of nonsupport from the judiciary certainly discourages the use of this type of recourse when seeking remedies to discriminatory university practices.

In addition to Fanshel (1976), Scanlon (1997) asserts that women rarely use the informal mentoring system which could make a "critical difference" in a career, while Hubbard and Robinson (1998) reported that female administrators were more likely to use mentors than male 
administrators and were more likely to have used them to obtain their current position. Scanlon (1997) also found that "when compared to women who have not been mentored, women who have had mentors attained higher levels of career development" (p. 47). Of course, mentoring is an institutional barrier combined with a cultural one. There are social and cultural proscriptions against cross-gendered mentoring, and there are not enough women to mentor all the new women due to lack of adequate numbers of female leaders. Bentley et al. (1994) found that among social work researchers, women are much more likely to report having no same-sex mentor $(41.4 \%$ vs. $5.3 \%)$ while the women were less likely to have not mentored a person of the same gender than men (2.4\% vs. $15.9 \%)$. The fact that women rarely use mentors may be a problem of lack of institutional support and institutional discrimination, not a personal choice or preference. In fact, women scholars are often blamed for the lack of gender equity in higher education when in fact societal, cultural, and organizational barriers are present (DiPalma, 2005; Glazer-Raymo, 1999; Petchers, 1996).

Lack of support at home is common problem (Fanschel, 1976) often overlooked by male administrators in higher education (Kimball, Watson, Kanning, \& Brady, 2001) simply due to differing life views. Kimball et al. (2001) interviewed female psychology professors who were mothers and determined that women often choose based on societal and personal ideals to work at lower status jobs within higher education in order to balance their home and work life more equitably. Women are at times making choices that are bad for their career due to "mommy guilt" and the lack of awareness at their workplace that child care responsibilities impact a mother's professional choices. For example, if the faculty meeting is at $4: 30$ and a faculty member who is a mother needs to pick up her child by 5:00 those two responsibilities are conflicting. When approached about the problematic nature of this meeting time, one male dean reported that his wife stayed home with their children so he never thought about it being a problem. These same parenting responsibilities impact research productivity, committee membership acceptance, and other aspects of academic life important for tenure. Of course, saying that faculty members who are mothers are making a "choice" to be less focused on career or work only at teaching universities (Schneider, 2000) would be fine if the choices applied equally as often to faculty 
members who were fathers. For whatever reasons, fathers take less responsibility for parenting and are less likely to feel guilty about their participation in career activities. Alternatively, in their survey of social work scholars, Bentley et al. (1994) found no reported differences in the career support level of family members. It is noteworthy that their sample included the top $5 \%$ of scholarly productive social work researchers; it is possible they receive more support from their spouses leading to more productive careers.

Petchers (1996) looked at progress for women social work educators determining that it is more likely institutional, societal, and cultural barriers that create the "glass ceiling" (the barrier to higher leadership positions) in universities. Petchers believes that in order to achieve gender equity, the easiest and most helpful changes should occur in the university institutions (1996). Advocating such strategies as tracking success of women, setting goals for proportionate representation of women faculty at all ranks, and supporting access and usage of grievance procedures, Petchers (1996) is very clear on the organizational steps that can be taken to improve the status of women in the universities.

Bentley et al. (1994) looked at the top $5 \%$ of women social work scholars and found that their professional time was very similar to comparable men with women spending slightly more than one third of their time in research while men spent about one fourth. Contrary to prior research (Sowers-Hoag \& Harrison, 1991), no differences in men's and women's distribution of professional time across clinical practice, teaching, and administration were found. Again, this could be a result of this particular sample of successful women scholars where such impediments were not present thereby increasing success levels. Bentley et al. (1994) did find that despite their outstanding achievements in social work research, the women in their sample rated themselves lower in research abilities and their abilities in teaching statistics.

With multiple organizational, societal, and cultural barriers it is somewhat amazing that women are making any progress toward leadership in social work education. Women in social work have the luxury of increasing their leadership numbers fairly dramatically when compared to other academic departments. The next section provides details for these gender discrepancies.

\section{Comparison with Academe in General}


Glazer-Raymo (1999) discusses gender inequality in academe at length, citing multiple "cultural, attitudinal, and structural constraints" as impacting the current state of affairs. By 1994 although women accounted for $38.7 \%$ of all faculty, less than two-fifths of them enjoyed full-time, tenure-track status with the other three-fifths holding part-time adjunct and non-tenure-track term appointments. In the fall of 1993 , women held $20 \%$ of all full-time faculty positions in United States universities (Glazer-Raymo, 1999). In social work, $45 \%$ of all full professorships were held by women in 1998 compared to the national average of $23 \%$ across all disciplines (DiPalma, 2005). Lennon (2004) found that in social work $45 \%$ of all full-time professorships are still held by women in 2002 four years later. This is in contrast to the $69 \%$ of women holding assistant professorships and the $63 \%$ of women holding associate professorships (Lennon, 2004). There is a leaky pipe at the top of the academic pipeline.

Scanlon (1997) depicts social work as one of the "predictable departments" along with nursing where women are predominantly working as academic administration specialists. Scanlon goes on to say the following:

When compared to men, the adjective less continues to describe the position and placement of women in the field of higher education administration-less representation, less power, less prestige. (p. 40)

This bodes well for social work where the professional roles are gender-role congruent, but not as well for differently situated professions.

Alpert (1987) looked at gender inequality in academic administration in general finding "it will take women about 90 years to be equally represented in the academic ranks at category I institutions" (p.12) where women were the least represented. Glazer-Raymo (1999) found that the higher status schools and departments had the lowest numbers of tenured professors and female administrators with women making less money at every level. DiPalma and Topper (2001) found little difference in academic rank of social work professors in the various types of institutions. DiPalma and Topper (2001) found that social work allows more women into academic leadership than other professions with women accounting for $57 \%$ (up from $43.4 \%$ in 1985) of accredited 
BSW program directors and $44.7 \%$ (up from $29.3 \%$ in 1985) of MSW Deans or Chairs of accredited MSW programs in 1996.

Although not proportionally commiserate with the gender make up of the social work profession, a higher than average female participation rate in social work educational leadership (DiPalma, 2005) indicates the accepted leadership style in social work is more female friendly. It is important to determine which leadership style is predominate in order to share that knowledge with other professional departments in the higher education system in order that they may benefit from this knowledge, as well. It is possible that any differences in leadership style of the profession as a whole may be attributable to the higher than average numbers of women in leadership positions, therefore, gender is one variable that will be explored in this study.

\section{Leadership Style Types}

There are many ways to study leadership style. Fiedler, Chemers, and Mahar (1977) developed contingency theory where leadership style is defined as a stable personality characteristic that after taking into account many other factors such as context to produce a leadership act. Over time many types of leadership styles have been identified including participative, autocratic, consideration, democratic, directive, relations-oriented, task oriented and charismatic (Conger, 1999; Burns, 2003). Over the decades each leadership style and their corresponding theories have had a significant amount of research. (Bass, 1990). More recently developed leadership styles include transforming (Burns, 1978), transformational, transactional, laissez faire (Avolio \& Bass, 2004), and feminist (Chin, 2004). These types are the focus of this research and will be briefly defined here. Concurrent sections in the literature review provide detailed information concerning each type.

Burns (1978) transforming leadership was the first to be developed and is described as follows:

The transforming leader recognizes and exploits an existing need or demand of a potential follower. But, beyond that, the transforming leader looks for potential motives in followers, seeks to satisfy higher needs, and engages the full person of the follower. The 
result of transforming leadership is a relationship of mutual stimulation and elevation that converts followers and may convert leaders into moral agents. (p.4)

Burns (1978) goes on to describe a concept of 'moral leadership' where leaders and followers share power including followers' awareness of alternative leaders and where leaders take full responsibility for their promises. Bass and Avolio (1989) developed their full range of leadership model with Burns' transforming leadership as a basis; however, they altered the definition somewhat over time.

Avolio and Bass (2004) outline the full range of leadership model with definitions for transformational, transactional, and laissez faire leadership and their related scales as defined for the MLQ (Form 5x-Short). Transformational leadership is defined as follows:

a process of influencing in which leaders change their associates' awareness of what is important, and move them to see themselves and the opportunities and challenges of their environment in a new way (Avolio \& Bass, 2004, p.96).

They go on to describe a proactive and influential person with high moral and ethical standards who positively empowers others to achieve high levels of performance. Mary (2005) states that this definition is congruent with the definition of social work leadership developed by Rank \& Hutchinson (2000).

Transactional leaders are those who practice constructive and corrective styles of leadership where leading others entails doling out rewards and punishments in an effort to encourage acceptable performance of followers (Avolio \& Bass, 2004). Laissez-faire leaders are characterized by avoidance and refusal to take responsibility for making decisions when needed (Avolio \& Bass, 2004).

The last type described here will be the feminist leadership style (Chin, 2004). Chin describes feminist leadership styles as having the achievement of feminist principles as a goal, and as being based on collaborative and egalitarian leadership behaviors. Feminist leaders "examine the power structures inherent in leadership" (p.4) and the process of utilizing collaborative process in these "hierarchical structures and masculinized contexts" (p.4) in the hope of adapting their style to effectively deal with barriers to women's and other's participation in 
decision making processes (Chin, 2004). This style is congruent with a transformational leadership style with the added specific moral imperative that feminist principles be advanced. In examining transformational leadership, a look at the feminist leadership style will also occur.

\section{Gender Differences in Leadership Style}

Despite ambiguous evidence in the research on leadership style (Bass, 1990; Eagley, Karau, \& Makhijani, 1995; Maher, 1997; Young, 2004), differences in leadership style based on gender have been found. Women tend to use a transformational leadership style that is closely aligned to their female gender role (Bass et al., 1996; Eagly et al., 2003; Eagly et al., 1995;

Helgesen, 1990; Rosener, 1990; vanEngen \& Willemson, 2004). These differences are heightened when people, both males and females, are in a job not congruent with their particular gender role (vanEngen \& Willemson, 2004). This means that in a job such as social worker educator where almost equal numbers of employees are female, higher transformational leadership ratings would be unusual. However, based on prior research women should be rated higher on transformational leadership behaviors.

There are very few studies of gender differences in leadership style within specific professions (Carless, 1998; Druskat, 1994; Havens \& Healy, 1991; Rutherford, 2001; vanEngen \& Willemson, 2004), and only three were found addressing this issue in social work (Gellis, 2001; Mary, 2005; Mizrahi \& Berger, 2001). Only two of those used a specific measure of leadership to measure transformational leadership (Gellis, 2001; Mary, 2005). A more detailed description of gender differences in leadership style in other professions and in social work is provided in the literature review.

\section{Effectiveness of Leadership Styles}

Higher ratings on transformational leadership behavior have been correlated with high leader effectiveness (Lowe, Kroeck, \& Sivasubramaniam, 1996; Yammarino, Spangler, \& Bass, 1993). Women use transformational leadership and contingent reward transactional behaviors more often then men (Eagly et al., 2003).

This leads to the conclusion that women are more effective leaders which is also supported by the literature (vanEngen \& Willemson, 2004). It is also clear that transformational 
leadership is congruent with the social work definition of leadership (Mary, 2005) developed by Rank and Hutchinson (2000). This leads to the further conclusion that women in social work are effective leaders. This study seeks answers to this topic.

The MLQ-5x Short (Avolio \& Bass, 2004) includes a subscale called "Outcomes of Leadership" that rates the effectiveness of the leader, satisfaction with the leader, and extra efforts toward work activities due to leader behavior. This subscale will be further explained in the Methodology chapter to follow, and it will be used in answering the question of effectiveness.

\section{Relevance of Topic}

Leadership is an area of great research interest in social work at this time (Rank \& Hutchinson, 2000). This study will add to the literature on leadership in the social work profession. By studying the impact of gender on leadership style, a greater understanding of the various ways that people lead will be developed. If there are gender differences in social work leadership, then it is very likely that these differences can be viewed as complimentary to each other and utilized for the benefit if all. If no gender differences are found, then it is important to report that leadership style is not influenced by gender in the educational leadership of the social work profession, thereby allowing prejudices against female leadership to be dispelled.

If women lead differently, it is imperative to increase the numbers of female leaders for social change to occur (Roa \& Kelleher, 2000). Women should not be forced into the same ineffective molds that are currently in use when it is, in fact, organizational change that is needed to produce a more equitable and socially just society (Petchers, 1996). As the general public becomes more comfortable with increasing numbers of highly visible female leaders, there is a developing awareness that different leadership does not mean ineffective leadership (Carli \& Eagley, 2001). If social work as a profession is to influence social change, effective leadership both within and outside of the profession is required (Brilliant, 1987)

It is possible that 'women's' leadership styles are threatening to male dominated organizations. In fact, the way towards social justice is likely to be built with shared power between male and female leaders. With the current emphasis on the positive nature of transformational leadership, a decidedly feminist leadership style, there is a great opportunity to 
counteract the previous misunderstandings between the genders. Some studies have showed no gender difference in the rates of transformational leadership (Eagley, Karau, \& Makhijani, 1995; Young, 2004), and it is possible that no matter what the gender social work educational leaders are very much the same in their utilization of this particular leadership style due to its close ties to our professional mission.

As a profession, despite the past history of political activism and current participation in a variety of practice settings (some of which are inhospitable to social work values) social workers are often uncomfortable with leadership roles. In order to successfully put forth ourselves and our professions it is important to have some clear understanding of effective leadership theory and practice (Briliant, 1987). In order to develop potential social work leaders, all leadership perspectives will need examination particularly when the literature points to disparities in leadership participation based on any particular factors. In this instance, leadership style will be examined as a possible factor in the relative success of women leaders in social work.

By examining the leadership styles of the social work educational system, particularly gender differences and the use of transformational leadership, it may be possible to apply that knowledge to improvement of the entire university system. Kezar et al. (2006) describe eight revolutionary leadership concepts that have been the focus of research on higher education leadership in the past 20 years including ethics and spirituality, empowerment, social collaboration and partnering, and accountability which will be described more fully in Chapter II. All of these ideas are very important in the social work profession, as well, so it is easy to see how social work leadership research is applicable to the entire higher education system.

\section{Research Questions}

In order to fill a gap in the research literature, this study seeks to answer several important research questions. With so little information on social work leadership style, and no information on social work educators' leadership style there is a definite need for this research. The following research questions are posed:

1) What types of leadership styles do social workers in educational administration typically practice? 
2) Is there a relationship between leadership style and gender in social work educational administration?

3) Is there a relationship between context of learning organization and leadership style of social work educational administration?

4) Is the predominant type of leadership style practiced by social workers in educational administration effective?

By answering these research questions the knowledge base of the profession of social work will be increased. In light of recent developments in the social work profession, such as workforce shortages and an inability to meet community needs due to that shortage (NASW, 2008), there is a great and pressing need to provide empirical evidence of the effectiveness of social work practice. This research may provide some compelling evidence toward that end facilitating community support such as that sought through the Social Work Reinvestment Initiative (NASW, 2008). 


\section{CHAPTER II}

\section{REVIEW OF THE LITERATURE}

In Chapter II, the concepts of leadership, leaders, and context will be developed. There will be a brief review of the historical development of leadership theory, and a detailed explanation of transforming (Burns, 1978) and transformational leadership theory with its accompanying full range of leadership model (Bass \& Riggio, 2006). Feminist theory's impact on general leadership theory will be discussed. The various leadership styles under study will be defined. Research on gender differences in leadership style, effectiveness of the various leadership styles, and the leadership styles in social work and other professions will all be explored in Chapter II.

\section{Concepts}

\section{Leadership}

Leadership definitions focus on a variety of leadership facets including but not limited to power relations and influence (Bass, 1990; Rost, 1993; Slater, 1995), change processes (Bass, 1990; Kouzes, 1999; Rost, 1993), differentiated roles, personalities, and skills of the individual (Barker, 1994; Bass, 1990), the initiation of structure (Bass, 1990; Katz \& Kahn, 1978), and any combination of these and other factors. Kezar et al. (2006) state "Various theories provide additional lenses, but there continues to be no agreed-upon definition of leadership." (p. 11). It is no wonder, then, that there is confusion in the literature. Bass (1990) alone presents twelve different definitions of leadership concluding that the distinction between leadership and other concepts is frequently unclear and that the definition must be study or context specific in order to make sense. This view is stated more strongly by Osborn, Hunt, and Jauch (2002) who vehemently argue that leadership and context are intertwined to such an extent that it is impossible to separate the two constructs. bell hooks stresses that leadership can't be 
conceptualized as unidimensional construct but must indeed be viewed in a multidimensional way (Hartman, 1999, p.109), and context adds multidimensionality.

The context of this study is social work. The context also includes the United States and the university system of education. There are multiple purposes of this study about leadership styles and gender in social work educational administration including the following:

1) To explore leadership styles of social work educational administration leaders,

2) To explore possible differences in leadership styles based on gender,

3) To explore the effect of organizational context on leadership style, and

4) To determine the effectiveness of various leadership styles in the social work context.

With these purposes in mind, a leadership definition must include values inherent in the social work profession. In their analysis of views of leadership in the social work profession, Rank and Hutchison (2000) surveyed social work leaders in the American professional social work organizations of the Council on Social Work Education (CSWE) and the National Association of Social Workers (NASW) to develop the following definition:

Social work leadership is the communication of vision, guided by the NASW Code of Ethics, to create proactive processes that empower individuals, families, groups, organizations, and communities. (p. 499).

This definition clearly includes all the above mentioned concepts and also clarifies the difference between leadership and management, a distinction not always clearly drawn in social work (or other professions for that matter.) The emphasis on empowerment and ethics are clearly focused on sharing power and changing the status quo based on a clear vision. This is very different from the typical management definition which would include functions designed to maintain stability of the current system (Barker, 1994).

All of the factors mentioned in the above definition (with the exception of the NASW Code of Ethics) can be easily utilized as management functions in any group, organization, or community. Communication, strategizing, and motivation are all either explicitly stated or implied in the above definition, yet when combined with power sharing or helping others find their power 
(instead of power wielding as in typical management paradigms) the distinction between leadership and management is clarified. This is important as Rost (1993) states that leadership is "a process entirely distinct from management" (p. 101), and he purports that many leadership theorists, by mistakenly equating leadership with management, have failed in their task to effectively and comprehensively describe leadership.

The problem with equating leadership with good management, according to Rost (1993), is that they come to mean the same thing. Obviously, the currently accepted view is sufficient for an understanding of industrial and organizational leadership where economic indicators are used to judge success. However, it is obviously insufficient for understanding leadership in other groups (for example, environmental and women's advocacy groups) where other indicators (such as preserving the environment for future generations or promoting social justice) are primarily important (Rost, 1993). In our chosen definition, the values piece fits well into the social work context and separates these two constructs in a sufficient manner. This definition is also useful in developing the theory section of this dissertation as it implies that the current focus on transformational leadership theory is an appropriate focus.

\section{Leader}

Just as there is a distinction between leadership and management, there is a difference between leaders and managers. What is this difference, and how is it that leadership theorists determine who is a leader? In the recent past, there has been an assumption that only managers display leadership ignoring informal leaders or non-management leader activities as well as the relationship between leaders and collaborators. Kouzes (2007) considers the idea that leadership is a position "pure myth" (p. 339). Displays of leadership are found in all levels of organizations, even outside the organization, and leaders often participate in fluid roles dependent upon the needs to achieve the vision of the group (Kouzes, 2007). According to Barker (1994) leaders often work outside the existing social and organizational structures because it is the leadership act itself that creates a new, changed structure. Leadership is a process; and a leader is a person. 
In this study we are focused on people, particularly people in social work education leadership positions engaging in the leadership process. With an awareness of the limitations of studying only formal leaders, the current study will define a leader by their appointment to a formal leadership position. To be considered a leader in social work higher education for this study, a person must hold the position of Dean, Assistant or Associate Dean, Department Head, Assistant or Associate Department Head, Director, or Assistant or Associate Director in an accredited university level social work department. The definition of leader based on position is justified due to the assumption that people in these positions not only influence but can directly change the structure, power relations, and vision of social work departments and possibly the entire university where they are employed. Another justification is that when looking at social work educational administration, these are the leaders that are currently in place. When attempting to study the leadership styles of a profession or a gender within that profession, the formal leaders are the most obvious to access for analysis.

\section{Context}

Pawar and Eastman (1997) have examined the effect of context on transformational leadership and transformational leadership processes on the context. In their conceptualization, the effectiveness of a particular transformational leader is dependent upon the context into which the transformational leadership act is introduced. Their finding suggest that if an organization is less receptive to transformational leadership then leaders are forced to neutralize the context before proceeding on with gaining commitment to their vision. In other words, transformational leaders must address organizational context by confronting, reshaping, or harnessing it (Pawar \& Eastman, 1997).

Decisions about transforming organizations (what changes to accomplish and how to go about it) cannot be made in a valueless vacuum. Madden (2005) stresses that context, specifically sociocultural context, has a "prominent influence" on leadership situations and that unless value standpoints are clearly stated different perspectives may not be included in the collaborative process. Madden (2005) specifically addresses "masculinized contexts" stating that organizations often have 'deeply embedded gender constructs' that do not allow women to be 
heard much less participate in leadership. Due to the seriously discriminatory nature of these organizations, they can not be improved to the point where equality is possible. The structures need to be changed (Madden, 2005). Women will remain in the minority in higher education holding fewer positions as the prestige of the college and the department increase (GlazerRaymo, 1999) or until there are dramatic changes in the campus climate (Madden, 2005). These dramatic changes will require transformational leadership, a value laden and empowering type of leadership that inspires others to action (Bass \& Riggio, 2006).

vanZyl's (2007) Rapid Organizational Learning Evaluation (ROLE) scale is a 20 item instrument developed to measure the culture of change (including its transformational nature) and the extent of learning behaviors exhibited by a learning organization. This scale will be used in this study to measure the level of organizational change as perceived by the social work administrators in this study.

vanEngen and Willemsen (2004) found that sex differences in leadership styles differ based on the type of organization in which the leader works. Study setting was also found to be a moderator of sex differences in leadership (vanEngen \& Willemson, 2004). Bommer, Rubin, and Baldwin (2004) similarly found that certain contextual organizational factors led to increase in transformational leadership behaviors. If peer leaders were using transformational leader behaviors, then the leader was more likely to use a transformational style, and this could even cancel out the negative effect of cynicism in the leader under review (Bommer et al., 2004). Yoder (2001) explored the effect of contextual factors on leader effectiveness. Yoder (2001) states that effective leadership strategies for women are affected by the context (gender make-up of the group, organizational culture, etc.). Stressing the importance of an awareness of gendered contexts and its effect on the leader, Yoder (2001) holds that there is no one-size-fitsall approach to leadership. Skills making a man an effective leader do not always work well for women. Not only do organizational contexts affect the utilization of transformational leadership (Bommer et al., 2004; Pawar \& Eastman, 1997), but specifically gendered or masculinized contexts affect women's use of transformational leadership (vanEngen \& Willemson, 2004; Yoder, 2001). 
Context, then, can be either a barrier or a facilitating factor in the use of transformational leadership practice. In this study, context will be examined through the use of multiple demographic questions regarding specific social work programs and the colleges and universities in which they operate. The ROLE (vanZyl, 2007) will be used as a more specific measure of organizational change and learning.

\section{Development of Leadership Theory}

General leadership theory is divided into four main groups: "Great Man" and Trait theory, Behavioral and Transactional theory, Contingency and Systems (or Transactional) theory, and Transformational leadership theory. In addition to these four theories, the impact of Feminist theory on leadership theory will be explored. Each contributes to an understanding of general leadership theory, and each will be discussed in this section.

\section{“Great Man" and Trait Leadership Theory}

The oldest and most relied on theory are the "Great Man" theory (Bass, 1990). This theory purports that certain men are born leaders, and it is only through their leadership that society moves in certain directions. These leaders influence and direct the masses to achieve certain goals or to believe certain ideas (Bass, 1990). For example, Ghandi led India to independence, and according to "Great Man" theory, without Ghandi India would still be under English rule. Of course, it is impossible to say whether this would or would not be the case. There is also no way to say whether or not the general population would be able to instigate societal changes without a "leader".

Although there have been many "Great Women" identified throughout the ages (Joan of Arc, Elizabeth I, and Margaret Thatcher to name a few), "Great Man" theory ignores their contributions (Bass, 1990) making this theory gender-biased. In addition, very few people of color are included in this elite group, exceptions being Martin Luther King, Jr., Confucius, and Ghandi among others. Leadership characteristics are generally viewed as being consistent with White and Male (Bass, 1990).

It follows from "Great Man" theory that a leader is born with traits differentiating him from his followers, and many theorists have attempted to identify these various differentiating qualities 
(Bass, 1990). It is important to note that "feminine" characteristics were left out of the equation of what makes a good and effective leader until relatively recently (Chin, 2004).

The belief that a person is born with certain traits such as self-confidence, risk-taking, capacity to influence, energy, and persistence among others (Beare, Caldwell, \& Millikan, 1997) is a main part of this body of theory, and much research energy was spent attempting to define the specific leadership traits effective leaders shared. Researchers during the early to mid 1900 s were somewhat successful (Bass, 1990), but quickly realized traits were not the sole determinant of great leadership. From the 1940's to the 1980's the focus turned to leader behaviors (Beare et al., 1997; Colarossi, 2006).

\section{Behavioral and Transactional Leadership Theories}

Over the course of five decades (1940s to 1980s), researchers focused on the determination of which behaviors were most effective in various particular situations. Leaders were believed to learn certain skills over the course of their life that enabled them to effectively lead. Participative leadership with its cooperative, non-autocratic emphasis and role theory emerged during this period (Bass, 1990; Colarossi, 2006). It was determined by Stogdill (1974) that there were two basic types of leadership behaviors, those that were system-oriented (task behaviors) and those that were person-oriented (consideration behaviors). These two categories were the subject of much intense research scrutiny and led to the more sophisticated situational and contingency theories that are described next (Slater, 1995).

\section{Situational and Contingency Theories}

Certain situational and contingency theories arose whereby the most effective leader was determined to be the one best able to change their skills utilization based on the most appropriate fit at that moment (Bass, 1990). Factors such as the situation, context, followership characteristics, and resources available were to be taken into consideration in order to make an informed decision as to which appropriate leadership skills to use. Fiedler, Chemers, and Mahar (1976) developed contingency theory where leadership style, defined as a stable personality characteristic, combines with leadership behavior and judgment of the appropriateness of skills and knowledge usage in the context to produce a leadership act. Hersey and Blanchard (1982) 
produced a situational leadership theory focused on defining the psychological and professional maturity of followers, and then choosing to use either task behavior or relationship behavior to manage groups effectively.

Heavily developed in the 1970's and 1980's with roots in the late 1950s transactional leadership theory is considered "traditional" management (Bass, 1990). Leaders set up clear reward and punishment structures utilize these structures as motivation for followers (Bass, 1990). Leader-member exchange, or LMX, (Graen, 1976) is a good example of this theory (Colarossi, 2006). These functionalist paradigms were the basis of management and leadership theory for decades and continue to be used in many organizations despite their shortcomings of failure to consider the perspective of the follower, an inability to encourage personal growth of "members" or followers, and the lack of a values base other than to increase profits or productivity of the organization (Bass, 1990).

Though these theories are useful and added to the theory base, they were incomplete (Bass, 1990). Their lack of understanding of the impact of social dynamics and follower behavior on leader effectiveness left several blank spots, such as the role of values and ethics in leadership choice and the charisma necessary to excite followers to action. With an upsurge of leadership studies focusing on leadership among nurses, social workers, police, and minorities and women in the 1980's, there was a clear divide between theory and practice leading to the development of other theories (Bass, 1990).

\section{Transforming versus Transformational Leadership Theory}

In the midst of an increasing understanding of the complexity of leadership,

"Transforming Leadership" Theory was developed by Burns in 1978. This theory of political leadership is focused around leaders and followers building a unified common interest in which motivation is underpinned by 'attempts to elevate members' self-centered attitudes, values and beliefs to higher altruistic attitudes, values and beliefs" (Gunter, 2001, p.69). This is the first theory to be developed outside of organizational theory and to emphasize values. Though leaders are seen as principle to this process, they are not the sole impetus, nor are they the sole beneficiary of successful leader-follower relationships. Burns (1978) holds that this type of 
leadership is beneficial to everyone involved in the process while acknowledging that leaders are only as strong and effective as their followers. Burns' (1978) work is considered groundbreaking and constituted a paradigm shift in the field of leadership studies.

With Transforming Leadership, there is an attempt to reduce status differentials between leaders and constituents, increase participative decision making, and increase power manifested through and with people instead of over them (Burns, 2003). Transforming leaders develop an inspirational vision in collaboration with others and work with others in the realization of the vision; both leader and collaborator are transformed. All the actions and methods are based on ethics, values, and collective empowerment of the leader and group members (Burns, 1978; Collarossi, 2006).

Graham (1991) also believes that values and morals must be imbedded in a leadership style in order to make it beneficial to all levels of the organization. Graham cites Greenleaf's servant leadership as a charismatic type of leadership that encourages followers to "become autonomous moral agents" (p.116), and in doing so to challenge the leader's motivations/moral judgments based on what is best for everyone.

Many researchers in educational administration are turning to transforming leadership theory as a way to add diversity and a value base of social justice to current leadership practices (Beare et al., 1997). This theory of leadership is consistent with the social work definition outlined earlier, as well (Rank \& Hutchison, 2000).

Bass and Avolio (1989) identified a type of leadership built upon Burns' (1978) that is called transformational leadership. They further developed a scale for its measurement, the MLQ (Avolio \& Bass, 2004; Bass \& Avolio, 1989). It is important to distinguish the two because they are used interchangeably in the research literature yet they are very different. Bass and Avolio (1989) describe a combination of transactional and transforming leadership whereby the inspirational and charismatic leader is able to manipulate followers into working toward the leader's agenda, not a shared collectively developed one. Without the value base for leader/follower decision-making, Bass and Avolio's transformational leadership is very different indeed. Graham (1991) suggests that moral difference is very important. 


\section{Feminist Leadership Theory Overview}

In the past 20 years, there has been a shift away from the Positivist and the Functionalist Paradigms mentioned above as leadership studies began to focus more on the complexities and ambiguities of leadership (Kezar, Carducci, \& Contreras-McGavin, 2006). Ethics and morals have come into focus as the paradigms of Social Constructivism, Critical, and Postmodern theory have gained popularity (Kezar et al., 2006). In fact, Kezar et al. describe eight revolutionary leadership concepts that have increasingly been the focus of research on higher education leadership in the past 20 years including ethics and spirituality, empowerment, social collaboration and partnering, and accountability. All of these ideas are very important to Feminist Theory, as well, and Kezar, Carduci, and Contreras-McGavin (2006) cite the influence of Critical and Feminist Theorists as one primary reason for recent interest in these particular leadership concepts (p.20). Over the past fifty years feminist researchers have documented gender inequalities due to the structure of school systems, characteristics of female leaders and the "institutional and professional cultures within which they work" (p.1), and the traditional leadership theories' dependence upon male experiences to explain leadership behaviors (Skrla, 2003). There is a clear awareness, however, that research has more recently begun to slow as the finer points of these various research topics are "deeply excavated" (p. 2).

Shakeshaft (1989) encouraged the use of research questions that study women on their own terms as a challenge to theory as it currently stands and as a way to transform theory in order to move towards improved understanding of women as educational leaders. In 1999 Hall continued advocating for a gendered view in order to not only add to the research base of educational leadership which has been predominantly androcentric (male oriented) to this point, but also to facilitate changes in the field itself.

Shakeshaft (1999) summarizes the changes in inclusion of women in educational administration positions by stating that "Many of the [feminist theory] researchers communicate a message of irrelevance [to women] of the traditional literature in educational administration" ( $\mathrm{p}$. 115) by expanding theoretical conceptions to include women's experience, women's understanding of the status quo, and women's ways of leading that are changing the way 
educational administration is done. This unique viewpoint based on gender is termed feminist standpoint research (Shakeshaft, 1999). Despite its importance and value with its ability to point out inequities and injustices in the current educational systems, feminist standpoint research is often deemed worthless by those in power and either not allowed to take place at all or not accepted as valid when the results are released (Fletcher, 1994; Reay \& Ball, 2000).

As Slater (1995) points out feminists are most concerned with "the use of gender as a criterion for determining superiority and subordination" (p.457) leading to gender oppression. Resistance to the current male dominated bureaucratic structures, leadership theories, and models of leadership that are in opposition to feminist leadership styles are their main concern, and they utilize research as a means of advocacy-- to uncover that the emperor [educational administration] has no clothes [concern for gender matters] and does not seem to care (Skrla, 2003).

Furthering feminist principles is always a goal with feminist theory, and Madden (2005) lays out five feminist principles as related to leadership quite clearly. Firstly, Madden (2005) believes that sociocultural context (perspective differences based on gender, culture, etc.) influences leadership situations. Secondly, power dynamics exist in every sociocultural structure including but not limited to higher education. Thirdly, individuals actively seek to change their environments and themselves using diverse strategies, and fourth, dichotomous positions are less useful than multiple perspectives (Madden, 2005). Madden's last feminist principle is collaboration is an effective and desirable strategy to use when changing organizations (Madden, 2005). More specific to this study, these principles are present and accounted for in transformational leadership, as well as feminist leadership, depicting a close relationship between these two styles.

Glazer-Raymo (1999) discusses the progression of feminist theory as applied particularly to academic leadership in universities. As advocates, the early feminists predictably provided most of the research on women in various settings despite the fact that their studies were often ignored or marginalized. Researchers such as Carol Gilligan (1982) and Elizabeth Kanter (1977) brought an awareness of the differences between women and men as well as the gender bias 
inherent in societal and organizational life. More currently, while still expanding knowledge regarding disparities and unequal treatment in job placement, salaries, and other indicators of well-being, postmodern feminists reject the 'contradictions' between unsuccessfully supported equity doctrines and their lived experiences as they dynamically attempt to describe their situations as a person in a social context and seek an equitable share of the power in academic leadership positions (Glazer-Raymo, 1999).e

Since the 1970 s feminist authors have increasingly contributed documentation of alternative forms of leadership that are effective for women and could be termed feminist leadership styles (Helgenson, 1990; Rosener, 1990). Researchers have shown through metaanalyses that women are effective in leadership positions, more effective than men (Eagly et al., 2003; vanEngen \& Willemson, 2004), even though they choose different styles of leadership which are more congruent with their female gender role (Bass et al., 1996; Eagly, Karau, \& Makhijani, 1995; Helgesen, 1990; Rosener, 1990) because the styles they choose are the most effective (Lowe, Kroeck, \& Sivasubramaniam, 1996; Yammarino, Spangler, \& Bass, 1993). Without the awareness of feminist principles (Madden, 2005) the impact of gender on leadership style would never have been studied and until recently have not been. Leadership styles, including feminist leadership style, will now be defined for the purposes of this study.

\section{Leadership Style Types}

The full range of leadership model is one method of understanding leadership style. The full range model includes the components of transformational leadership, transactional leadership, and laissez-faire leadership behaviors, and this model is also indicative of leader effectiveness as a person with laissez-faire leadership is more likely to be a poorly performing leader (Bass \& Riggio, 2006). The full range of leadership model represents nine factors: four transformational leadership factors, four transactional leadership factors, and one laissez faire leadership factor which is neither transformational nor transactional, and these factors are clearly delineated as subscales of the Mutlifactor Leadership Questionairre or MLQ (Antonakis, Avolio, \& Sivasubranamiam, 2003). In the full range of leadership model, every leader is assumed to display each leadership style to some degree (Bass \& Riggio, 2006). The MLQ measures all 
behaviors, and then identifies the most often used style for the leader in question (Bass \& Riggio, 2006).

\section{Lassiez Faire}

Bass and Riggio (2006) define lassiez faire leadership as "the avoidance or absence of leadership...Necessary decision are not made. Actions are delayed...Authority remains unused." (p.8-9). Antonakis et al. (2003) define the lassiez faire leadership style as the absence of a transaction. The leader "avoids making decisions, abdicates responsibility, and does not use their authority" (p. 265). This leadership style is considered the least effective and most passive leadership style in the full range leadership model (Bass \& Riggio, 2006). In the academic world, this type of leadership behavior might be present when a dean refuses to get involved in faculty disagreements in any way despite a negative effect on the entire department due to that inaction.

\section{Transactional}

Starratt (1999) defines transactional leadership behaviors as "self-interested exchange of some sort" (p.25) whereby the leaders exchanges some favor of the follower for one of his own. This type of leadership is instrumental in that it accomplishes a task for both leader and follower, and yet it is built on trust between the leader and the follower. It is based on clear and concise transactions that take into account the needs and rights of both parties while clearly occurring for the benefit of the leader's goals. He bases this definition on Burns (1978) definition of transactional leadership as follows: "They [leader and follower] are bargainers seeking to maximize their political and psychic profits" (p. 258), or a kind of social exchange where the exchanges are usually not repeated, but instead where both the leader and follower must experience a different exchange in order to achieve 'transactional gratification' and continue their relationship (Burns, 1978).

Bass (1990) defines transactional leadership behavior as "the transactional exchange between the leader and the led. The leader clarified what needed to be done and the benefits to the self-interests of the followers for compliance." (p. 902). Bass and Riggio (2006) define transactional leadership as when the leader rewards or disciplines the follower, depending on the 
adequacy of the follower's performance. This is somewhat different than Burns (1978) definition whereby both leader and follower are gaining or losing something in a social exchange.

According to Bass and Riggio (2006) transactional leadership when placed in the full range of leadership model can be effective or ineffective and active or passive depending on the context, but in general lie in the mid range of leader effectiveness. There are three types (or factors) of transactional leadership: (1) contingent reward, (2) management-by-exception active, and (3) management-by-exception passive. Contingent reward leadership behaviors where leaders reward followers for satisfactorily completing a task is the most effective of the three transactional styles. Management-by-exception active (the leader actively monitors followers' actions and encourages corrective actions if necessary) is effective dependent upon the context, while Management-by-exception passive is least effective of all the transactional styles. Management-by-exception passive behaviors occur when the leader takes action only when follower performance is noticed to be unsatisfactory. (Bass \& Riggio, 2006)

There is nothing inherently wrong with a transactional leadership style; it is often appropriate, empowering, and effective (Bass \& Riggio, 2006). For example, in the academic world knowing the expectations for tenure and being guided there by a transactional style mentor would be a great help in achieving that particular career goal, and both parties would likely get recognition from the other for their efforts. This style of leadership is most effective when liberally augmented by the transformational leadership behaviors described in the next section (Bass \& Riggio, 2006). Demonstrations of the augmentation effect have been reported in several leadership studies since the 1980s (Bass, 1997; Gellis, 2001) and are not dependent on context (Antonakis et al., 2003). Leaders may in fact "use the organizational context as their vehicle by both confronting and reshaping it or by merely harnessing it" (Pawar \& Eastman, 1997, p.105).

\section{Transformational}

Antonakis et al. (2003) states "Transformational leaders are proactive, raise follower awareness for transcendent collective interests, and help followers achieve extraordinary goals" (p.264). Bass and Riggio (2006) describe the transformational leader as one who "stimulates and inspires followers to both achieve extraordinary outcomes and, in the process, develop their own 
leadership capacity" (p.3). These leaders "empower" their followers and "align" individual, group, leader, and organizational goals. Transformational leadership behaviors have been correlated with "high levels of follower satisfaction and commitment to the group and organization" (Bass \& Riggio, 2006, p.3). An example of this type of behavior in higher education would be an associate dean who spearheads the development of a collaborative research model in her unit leading to the surpassing of the research publication goals for herself, her unit, all her individual unit members, and the entire social work department.

This leadership style was initially proposed by James M. Burns (1978) in his book Leadership. Burns (1978) depicts "transforming leadership" as a relationship between the leader and follower where both are transformed by raising each other to higher levels of motivation and morality. While the moral action component is not emphasized as clearly in Bass'

transformational leadership style, it is not completely absent. The idealized influence component emphasizes the leader's actions based on "values, beliefs, and a sense of mission" and the leader's focus on "higher-order ideals and ethics" (Bass \& Riggio, 2006). Burns (1978), however, believes that influence is irrelevant to leadership because influence is not power; leaders have power in that they effectively cause changes that they want. Influence may cause unintended or unwanted outcomes to occur thereby demonstrating a lack of power to do what the "influencer" wished.

Burns (1978) clearly differentiates transactional leadership behaviors as a relationship between leader and follower without an enduring, higher, mutual purpose binding them together such as that occurring in transforming leadership relationships. In transactional leadership, when the bargaining is complete leader and follower often part ways. In fact, they only come in contact with one another for the joint purpose at hand. In transforming leadership, the leader and the follower both act in accordance to meet a certain goal that both share at the leader's inducement (Burns, 1978). Since both parties are getting their needs and wants met, they will participate in an ongoing relationship to continue towards these mutual ends (Burns, 1978).

With apparent differences in the transformational leadership (Bass \& Riggio, 2006) and transforming leadership (Burns, 1978) there is still enough similarity between the two to share a 
name. Bass and Riggio (2006) give credit to Burns for his "new paradigm of leadership". They

follow that with a clear description of their transformational leadership style as included in the full range of leadership model and measured by the MLQ 5x-Short (Avolio \& Bass, 2004).

In the full range of leadership model, transformational leadership style is comprised of five separate factors or "I"s including (1) idealized influence-attributed, (2) idealized influencebehavior, (3) inspirational motivation, (4) intellectual stimulation, and (5) individualized

Table 1.

Social Work Elements of Leadership and 'Transformational Leadership

Factors.

\begin{tabular}{l|l}
\hline $\begin{array}{l}\text { Elements of Leadership as Defined by } \\
\text { Rank \& Hutchinson (2000) }\end{array}$ & $\begin{array}{l}\text { Five Factors of Transformational } \\
\text { Leadership (Antonokis et al., 2003) }\end{array}$ \\
\hline $\begin{array}{l}\text { Proaction: acting in anticipation of future } \\
\text { problems }\end{array}$ & $\begin{array}{l}\text { Idealized influence (behavior): } \\
\text { "charismatic actions of the leader } \\
\text { centered on values, beliefs, and a } \\
\text { sense of mission" }\end{array}$ \\
\hline $\begin{array}{l}\text { Values and Ethics: acting in accordance } \\
\text { with the NASW Code of Ethics }\end{array}$ & $\begin{array}{l}\text { Idealized influence (attributed): } \\
\text { socialized charisma of the leader, } \\
\text { whether the leader is perceived as } \\
\text { confident, powerful, focused on } \\
\text { higher-order ideals and ethics }\end{array}$ \\
\hline $\begin{array}{l}\text { Empowerment: "the process of helping } \\
\text { individuals, families, groups, and } \\
\text { communities to increase their personal, } \\
\text { interpersonal, socioeconomic, and political } \\
\begin{array}{l}\text { strength and to develop influence toward } \\
\text { improving their circumstances" (Barker, }\end{array}\end{array}$ & $\begin{array}{l}\text { Individualized consideration: ways } \\
\text { that a leader contributes to follower } \\
\text { satisfaction with advising, supporting, } \\
\text { and paying attention to individual } \\
\text { needs of followers and facilitating their } \\
\text { self-actualization }\end{array}$ \\
\hline $\begin{array}{l}\text { Vommunication: the verbal and nonverbal } \\
\text { exchange of information including all the } \\
\text { ways in which knowledge is transmitted } \\
\text { and received." (Barker, 1994) }\end{array}$ & $\begin{array}{l}\text { Intellectual stimulation: leader actions } \\
\text { that appeal to follower logic and } \\
\text { analysis by encouraging creative } \\
\text { thinking and problem solving }\end{array}$ \\
\hline $\begin{array}{l}\text { Webster, 1999) } \\
\text { the mer of anticipating that }\end{array}$ & $\begin{array}{l}\text { Inspirational motivation: ways that a } \\
\text { leader energizes followers by focusing } \\
\text { on an optimistic future, stressing } \\
\text { ambitious goals, projecting an } \\
\text { idealized vision, and communicating } \\
\text { the achievable nature of the vision }\end{array}$ \\
\hline
\end{tabular}


consideration (Antonakis et al., 2003). These five factors correspond nicely to the five common elements of leadership in the social work profession developed by Rank and Hutchinson (2000).

Rank and Hutchinson (2000) examined views of presidents and executive director members of the National Association of Social Workers (NASW) and dean members of the Council on Social Work Education (CSWE) providing an inclusive idea of perceptions of leadership in the social work profession by surveying both practice (NASW) and educationallyfocused (CSWE) social workers. This survey identified five common elements defining the concept of leadership: (1) proaction, (2) values and ethics, (3) empowerment, (4) vision, and (5) communication (Rank \& Hutchinson, 2000). Table 1 clearly shows connections between the construct of transformational leadership and the recent definition of social work leadership developed by Rank and Hutchinson are apparent (2000). This definition follows:

Social work leadership is the communication of vision, guided by the NASW Code of

Ethics, to create proactive processes that empower individuals, families, groups, organizations, and communities. (Rank \& Hutchison, 2000, p.499)

This definition definitely embraces the transformational leadership style. Mary (2005) calls it "congruent with the transformational leadership style". It remains to be seen whether or not the social work educational administrators are actually using this definition and the transformational leadership style in actual practice. This study will explore social work educational leadership styles as a way of determining how often transformational leadership practices are utilized and how effective they are.

\section{Gender Differences in Leadership Style}

Bass (1990) stated "...no consistently clear pattern of differences can be discerned in the supervisory styles of female and male leaders" (p.723). In later research Bass and Avolio (1994) found that women managers were higher in all the transformational leadership scales on the MLQ and in leader effectiveness. Bass (1995) encouraged use of gender as a research variable due to these ambiguous findings. Young (2004) cites a "confusing range of ideas" regarding leadership styles of managers in higher education" that were replicated in her own case study where all 
managers "demonstrated surprisingly high levels of transformational leadership" (p.101) no matter what their gender. Eagley, Karau, and Makhijani (1995) found no differences in the leader effectiveness of men and women with the exception that women were slightly more effective in less masculine settings such as education and slightly less effective than men in more masculine settings such as the military.

Maher (1997) found no differences in the leadership styles of men and women in various contexts. Maher (1997) instead linked previous differences in leadership style to sex role stereotypes and suggested that context may interact with gender to produce certain stereotypical expectations about leadership that interfere with accurate evaluations. Heilman (2001) discusses how gender stereotypes impact the evaluation of women in leadership positions thereby preventing ascent up the organizational ladder.

Simply put, Heilman (2001) describes a perceived "lack of fit" between the female gender stereotype with its accompanying stereotyped-based norms and the masculine sex-type positions at the top rungs of most male developed organizations. When a person applies for an opposite sex-type position, they are less likely to be hired and predicted to be less successful at the job if hired. Even if that person proves to be successful at the opposite sex-type position, the violation of gender related stereotyped-based norms often leads to social disapproval which might lead to lack of promotion or rewards in an organizational setting (Heilman, 2001). vanEngen and Willemson (2004) noted that if leaders are in gender role incongruent professions (ie. Male nurse/teacher or female business leader) then their leadership behavior is more differentiated by gender. This is particularly problematic in organizations such as higher education (with tenure processes) where not only competence, but also social acceptance and approval are used as a basis for decision-making.

Others (Carli \& Eagly, 2001; Eagly, 2003; Eagly, Johannesen-Schmidt, \& vanEngen, 2003) have found that incongruity between the female gender role and the leader role is problematic for women aspiring to leadership. Eagly et al. (2003) note role incongruity between leader role and female gender role. According to Eagly et al., due to role incongruity women will face two specific forms of prejudice if they choose to be leaders: (1) biased evaluation (less 
favorable than men) of their potential for leadership and (2) biased evaluation (again less favorable than men) of their actual leadership behavior. This leads to the glass ceiling phenomenon where women are not allowed access into the highest echelons of organizations based on prejudice alone (Eagly et al., 2003). Without equal access to and participation in those highest 'positions of power', social justice will not be achieved (Carli \& Eagly, 2001).

However, role incongruity may lead women to utilize more "feminine" leadership styles such as transformational leadership as suggested by Eagly et al. (1995). Kravetz and Austin (1984) report one comment by a female social work administrator that sums up the positive aspects of this gender role incongruity: "There is always a positive effect in a women being a superior since the traditional view of a boss is automatically broken, regardless of the style of the woman." (p.32). Kravetz and Austin (1984) found that female administrators in social service organizations identified their gender as having a significantly positive influence on their behavior with their subordinates, including being "more open, less formal, and more sensitive than male administrators; and as more understanding of personal issues and problems than men." (p. 32).

Some authors (Helgesen, 1990; Rosener, 1990) suggest that women are more likely than men to demonstrate a transformational leadership style while others suggest style is contextually bound with women and men behaving the same in the same leadership roles (Kanter, 1977). With a clear understanding of the impact of the leadership role, gender roles, and contextual influences it may be possible for women to utilize knowledge about these concepts to increase their leadership effectiveness (Yoder, 2001). This may lead women to utilize transformational leadership behaviors or other less orthodox methods to achieve leadership goals (Stratham, 1987 ) as the following studies demonstrate.

Bass and Avolio (1994) found that women are more transformational than men and are therefore more effective leaders that should be sought out by businesses for their skills and benefits they will bring to the table. Bass, Avolio, and Atwater (1996) declared that women were rated as more effective leaders than men by themselves and their subordinates. Additionally, women leaders were found to be more likely than males to use the transformational leadership style and to use more rewards with employees (Bass et al., 1996). vanEngen and Willemsen 
(2004) found that women use more democratic or transformational types of leadership styles, but no gender difference in the use of lassiez faire or transactional styles.

In their meta-analysis, Eagly et al. (2003) determined that in the forty four studies they reviewed, "female leaders were more transformational than male leaders in their leadership style" (p.578). No social work studies were included here. Women scored higher on all the transformational leadership subscales previously discussed except one, idealized influence behavior, as well as on the contingent reward subscale of the transactional leadership behaviors. Men scored higher on active and passive management-by-exception and laissez-faire leadership subscales, and their data suggested that male and female styles differed even when they were in the same leadership role (Eagly et al., 2003) contrary to Kanter's (1977) belief that leadership style was position-based.

To recap, differences in leadership style based on gender have been found. Women tend to use a transformational leadership style that is closely aligned to their female gender role (Bass et al., 1996; Eagly et al., 2003; Eagly et al., 1995; Helgesen, 1990; Rosener, 1990; vanEngen \& Willemson, 2004). Before turning our attention to social work professionals and their leadership styles, gender differences in leadership styles in other professions will be reviewed.

\section{In Other Professions}

Only five studies looking at the differing leadership styles of men and women in specific professions were found. Three of these studies used the MLQ (Avolio \& Bass, 2004) as a measure of leadership style (Carless, 1998; Druskat, 1994; vanEngen \& Willemson, 2004), one used a mixed methodology with survey questionnaire, shadowing key personnel, and interview techniques (Rutherford, 2001), and one used focus group methodology to gather data (Havens \& Healy, 1991). Professions included government administrators (Havens \& Healy, 1991), leaders of Roman Catholic religious orders (Druskat, 1994), large international bank managers from Australia (Carless, 1998), airline managers of varying sectors (Rutherford, 2001), and business and educational settings (vanEngen \& Willemson, 2004).

Havens and Healy (1991) used focus groups to discern the differing leadership styles of women administrators in government agencies finding that women report having specific 
differences in the way they lead including more democratic decision-making processes, relying more on personal power in business dealings, and bringing awareness of women's issues to decision making processes. Women also report sexism at top positions where there had been none at middle management positions (Havens \& Healy, 1991), a fact that ties in with the glass ceiling hypothesis. Overall, Havens and Healy (1991) report a feminist and transformational leadership style in their women leaders that affected the men in that they were held to feminist principles in decision making processes.

Rutherford (2001) utilized a mixed methodology in her examination of the possible gender differences in leadership style at a large airline. The managers reported that women and men did indeed manage differently ( $74 \%$ agreed: $84 \%$ women and $55 \%$ men). Women were seen as (1) having better people skills (relationship oriented, better listeners, empathetic, etc.), (2) having fewer status concerns (using a more democratic decision-making process), and (3) having better managerial skills (creativity, flexibility, strong character, etc.) (Rutherford, 2001). Interestingly, in Rutherford's study (2001) the women managers reported that managers in their company were often promoted based on skills having nothing to do with productivity or leader effectiveness, skills such as visibility, concern with status, and single-mindedness. Evidence of a gender difference in leadership style was thus provided by Rutherford's study (2001).

Druskat (1994) explored transformational versus transactional leadership style in the Roman Catholic Church utilizing the MLQ (Avolio \& Bass, 2004). Druskat chose Roman Catholic religious orders due to the nontraditional same gender makeup where only women supervised women and only men supervised men. This nontraditional gender division was postulated to allow women's true leadership style to emerge more easily. There were indeed gender differences in leadership style with women exhibiting more transformational leadership behaviors than men, and both genders exhibiting more transformational behaviors than transactional ones. There was an interesting finding related to the active management-by-exception; this transactional leadership style was preferred by males and was related to greater worker satisfaction than when used by the female leaders. Evidence of a gender difference in leadership with women being more transformational was found in this study (Druskat, 1994). 
Carless (1998) utilizing the MLQ (Avolio \& Bass, 2004) and the Leadership Practices Inventory, or LPI, another measure of transformational leadership (Kouzes \& Posner, 2007) found that in Australian bank managers women were more transformational than men (by their own and their superiors accounts). Their subordinates, however, saw no difference in leadership behavior by gender. Female managers were more likely to demonstrate transformational leadership style traits consistent with their gender role (ie. Involving staff in decision making, caring for individual needs, and praising individual and team accomplishments) than the more traditionally masculine task-oriented roles (such as visionary leadership or innovative thinking) by self-report and supervisor report (Carless, 1998). Again, we find some support for a difference in leadership style based on gender.

vanEngen and Willemsen (2004) found that professionals in a job that is not typical for their gender (male educational leader or female business leader) are shown to increase their leadership behavior differences dependent upon contextual influences. Male and female leaders apparently "compensate for their being 'out of role' by showing higher leadership behavior" (p.15). The finding that women are more transformational than men is stronger in business settings, a traditionally more masculine workplace, is somewhat surprising.

All five studies that held context constant found gender differences in leadership style were present (Carless, 1998; Druskat, 1994; Havens \& Healy, 1991; Rutherford, 2001; vanEngen \& Willemson, 2004). The present study will examine context as a possible factor impacting gender differences in leadership style choices. Both social work program variables and college or university variables will be included in the data analysis.

\section{Within Social Work}

Even fewer studies, only three, examining leadership style were found in social work literature (Gellis, 2001; Mary, 2005; Mizrahi \& Berger, 2001). None discussed the impact of gender on leadership style or the leadership style of social workers in educational administration.

Mary (2005) explored leadership style in social work management utilizing the MLQ Form 5x-Short (Avilio \& Bass, 2004) and a rating scale of the style of the social worker's organization (autocratic, bureaucratic, democratic, or laissez-faire on a 10 point likert scale). Her population 
included members of two nationwide groups: the National Network for Social Work Managers with three hundred forty members and the Association of Community Organizations (ACOSA) with 495 members. Five page questionnaires were sent to the total sample of eight hundred forty five along with a self-addressed stamped envelope, informed consents, and debriefing explanations. The respondents rated an actual leader they had worked with at some time (Mary, 2005).

Mary (2005) reports that participants in her study were primarily female (118), master level (109), and averaged forty eight years old with a range of twenty two to eighty three years old. Sixty percent of the agencies where the leaders worked were spread evenly among mental health, education, and child welfare fields, and were generally private nonprofit (108), public (58), with the remaining eight agencies being private for-profit. It is important to note that ninety five or $54 \%$ of the rated leaders had social work backgrounds. Twenty eight leaders (16\%) were educated in business or public administration, while nineteen (11\%) had education degrees. Psychology, divinity, law, public health, and medicine educational degrees were held by the remaining thirty five leaders. The one hundred seventy seven respondents rated their leaders as predominantly transformational, and they rated both transformational behavior and the transactional leadership behavior of contingent reward as highly correlated with successful leadership outcomes. An additional finding of a perceived "democratic" organizational style being correlated with successful leadership outcomes was documented, as well (Mary, 2005).

Mary (2005) clearly states that her findings on transformational leadership being correlated with successful leader outcomes replicate Gellis' (2001) findings. Gellis (2001) used the MLQ Form 5x (Bass \& Avilio, 1997) to explore social work perceptions of transformational and transactional leadership practices in the health care setting. Gellis (2001) surveyed two hundred thirty four hospital social workers, and her sample was rather homogenous with 168 (89\%) having an MSW (11\% BSW), being female ( $86 \%$ ), and working in the medical/surgical unit $(51 \%)$. The other units worked included psychiatric, emergency, pediatrics, rehabilitation, geriatric, intensive care, neonatal and maternity, burn unit, and cardiology, and the average age of respondent was 42.9 years. Gellis (2001) found that the two hundred thirty four hospital social workers located in a large urban setting (population of 2.5 million) perceived their social work managers as 
transformational and that there was a significant augmentation effect when transformational leadership behaviors were 'added' to transactional leadership behaviors. This increased the level of perceived effectiveness and satisfaction with the leader in question in these particular health care settings. A transformational leadership style was also correlated with extra effort on the part of the employee (Gellis, 2001).

Mizrahi and Berger (2001) in a study of hospital social work leaders determined that most of the leaders in their study practiced strategic and transformational leadership styles through their responses to an open ended questionnaire. They drew a stratified random sample of 750 (of 3,700 hospitals) from the member list of the American Hospital Association. The sample was stratified according to stage of managed care development, geographic location, and bed size. Although not focused on a specific leadership styles, Mizrahi and Berger (2001) using grounded theory method they outlined specific skills currently in use by social workers in these health care settings. Skills such as management of interpersonal conflict, creating a vision for the future, motivating and supporting employee morale, and others were mentioned (Mizrahi \& Berger, 2001), and all are consistent with a transformational leadership style as previously described (Bass \& Riggio, 2006).

No other studies were found about leadership style in social work, and this gap in the literature is an important area to explore as was further discussed in the section on relevance of this topic. This study will begin to fill that gap.

\section{Effectiveness of Various Leadership Styles}

The three types of leadership in the full range of leadership model (Bass, 1990) are reviewed here as to their effectiveness. Transformational, transactional, and laissez faire leadership types are explored.

Yammarino, Spangler, and Bass (1993) developed a model of transformational leadership and performance and tested it on United States Navy officers over time in different settings (four years of academic training and officer fleet performance at four and ten years after graduation). They found a significant long term connection between leadership style and performance with transformational leaders being the most effective. 
Lowe, Kroeck, and Sivasubramaniam (1996) completed a meta-analysis of ninety eight studies (of which thirty nine were usable) utilizing the MLQ (Avilio \& Bass, 2004) in order to review the effectiveness of the three leadership styles. Transformational leaders were found to be more effective across all studies reviewed, and the charisma subscale (currently the idealized influence-behavior and idealized influence-attributed) was found to be the most likely to correlate with leader effectiveness. Type of organization did have a significant effect on the use of transformational leadership with public organization subordinates reporting higher use of transformational leadership behaviors than private ones. Leader level also had a significant effect on leader effectiveness with the low level leaders exhibiting more transformational leadership behaviors on average (Lowe et al., 1996). A correlation between transformational leadership and effectiveness was found whether the assessment was subordinate based or another measure of organizational effectiveness (Lowe et al., 1996).

vanEngen and Willemsen (2004) reviewed twenty six studies reported in twenty documents in their meta-analysis of leadership style. They found that sex differences in leadership styles differ based on the type of organization in which the leader works. Study setting was also found to be a moderator of sex differences in leadership (vanEngen \& Willemson, 2004). Bommer et al. (2004) similarly found that contextual organizational factors led to increase in transformational leadership behaviors. Cynicism of the leader under study and peer leader's use of transformational leadership behavior were correlated with use of a transformational style. If the leader was more cynical and had little faith in their ability to change the organization, less transformational behavior was utilized. If the peer leaders were using transformational leader behaviors, then the leader was more likely to use a transformational style and this could even cancel out the effect of cynicism in the leader under review (Bommer et al., 2004).

Three studies were found that examined leader effectiveness and gender. Two of these looked at contextual factors and leader effectiveness. Yoder (2001) states two important points regarding leader effectiveness: (1) effective leadership strategies for men may not carry over for women and (2) effective leadership strategies for women are further affected by the context (gender make-up of the group, organizational culture, etc.). Stressing the importance of an 
awareness of gendered contexts and its effect on the leader, Yoder (2001) holds that there is no one-size-fits-all approach to leadership. What makes a man an effective leader does not always work for women.

Rosser (2003) studied male and female differences in leadership effectiveness by looking specifically at deans in higher education. In this study, female deans were found to be more effective leaders in all areas; however, all deans were viewed as effective by both men and women. There was no difference (for example, harsher ratings for women, more favorable reports for men) noted in cross-gendered or same-gendered supervisor evaluations. Rosser (2003) concluded that these findings call into question the notion of leadership being a gendered construct while confirming that women's leadership style is different than men's but just as effective.

Eagly et al. (2003) completed a meta-analysis of forty two relevant documents containing forty five studies utilizing the MLQ (Avilio \& Bass, 2004). They found that women were more likely than men to use all transformational leadership scales and the contingent reward subscale of transactional leadership behaviors (Eagly et al., 2003). Transformational leadership scales were previously found to be linked to increased leader effectiveness (Lowe et al., 1996). This may suggest that women are more effective leaders.

It is clear from the literature that transformational leadership leads to increased leader effectiveness (Lowe et al., 1996) and that women use transformational leadership and contingent reward transactional behaviors more often then men (Eagly et al., 2003). It is also clear that transformational leadership is congruent with the social work definition of leadership (Mary, 2005) developed by Rank and Hutchinson (2000). Utilizing the Outcomes of Leadership subscale of the MLQ-5x Short (Avolio \& Bass, 2004), this study will assess effectiveness of the various leadership styles.

\section{Conclusion}

In conclusion, this literature review has defined the concepts of leadership, leader, and context, and clearly outlined a brief history of leadership theory. The impact of feminist theory on leadership theory has been discussed. Leadership styles have been clearly defined, and the 
research literature on gender differences in leadership style and the effectiveness of various leadership styles has been presented. There is a notable gap in the leadership literature regarding social work leadership style that the current research proposes to fill. In review, the next chapter will put forth a proposed methodology to answer the following research questions:

1) What types of leadership styles do social workers in educational administration typically practice?

2) Is the type of leadership style social workers in educational administration typically practice variable by gender?

3) Is there a relationship between the type of learning organization and leadership style?

4) Is the predominant type of leadership style practiced by social workers in educational administration effective? 


\section{CHAPTER III}

\section{METHODOLOGY}

This chapter will describe the methods that will be used in attempting to answer the research questions previously specified. The research study design will be explained, key variables and concepts will be identified and operationalized, and research hypotheses will be proposed (Rubin \& Babbie, 2001). The sampling procedures, data collection and analysis procedures, and human subjects' protections will be discussed, as well.

\section{Overview of the Study}

The purposes of this study are three fold: (a) to describe the leadership styles of social workers in educational administration, (b) to explore relationships between leadership style, gender, and leadership style and learning organization, and (c) to explore the relationship between leadership style and effectiveness in social work educational administration. This study will explore and describe the leadership styles of social work education administrators at the BSW, MSW, and Ph.D. levels in the United States.

\section{Research Design}

The research design is a cross-sectional survey design. The three major advantages of survey research are (a) large-scale probability sampling, (b) use of a systematic questionnaire, and (c) use of statistical techniques for analyzing data (Singleton \& Straits, 1999).

Leadership styles will be explored primarily through the collection of quantitative data using the MLQ 5x-Short (Avolio \& Bass, 2004). Quantitative scale data on the type of organization within which the respondent leads will be gathered in the ROLE instrument (vanZyl, 2007). Demographic data will also be collected. Without open-ended questions it would be difficult to uncover some of the factors impacting leadership style as quantitative data often cannot fully describe the situation (Kjeldal, Rindfleish, \& Sheridan, 2005), and they will be utilized, as well. The use of these methods for each purpose is summarized in Table 2. 
Table 2.

Research Purposes and Methods to Achieve Objectives.

\begin{tabular}{|c|c|c|c|c|}
\hline Purpose & $\begin{array}{c}\text { MLQ Form 5x- } \\
\text { Short }\end{array}$ & $\begin{array}{c}\text { Other Scale } \\
\text { Questions }\end{array}$ & $\begin{array}{c}\text { Open-ended } \\
\text { Questions }\end{array}$ & $\begin{array}{c}\text { Demographic } \\
\text { Questions }\end{array}$ \\
\hline $\begin{array}{l}\text { Explore the relationship } \\
\text { between leadership } \\
\text { style and effectiveness } \\
\text { in social work } \\
\text { educational } \\
\text { administration }\end{array}$ & $x$ & & & \\
\hline $\begin{array}{l}\text { Describe the leadership } \\
\text { styles of social workers } \\
\text { in educational } \\
\text { administration }\end{array}$ & $x$ & & & $x$ \\
\hline $\begin{array}{l}\text { Explore the relationship } \\
\text { between leadership } \\
\text { style and gender }\end{array}$ & $x$ & & & $x$ \\
\hline $\begin{array}{l}\text { Explore relationships } \\
\text { between leadership } \\
\text { style and organizational } \\
\text { culture }\end{array}$ & $x$ & $x$ & $x$ & $x$ \\
\hline
\end{tabular}

\section{Sampling and Data Collection Procedures}

\section{Sampling Design}

Purposive sampling will be used to obtain knowledge about the leadership practices of social work educational leaders. Each dean, department head, and director listed in the Council on Social Work Education (CSWE) National Association of Deans and Directors (NADD) online directory for Fall 2008 will be solicited via email communication regarding the purposes of the research and how to access the survey. This process is further described in the section entitled Subject recruitment.

A sample of all deans, directors, and chairs listed in the CSWE NADD list from the United States will be utilized. A list of all deans, directors, and chairs in accredited social work programs in the United States will be obtained from the NADD, and all will receive the study materials. This will be a complete population because leaders at all levels of social work education - bachelors, masters, and doctoral - in all CSWE accredited schools will be offered the survey. For the 
purposes of this study a leader is defined as: a person in social work higher education holding the position of Dean, Department Head, or Director in an accredited university level social work department. All social work educators associated with leaders who have returned surveys will also be invited to participate by anonymously rating their leaders. Employees/raters are defined as direct reports of the deans, directors, and chairs and may include administrative assistants, instructors, lecturers, part-time faculty, and full-time faculty who have worked with the leader for at least 6 months.

The unit of analysis is individual whereby individuals are rating (1) their own and others leadership practices and (2) their organization's level of openness to change as well as (3) sharing their personal experiences and beliefs regarding the impact of gender and organizational culture on leadership practices. The unit of analysis is also group whereby the general nature of the leaders' behavior will be analyzed according to type of organization.

\section{Internet based research}

The internet provides a vehicle of communication that is efficient, accessible, and cost effective. Cook, Heath, and Thompson (2000) found that internet survey response rates were significantly higher and more representative than paper and pencil based survey methods. Schaefer \& Dilman (1998) had similar results in their experiment. Enhancement of both response rate and representativeness will be a definite advantage in this research by reducing sampling and nonrepsonse error (Dillman, 2007). Other advantages of internet based research include speed, economy, anonymity and the ability to ask sensitive questions, and expanded question types and content options (Sue \& Ritter, 2007).

Examination of this particular population as suggested by Dillman (2007) demonstrates the appropriateness of web survey data gathering as an appropriate mode of data collection. Social work leaders in higher education are required to utilize computer and internet technology on a regular basis as part of the job duties. In fact, they are often provided with the latest technology in order to improve their job performance. In addition, due to the diverse geographic locations of respondents and the short time frame for completion of the study, web based survey administration is very cost effective for the researcher (with easy download of data into the 
appropriate statistical software, minimal cost for use of the QuestionPro software and web survey host site, and no travel expenses involved) and very respectful of the respondents' time by allowing them to complete their survey in their own available time within the constraints of the study. The confidentiality and anonymity of the respondents will enhance their responses to the sensitive topics under study which include leadership practices, gender, and organizational culture.

The decision to utilize web based survey data collection also included an awareness of the limitations of this particular type of data collection including abandonment of the survey prior to its completion and dependence on software for appropriate administration (Sue \& Ritter, 2007). These disadvantages have been minimized by careful choices in the design of the survey following Dillman's Tailored Design Method principles (Dillman, 2007) and in the choice of survey software and web survey host which are in this case one and the same, QuestionPro.

\section{Tailored Design Method}

Approaching survey response as a social exchange, Dillman (2007) presents a three part model whereby rewards, costs, and trust combine into a personal decision about survey completion. It is up to the researcher to influence that decision positively by increasing rewards, reducing costs, and establishing trust so that rewards exceed costs. Dillman (2007) outlines multiple ways to achieve these ends (See Table 3), and encourages researchers to include more than one method in any specific design feature. For example, in explaining the reasons why survey completion is rewarding in an advance contact with the possible respondent, a researcher might describe sponsorship by a legitimate authority, point out the convenience of web-based survey methods, and say thank you in advance, thereby utilizing all three areas of the model to encourage completion of the survey. According to Dillman (2007) tailored design is successful when survey errors (such as coverage, sampling, measurement, and nonresponse) are reduced.

In this survey, both sampling error and coverage error will be kept to a minimum because the entire population is invited to participate. The National Association of Deans and Directors (NADD) contact list will be obtained from Alberto Godenzi, President of the National Association of Directors and Deans. Measurement error will be reduced by collecting data through the online 
Table 3.

Dillman's Methods for Obtaining Improved Survey Response.

Increasing Rewards

Show positive regard. Avoid subordinating language.

\begin{tabular}{|c|c|c|}
\hline increasing hewaras & Reducing Socral Costs & Establishing Trust \\
\hline Show positive regard. & Avoid subordinating language. & $\begin{array}{l}\text { Provide a token of } \\
\text { appreciation in advance. }\end{array}$ \\
\hline Say thank you. & Avoid embarrassment. & $\begin{array}{l}\text { Sponsorship by legitimate } \\
\text { authority. }\end{array}$ \\
\hline Ask for advice. & Avoid inconvenience & $\begin{array}{l}\text { Make the task appear } \\
\text { important. }\end{array}$ \\
\hline Support group values. & $\begin{array}{l}\text { Keep requests similar to other } \\
\text { requests to which the person } \\
\text { has already responded. }\end{array}$ & $\begin{array}{l}\text { Invoke other exchange } \\
\text { relationships. }\end{array}$ \\
\hline Give tangible rewards. & $\begin{array}{l}\text { Minimize requests to obtain } \\
\text { personal information. }\end{array}$ & \\
\hline $\begin{array}{l}\text { Make the questionnaire } \\
\text { interesting. }\end{array}$ & $\begin{array}{l}\text { Make questionnaire appear } \\
\text { short and easy. }\end{array}$ & \\
\hline \multicolumn{3}{|l|}{ Give social validation. } \\
\hline $\begin{array}{l}\text { Inform respondents that } \\
\text { opportunities to respond are } \\
\text { scarce. (Dillman, 2007) }\end{array}$ & & \\
\hline
\end{tabular}

\section{Reducing Social Costs Establishing Trust}

survey company QuestionPro. After downloading the data into Microsoft Excel and subsequently into the Statistical Package for Social Sciences (SPSS), the data will be analyzed as detailed in the data analysis section. A reduction in nonresponse error will be gained by creating a respondent friendly survey with a cover letter stating the purpose of the survey, timeframes for study completion, and the importance of the research. The cover letter will also describe the sponsorship of University of Louisville, Dean Singer (Kent School of Social Work), and Alberto Godenzi (NADD President) for this particular research as suggested by Dillman (2007).

Dillman (2007) also specifically discusses the principles of web survey design. First and foremost, the most advanced web survey features available should not be used due to the likelihood of increasing nonresponse error due to inability of respondents to access the survey. 
This will be less of a concern with a university population due to the ready availability of advanced technology, but the advice to keep it conservative will be heeded. Some of Dillman's (2007) specific concerns will be addressed with the web-based survey software that has been chosen. With QuestionPro there are safeguards against one person completing the survey more than once, preventing duplicate survey entry into the database, and providing specific guidance on color usage and other design factors that lead to successful data collection.

In addition to a web-based survey, data will also be collected through a Word document fill-in form that can be emailed or mailed to the researcher. Subjects may also be called and give data via a phone based interview. These details are outlined further in the next section.

\section{Data Collection}

Information will be gathered via the Internet through a secure survey website with software designed specifically for that purpose (QuestionPro). The internet survey software includes a built-in mechanism that does not allow duplicate survey responses from participants, and all participants will be provided with a password to add further assurance that only those invited to participate will be able to do so. Because this survey will be administered to a national sample, the Internet will be used in addition to the Tailored Design Method to be explained fully later (Dillman, 2007). If preferred, study participants will have the opportunity to download the survey in Word document fill-in form attached to an email soliciting participants (Schaefer \& Dillman, 1998). Those who choose to complete the survey may email it back as an attachment.

Data will be securely stored so that only the principal investigator and co-principal investigator have access to them. Completed surveys will be stored in the co PIs' locked office on password protected computers not accessible to the general employees. Neither leaders nor their employees will have access to completed survey results on an individual basis. In fact, once the surveys are matched by name and prior to data analysis, the survey data will be deidentified by assignment of matched numbers in place of the names. The two endorsers (Terry Singer, Dean of the Kent School of Social Work and Alberto Godenzi, President of the National Association of Directors and Deans) are not members of the research staff and will not have access to any individualized or aggregate raw data; they will only receive data analysis results. 
The Multifactor Leadership Questionnaire Form 5x-short (Avolio \& Bass, 2004) along with a demographic and open-ended questionnaire will be available in an online survey format and in an electronic Word document format. There will be an email address and phone number on the web based survey site for questions. This data will be gathered primarily via the internet, and, if needed, phone surveys that are gathered will be hand entered into the SPSS software package directly.

\section{Subject recruitment}

Emails will be sent following receipt of the University of Louisville's Institutional Review Board (IRB) approval to conduct this research. The introductory email (Appendix A) will invite all deans, directors, and chairs from all of the CSWE accredited schools of social work listed in the NADD directory to participate in the survey which will be attached in a Word format. In a second email contact two weeks following the first, the leaders will be reminded to complete the survey (Appendix B). All subsequent contacts will be sent to the leaders in accordance with response rates. A third contact will occur one week later and be worded as a thank you and a reminder to complete the survey (Appendix C). The fourth contact occurring two weeks after the third will be a stronger appeal to nonrespondent subjects reminding them of the importance of the research and their participation in it (Appendix D). The final contact occurring one week after the fourth will be delivered to nonrespondent subjects by mail or phone and will have a gentle but urgent tone designed to entice the subject to respond to the survey (Appendix E). This five contact method is described in detail by Dillman (2007) and is used in this study to increase response rates. The entire follow up process takes six weeks, and so the data collection period will be for eight weeks in totality. All correspondence will include both letters of support from Alberto Godenzi (See Appendix F) and Dean Terry Singer (See Appendix G).

As deans, directors, and chairs from the CSWE NADD list respond with a completed leadership survey, email invitations will be sent via the leader's identified email contact person to all possible employees/raters in their school/unit to complete a corresponding employee/rater survey on that particular leader's leadership practices. Employees/raters are defined as direct reports of the deans, directors, and chairs and may include administrative assistants, instructors, 
lecturers, part-time faculty, and full-time faculty who have worked with the leader for at least 6 months. Raters will be provided two ways to complete and return their rater surveys including (a) an attached Word document survey that they may complete without printing out and return via email or (b) a secure online web-based survey address where they may click and go to complete the anonymous survey. Employees/raters will receive reminder contacts until at least two rater surveys are returned or until a maximum of four follow up contacts have been made. These contacts will be primarily email but may include phone contacts or mail contacts. Any phone survey data collected will be entered directly into SPSS as mentioned above. Appendixes $\mathrm{H}, \mathrm{I}, \mathrm{J}$, $K$, and $L$ show the letters that will be emailed to the raters as per Dillman's Tailored Design Method (2007).

The leader's name will be in both leader and rater surveys in order to facilitate the matching of MLQ surveys; the identified data will be destroyed following the completion of data matching. For example, the first leader to respond will be assigned the code of $A$. Each corresponding rater survey will be numbered consecutively starting with the code $\mathrm{A} 1$. Once all leader and rater surveys are matched, data will then be deidentified. At that time, all names will be deleted from the SPSS database. Data analysis will then take place.

\section{Data collection tools}

The survey in this study is comprised of five main sections: (1) preamble (Appendix M), (2) demographic and open-ended questions for leaders (Appendix N), (3) the Multifactor Leadership Questionnaire Form 5x-short both leader and rater forms (Avilio \& Bass, 2004) (See Appendix $O$ and $P$ for sample items), (4) demographic and open-ended questions for raters (Appendix Q), and (5) the Rapid Organizational Learning Evaluation (ROLE) developed by vanZyl (2007) for leaders only (See Appendix R for sample items). The scale items and the demographic and open-ended questions regarding the research topics will be entered into the QuestionPro software and placed on QuestionPro's web survey host site on the World Wide Web.

The Multifactor Leadership Questionnaire Form $5 x$-short, both leader and rater forms, (Avolio \& Bass, 2004) have been purchased in bulk from MindGarden for use in this research in accordance with copyright law. As previously mentioned, the MLQ Form 5x-short measures a 
leader's leadership style using the full range of leadership model and includes the Outcomes of Leadership Subscale. See Appendix S for permission to use MLQ.

The Rapid Organizational Learning Evaluation (ROLE) is used in this research with permission from the author in accordance with copyright law (vanZyl, 2007). This instrument has demonstrated a Cronbach alpha $=0.89$ in administration to a group of employees from the Louisville Metro Health Department.

This survey will be pretested to insure validity and reliability of the information gathered, ease of access to the survey itself, and clearness of the question and answer choices (Sue \& Ritter, 2007). For pretesting a small sample of the target population will be selected to complete the survey and provide feedback on the instrument. In this case pretesting will occur in the state of Kentucky at three schools, Brescia University (a small BSW level school), Western Kentucky University (a medium size BSW/MSW level school), and the University of Louisville (a large size MSW/Ph.D level school) in order to provide initial impressions of the survey instrument. The pretest survey will include an extra section about the ease of completion and any concerns about the survey that will not be included in the actual survey.

The web survey design includes elements such as a progress marker to discourage respondents from dropping out, fixed format question construction, and limited differences in visual appearance of the questions (Dillman, 2007). Other principles of the Dillman's Tailored Design Method will be utilized, as well, as described previously in the Tailored Design Method section (Dillman, 2007).

\section{Protection of Human Subjects}

\section{Issues of confidentiality/informed consent}

Respondents will be invited to participate in this research. The survey length and voluntary nature of participation will be outlined in the introductory letter/email, along with contact information whereby the researcher may be reached. The confidential nature of survey responses will be assured with the following statement in all subject recruitment letters:

Your survey responses will be strictly confidential and data from this research will be reported only in the aggregate. No attempt will be made to ascertain your identity or the 
IP address of the computer from which the survey was accessed. Your name will not be mentioned in any reporting, publication or presentation. Your information will be coded and will remain confidential.

The procedures for the confidential handling of data outlined above will be explicitly followed in this study. Assurances of confidentiality are presented in both the online survey and the Word document survey as preambles. See Appendix M.

\section{Benefits and risks}

The benefits of this study include (a) contributing to the literature on leadership in social work and (b) contributing to the literature on leadership style, in general. This study poses no foreseeable risks or threats to social work educators.

\section{Institutional Review Board}

In accordance to standard institutional procedures of research, an application to the University of Louisville's Institutional Review Board will be submitted for approval. See appendix S.

\section{Variables Operationalized}

The variables of leadership style, gender, and organizational culture will be operationalized in this section. These variables are integral to the nature of this study.

\section{Leadership style and the MLQ Form 5x-Short}

One measurement of leadership style will be used in this study. The MLQ Form 5x-short, both leader and rater forms will be used (Avolio \& Bass, 2004). One leader completes a leader form AND either three subordinates or two peers complete a rater form. The leader and rater forms are combined to provide one score of leadership style derived from the full range of leadership model (Bass \& Riggio, 2006) that may or may not include transformational, transactional, and laissez faire style scores and will include a leadership outcomes score. The scale takes approximately fifteen minutes to complete.

The MLQ Form 5x-Short (Avolio \& Bass, 2004) consists of forty five items, four intercorrelated items for each of nine leadership components and nine items for three leadership outcomes components (Exta effort - three items; Effectiveness - four items; Satisfaction - two 
items). Each item is rated on the frequency it occurs based on a five point rating scale with anchors ranging from $0=$ not at all to $4=$ frequently, if not always.

The MLQ Form 5x-Short (Avolio \& Bass, 2004) scale is an established and widely used instrument. The MLQ has been in use since 1985, and this is the $3^{\text {rd }}$ iteration of the instrument. Leaders in a variety of settings including the military, government, educational, manufacturing, high technology, church, correctional, hospital, and volunteer organizations have been examined using the MLQ. A variety of leaders of many ages, genders, and educational levels from over thirty countries have used the MLQ, and it has been successfully translated into German, Italian, Portuguese, Spanish, Swedish, and Turkish (Avolio \& Bass, 2004).

The current MLQ Form 5x-Short (Avolio \& Bass, 2004) was normed on data from the MLQ U.S. normative data base collected until the year 2004. This database includes three thousand three hundred and seventy five leaders and twenty seven thousand two hundred eighty five raters in the U.S. and can be used in analysis of the current study data to determine to what extent social workers differ from the norm. Permission to use the instrument was given by the publishers, Mind Garden Inc. See Appendix T.

\section{Validity of the MLQ}

Good internal validity of the MLQ has been established (Bass \& Riggio, 2006). The MLQ scales have demonstrated good to excellent internal consistency with alpha coefficients above the .80 level for all MLQ scales (Bass \& Riggio, 2006). Intercorrelations among the twelve MLQ Factor Scores range from .69 to .83 . (Avolio \& Bass, 2004). Debate surrounding the individuality of the components of transformational leadership as defined by the MLQ is frequent, however, Bass and Riggio (2006) defend the close relationships between the components as evidence that the construct is multidimensional yet still one construct where each dimension influences the others.

Construct validity has been established, as well (Bass \& Riggio, 2006). Antonakis et al. (2003) used confirmatory factor analysis to find support for the nine-factor model used in the MLQ Form 5x-Short (Avilio \& Bass, 2004). Antonakis et al. (2003) found that across 36 items factor 
loadings were significant and averaged .65 across all items and speculated that earlier findings of nonsupport of the model were due to the large sample variability.

\section{Test-retest reliability}

Test-retest reliability coefficients for the MLQ were established early on with rates ranging from .44 to. 73 for leader self-ratings and from .52 to .82 for follower ratings of leaders on the various scales with even higher reliability coefficients obtained in later research (Bass, 1997).

Measuring the variable of leadership style with the MLQ Form $5 x$-Short (Avolio \& Bass, 2004) will require names of leaders which brings up a possible concern regarding confidentiality on the leader's part. However, gathering this information is vital to the study purpose, and confidentiality will be assured. The accuracy of measurement achieved with these measures is well worth the sharing of personal information.

\section{Gender}

Gender will be defined as self definition of either male or female gender in the demographic questions section of the survey. Gender will be provided by both leaders and raters.

\section{Organizational culture}

Organizational culture will be measured by the type of higher education institution the social work educator works within as operationalized by their answer to survey questions regarding status of the university. They will be given choices between (a) type of social work program: four year bachelors, masters, or doctoral granting, (b) size of school, (c) state of school, and (d) size of city setting. Participants will be asked to place their organization on a continuum with the anchors of $0=$ Completely traditional/frowns on change to $5=$ Completely modern/extremely open to change and to rate the degree to which their organizational context impacts their leadership style with the anchors of $0=$ Not at all to $5=$ Completely dictates my leadership style.

The Rapid Organizational Learning Evaluation (ROLE) (vanZyl, 2007) will also be used to assess the organizational learning and openness to change in the culture of each leader's university. The ROLE was designed to measure organizational learning, and it contains many items relevant to teamwork, leadership, vision, and success. 


\section{Statistical Analyses}

Data will be primarily gathered into the web survey host site, Question Pro, where it will be placed in an excel database. Following data cleaning, this database will be downloaded and exported into SPSS for analysis purposes. Data gathered from the Word format surveys returned by email will be hand entered into SPSS. In order to perform statistical analyses at the $90 \%$ confidence level with a $5 \%$ margin of error an estimated sample size of 272 will be needed. With over 600 CSWE accredited schools of social work in the United States and assuming multiple leaders per school, this sample size is achievable.

\section{Descriptive, Univariate, and Bivariate Analyses}

A series of univariate and descriptive analyses will be conducted to determine the range or dispersion among many of the key variables. Results from the univariate analyses will be able to describe the response pattern to the dependent (leadership style) and independent (gender, organizational culture) variables within the data set (Mertler \& Vannatta, 2002).

To examine the relationships between key variables and specifically test the proposed hypotheses, a series of bivariate analyses will be conducted (e.g. Independent t-tests, bivariate correlations, and tests of Chi-square) (Mertler \& Vannatta, 2002).

\section{Multivariate analyses.}

Two way ANOVA will be utilized to examine the relationship between leadership style (DV) and gender and organizational culture (IVs), and ANOVA may be used to test the significance of group differences and predict group membership if group differences are found (Mertler \& Vannatta, 2002).

\section{Study Hypotheses}

Three main hypotheses are stated in this section stating the predicted relationships between study variables as suggested by the literature.

Hypothesis 1: Social work educators utilize a transformational leadership style more often than transactional or laissez faire styles.

Hypothesis 2: Female social work educational leaders utilize a transformational leadership style more often than male leaders. 
Hypothesis 3: Organizational culture has an impact on the social work leader utilization of transformational leadership styles with low status institutions allowing more utilization of transformational leadership style.

Hypothesis 4: Organizational culture and gender combine to predict the utilization of a transformational leadership style by social work educational leaders.

Hypothesis 5: There will be a positive correlation between transformational leadership style and effectiveness among social work educational leaders.

\section{Conclusion}

The research study design has been clearly explained and key variables and concepts have been identified and operationalized, and study hypotheses have been stated (Rubin \& Babbie, 2001). The sampling procedures, data collection and analysis, and human subjects' protections have been detailed, as well. 


\section{CHAPTER IV}

\section{DATA COLLECTION AND ANALYSIS}

Two different questionnaires (one for leaders and one for employee raters) including demographic data, the MLQ-5x Short Scale (both leader and employee rater forms) and the ROLE scale instrument (for leaders only) were utilized in this study to gather information on leadership style, organizational context and demographics. These instruments were accessible online with a pass code only and in a Microsoft Word document format. The instrument in Word document format could be returned via regular mail or email.

The total population included the entire National Association of Deans and Directors (NADD) listserv with a total of one hundred ninety five member leaders. A total of thirty three (33) leader surveys were returned from deans, directors and chairs of social work departments in CSWE accredited schools in the United States and Puerto Rico. Returned leader surveys included almost seventeen percent $(16.9 \%)$ of the total NADD list.

Seventy four employee surveys were returned from the faculty and staff employees of deans, directors and chairs of social work departments in CSWE accredited schools in the United States and Puerto Rico. The leaders reported five hundred sixty nine (569) faculty employees. A return rate of twelve percent $(12.3 \%)$ of faculty employees was established for this study.

The surveys were returned in three different formats. Eighty seven surveys were completed online, eighteen were completed in a Word document and returned by email and two in regular mail for a total of one hundred and seven completed surveys. Interestingly, out of the returned surveys the online leader survey completion rate was forty one percent $(41 \%)$ while the online employee survey completion rate was seventy three percent $(73 \%)$.

\section{Difficulties in Obtaining Data}

Prior to data collection two letters of support were garnered (See appendix F and G), one from Dean Terry Singer of the University of Louisville and the other from Alberto Godenzi, 
President of the National Association of Deans and Directors (NADD). These letters were included with all email requests for participation to both the leaders and their employees.

Data collection occurred in a two phase process. Initially, leaders were sent two emails through the NADD listserv requesting participation in this study. This was supposed to be six emails as per sampling procedures, but due to respect for time of social work leaders and the amount of email sent on the NADD listserv by others, this was reduced to two emails. After a six week data collection period, only thirty leaders ( $15.4 \%$ of the total sample) had returned surveys. With one hundred ninety five members of the National Association of Deans and Directors, another attempt to increase the sample was made as predetermined by sampling procedures.

As predetermined in the methodology, scripted phone calls to over one hundred randomly chosen CSWE accredited schools were made over a four week period resulting in the return of three more surveys. Phone calls were discontinued due to low response rate. At survey completion, thirty three leaders $(16.9 \%$ of the total population) had returned surveys.

Implementation of the second phase of data collection happened six weeks past schedule after all thirty three leader surveys were gathered. Email solicitations for employee surveys were sent to the leader's chosen contact person as listed on the leader survey. Six emails were sent as put forth in Chapter III (Dillman, 2007). A total of seventy four rater surveys were returned. Ten of those employee surveys had no corresponding leader survey. The total group of matched surveys included fifteen leaders (45\%) of the total leader group $(n=33)$, and sixty four $(86.4 \%)$ corresponding total employee surveys $(n=74)$.

\section{Methodological Changes}

Initially, only the matched group was to be used for analysis, however, in an effort to maximize data, it was decided to analyze not only the matched group $(n=79)$ but also the leader only $(n=33)$ and the employee only groups $(n=74)$ in separate analyses. The results follow the respondent demographic section. Specific procedures used in this data analysis are shown in Table 4.

\section{Respondent Demographics}

Many demographic variables were explored in this study including age, years of 
Table 4.

Analysis of research questions.

Research Questions

Data Analyses

Conducted t-tests on each scale of the MLQ $5 \mathrm{x}$-short.

What types of leadership styles do social workers in educational administration typically practice?

Compared means of three groups to national norms of MLQ $5 x$-short utilizing t-tests.

Does the type of leadership style social work leaders practice vary by gender?

Recoded leadership style into groups of low, medium and high based on score distributions in this sample.

Conducted one way t-tests.

Conducted correlation analysis on multiple organizational context variables, the ROLE Is there a relationship between the type of learning organization and leadership style? data, and leadership style.

Conducted frequency analysis on scale questions about context.

Is the predominant type of leadership style practiced by social workers in educational administration effective?
Conducted correlation analysis on predominant type of leadership style (transformational) and effectiveness.

Conducted multiple regression. Unable to

Do organizational culture and gender complete due to homogeneity of variance.

combine to predict leadership style? Conducted two-way ANOVA.

Experience, and degree. In this section demographics of the study group are compared to CSWE statistics (Lennon, 2004).

\section{Leader Demographics}

The total number of deans, directors and chairs responding to this survey was thirty three. This group of leaders included fourteen males and nineteen females. Thirty two of the leaders (97\%) had a Ph.D. or a DSW as their highest degree with disciplines ranging from social work $(66.7 \%)$, psychology (12.1\%) and various others (21.2\%) (see Figure 1). Their titles were equally divided between dean and director ( $42.4 \%$ each) with four leaders holding the title of chair $(12.1 \%)$ and one being an interim director $(3 \%)$. There was no incentive for them to participate 


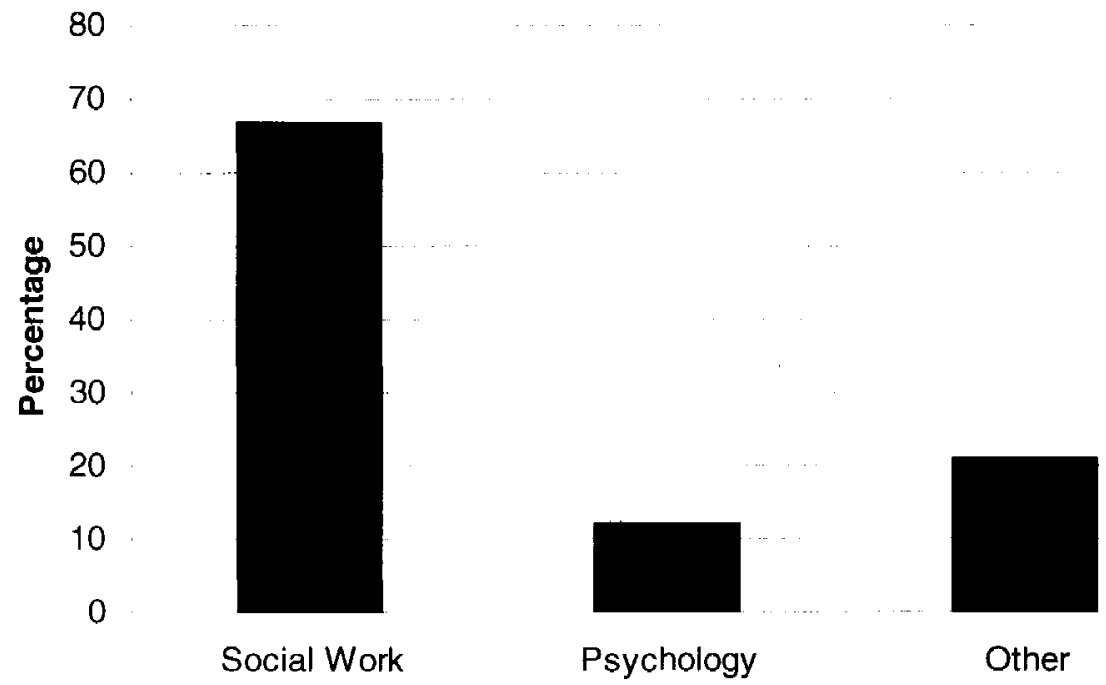

Figure 1.

Disciplines of deans, directors and chairs by percentage.

other than to assist with increasing the knowledge base of the social work profession. All respondents were volunteers.

In 2002, Lennon reported there were a total of 856 social work administrative professionals in graduate and joint CSWE accredited social work programs. This included 144 deans and directors ( 70 male and 74 females). This means that this study includes $20.14 \%$ of deans and directors in these programs.

Twenty-two (22) were in the age category of 56-65 years old. However, the range was 30-75 years, and only one of the remaining age categories contained more than three leaders (see Figure 2). The mean years of experience at any college is 22.67 years with 25 years being the most commonly given answer. Mean years at their current college is 12.16 years with the mean for years at their current position being 3.89 years.

The respondents represent deans, directors and chairs of social work schools located in 23 states in the US as well as Puerto Rico. Their schools include the entire range suggested in the survey, but the majority of the colleges and universities represented had over 10,000 students $(75.8 \%)$ and were combined undergraduate and graduate/professional schools (81.8\%). Overall, 
these social work deans, directors and chairs directly influenced 569 social work faculty members in CSWE accredited schools by their own report. According to Lennon (2002) there were a total of

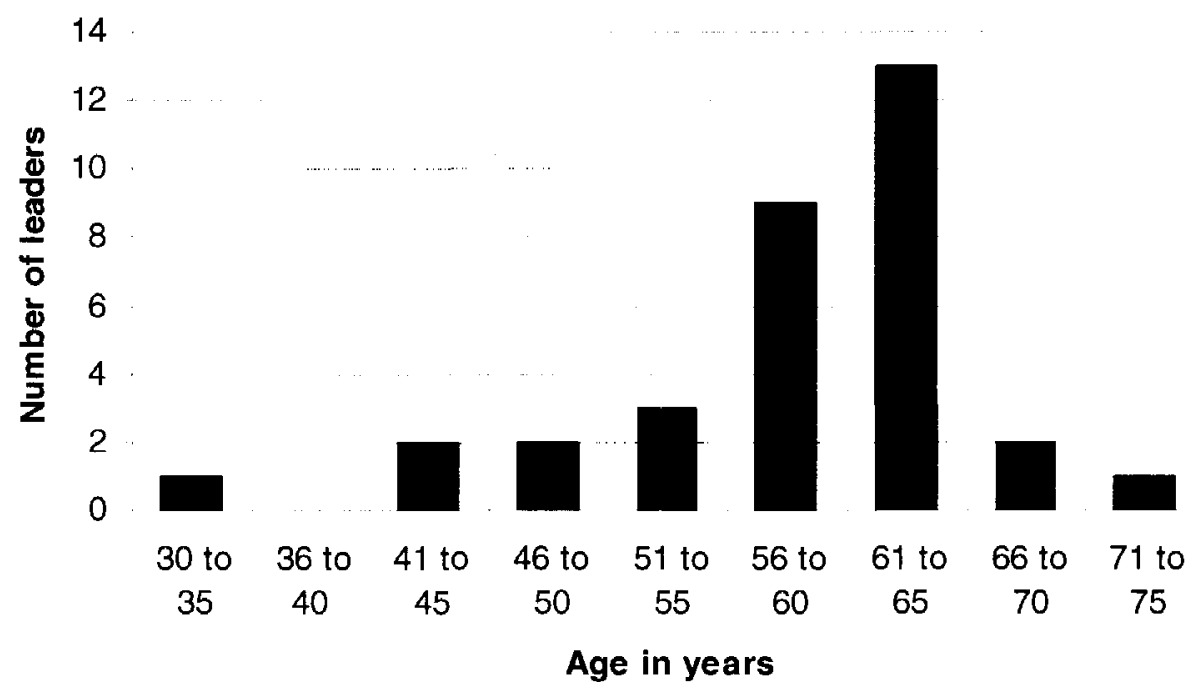

Figure 2.

Deans, directors and chairs by age.

3,371 social work faculty members in CSWE accredited schools, so these leaders influence $16.9 \%$ of all faculty members. It is important to note that leaders from four programs with a reported total of 2,666 students reported zero faculty. One of these reported that there was no way to divide the faculty into areas of primary teaching responsibility (bachelor, master and Ph.D faculty), therefore, this leader left that item completely blank. If an average of 20 students per faculty member was used, then for those four leaders reporting 2,666 students another 133 faculty would have been reported.

These leaders indirectly influence 12,732 social work students yearly or $18.5 \%$ of the 68,837 social work degree seeking students in CSWE accredited programs (Lennon, 2002). This study offers an important exploration of leadership in social work education but will not be generalizable to all deans and directors in CSWE accredited schools.

\section{Employee Demographics}

The total number of peer employee raters responding to this survey was 74 . With $73 \%$ of the respondents female, the employee sample is predominantly female which tends to mirror the 
general demographic pattern of the social work profession (Lennon, 2002). The age of the employees is much more diverse than that of the leaders with no category containing more than 14 employees (or $18.9 \%$ of the total sample). The age of employee respondents range from 30 to 75 years (see Figure 3 ).

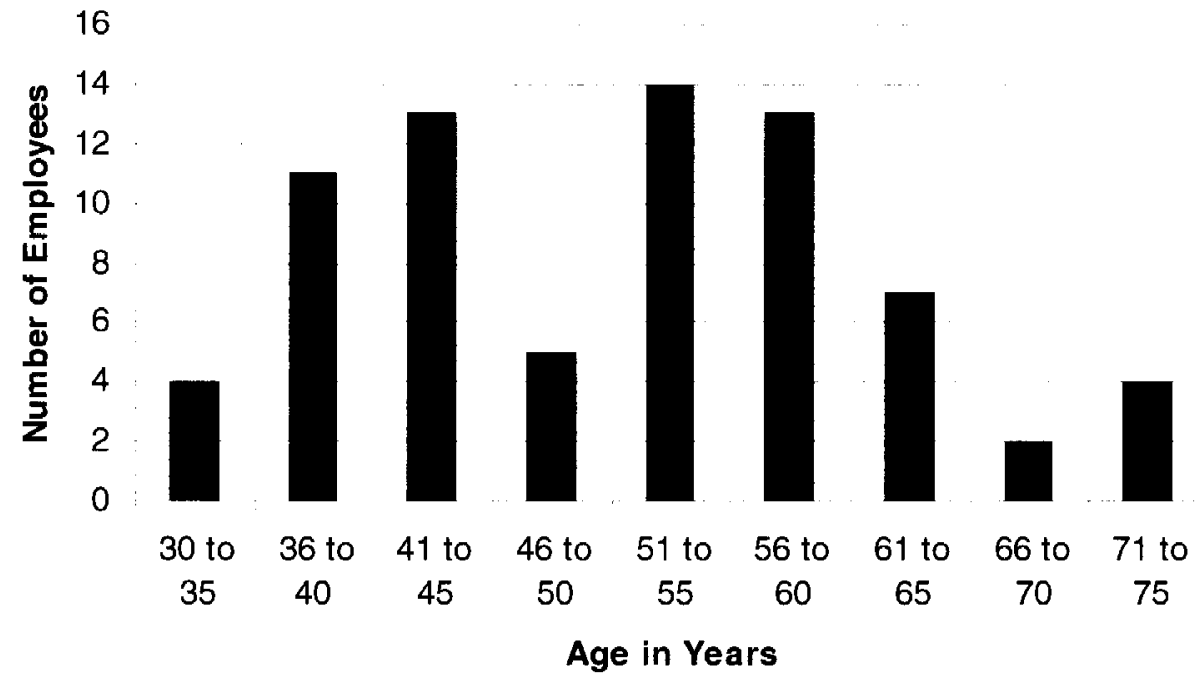

Figure 3.

\section{Employees by Age.}

The employee group has a $66.2 \%$ rate of Ph.D. attainment and a $25.7 \%$ rate of masters degree attainment in disciplines including social work (68.9\%), psychology (6.8\%) and education (2.7\%). Others (21.6\%) included public administration, anthropology, business, mass communications, information technology, health sciences and public health.

The employee respondents have an average of 7.5 years at their current position with one year given as the most commonly given response. Their experience, however, is much higher with a mean of 14.5 years experience at any school with a mode of ten years. This falls far short of the leader's average years of experience at any college of 22.7 years with 25 years being the most commonly given answer.

\section{School Demographics}

\section{School/university size.}


Over $80 \%$ of the leaders in this study reported a college/university type of combined undergraduate and graduate/professional and over $75 \%$ reported a college/university size of over 10,000 students. The colleges/universities where these leaders work were predominantly located in cities with over 100,000 people $(58 \%)$ while the remaining city sizes were divided into two categories 50,001 to $99,999(21 \%)$ and 5,001 to $50,000(15 \%)$.

When the size of the college/university was compared to the CSWE report of baccalaureate only, graduate only and joint programs, the distribution was not consistent (Lennon, 2004). The main difference in the study respondents and the total CSWE population of accredited schools was that only two baccalaureate program leaders responded to this study. This was far lower $(6.1 \%)$ than the percentage of BSW programs among all social work programs $(63.1 \%)$.

\section{Program descriptions.}

As noted earlier the programs described by their leaders include programs in 23 states and Puerto Rico. The programs in this study were predominantly large programs with a mean of 400 students and 29 faculty members in the matched group; these numbers changed minimally in the leader group with a mean of 380 students and 21 faculty. It is important to note that four leaders of some of the larger programs didn't answer the faculty number questions which could have resulted in higher numbers of faculty overall. Programs ranged in student body size from 42 to 1,004 students with faculty member size ranging from 2 to 94 . There was one extreme outlier response to the Ph.D. faculty size question. A response of 53 was extreme given the number of Ph.D. students reported (100 Ph.D. students), however, that program has 800 students total so it is possible that this number was entered into the wrong category. Alternatively, faculty could have taught in both MSW and Ph.D. degree programs at that school. This response was included in all analyses. Comparatively, a similar size program with 740 students reported 40 total faculty members, much less than the 94 total faculty reported by the outlier. Without the 53 response, the range would have been 2 to 47 faculty members. CSWE reports that 14 joint programs and 10 graduate only programs have 60 or more faculty members, so it is possible that this response is correct (Lennon, 2004). 
Most of the programs in this study were joint programs $(90.9 \%)$ in varying combinations of baccalaureate, graduate and Ph.D. level programs. The most common type of joint program reported was a BSW/MSW program at $13(39.4 \%)$ followed closely by BSW/MSW/Ph.D. programs at $11(33.3 \%)$ and MSW/Ph.D. programs at $6(18.2 \%)$. The remaining three programs were BSW $2(6.1 \%)$ and MSW $1(3 \%)$. When compared to the CSWE report of program types (which doesn't include Ph.D. programs) there is a difference. CSWE reports that joint programs make up $27 \%$ of the total CSWE accredited population of programs whereas this study includes over $90 \%$ joint programs (Lennon, 2004).

\section{MLQ 5x-Short Findings}

The findings were divided into two sections: comparison with national norms and exploration of this particular sample. The MLQ 5x-Short normative group included leaders from industries as varied as banking, education, government, health care, manufacturing, retail, and mining (Avolio \& Bass, 2004). While these groups did not specifically include social workers, there were most certainly social workers among these leaders.

\section{Social Work Leadership Compared to National MLQ Norms}

This section will highlight the various MLQ $5 x$-Short scales comparing these social work leaders to the national sample used to validate norms for the MLQ 5x-Short form. Analysis will begin with the transformational leadership scales. Due to missing data, there were different numbers of leaders for some scale analyses (see Table 5). If a leader did not rate a particular item, the item was thrown out for that leader.

\section{Transformational leadership}

Transformational leadership as measured by the MLq $5 X$-Short form includes 5 subscales: Idealized Influence (Attributed), Idealized Influence (Behavior), Inspirational Motivation, Intellectual Stimulation, and Individualized Consideration (Avolio \& Bass, 2004). Each of these subscales measures a different aspect of transformational leadership, and each will be explored separately in this section. In addition, the average of the five subscales will be used as

\section{Table 5.}

\section{Missing data for the MLQ 5x-short scales.}




\begin{tabular}{l|c|c}
\hline \multicolumn{1}{c|}{ MLQ 5X-Short Scale } & \# of Items & Number of Leader Responses $(n=15)$ \\
\hline Idealized Influence (attributed) & 4 & 15 \\
\hline Idealized Influence (behavior) & 4 & 15 \\
\hline Inspirational Motivation & 4 & 15 \\
\hline Intellectual Stimulation & 4 & 14 \\
\hline Individualized Consideration & 4 & 15 \\
\hline Transformational & 20 & 15 \\
\hline Contingent Reward & 4 & 15 \\
\hline Management by Exception (active) & 4 & 14 \\
\hline Transactional & 8 & 14 \\
\hline Management by Exception (passive) & 4 & 15 \\
\hline Laissez Faire & 4 & 15 \\
\hline Passive Avoidant & 8 & 15 \\
\hline Extra Effort & 3 & 14 \\
\hline Effectiveness & 4 & 15 \\
\hline Satisfaction & 2 & 15 \\
\hline
\end{tabular}

an overall measure of transformational leadership.

Avolio and Bass (2004) define transformational leadership as a "process" where leaders influence the awareness, values and behaviors in ways that improve individual, group and

4.5

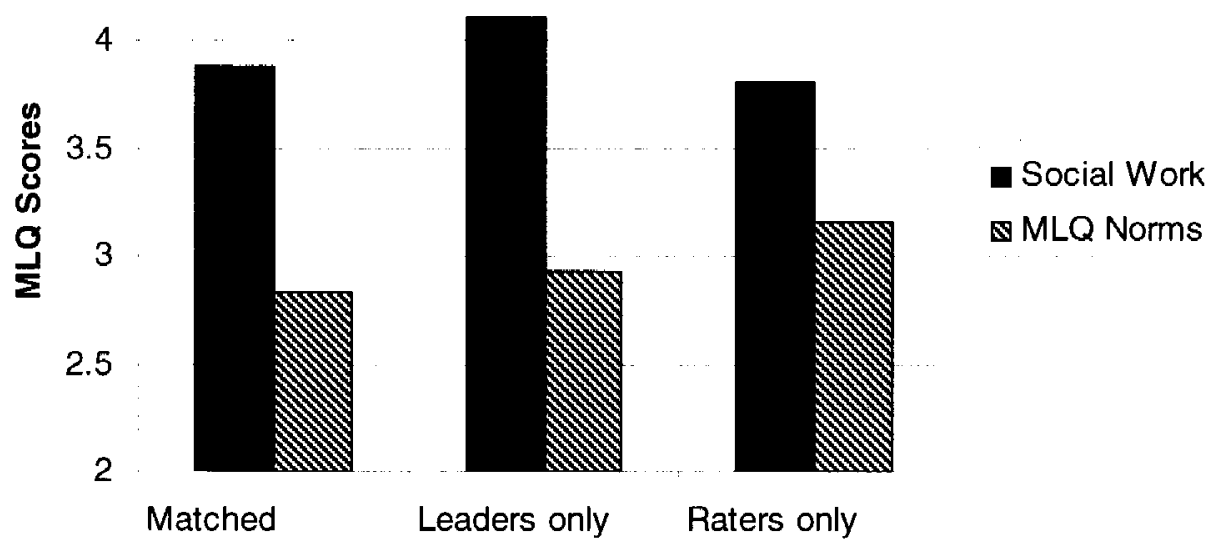

Figure 4.

Transformational leadership (combined) scales comparing social work leader scores to national norms.

organizational performance outcomes. In this study all five of the subscales of transformational leadership were statistically significant. Figure 4 demonstrates the differences between the social 
work leaders under study and the MLQ norm groups. The combination of the five scales into one measure of transformational leadership demonstrates that as a group social work administrators are higher than the MLQ national norms. The difference between the transformational leadership scores of matched leaders and raters and the MLQ norm is statistically significant, $t(14)=6.280$, $p<.001$. The difference between the mean of leader self-ratings and the MLQ norm was statistically significant, $t(32)=14.143, p<.001$. Also significant was the difference between the rater only scores and the MLQ norm, $t(15)=5.999, p<.001$. Additionally, there was no significant difference between the raters and their matched leader's self-ratings, $t(14)=-1.055, p=.309$.

Table 6 displays Ms and SDS for all scales of the MLQ 5x-Short.

\section{Idealized Influence.}

According to Avolio and Bass (2004) this particular subscale measures the admiration, respect, and trust that leaders are able to elicit from their followers. This concept has to do with considering follower or employee needs over the leaders' own, sharing risks with followers and

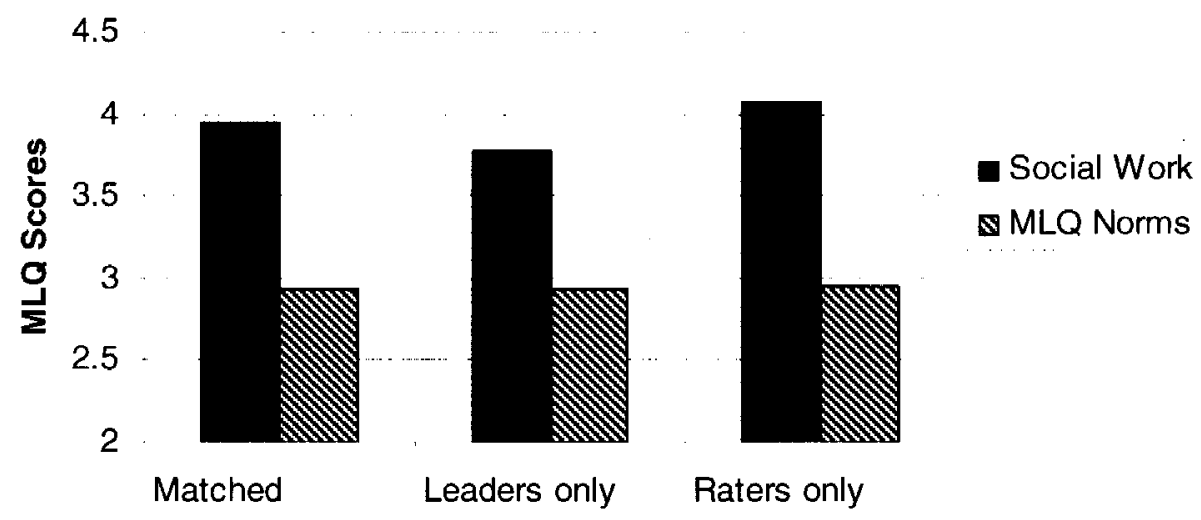

Figure 5.

Idealized influence (attributed) scale comparing social work leader scores and national norms. 
Table 6.

MLQ 5x-Short form scale scores with means and SDs.

\begin{tabular}{|c|c|c|c|c|c|c|c|c|c|c|c|c|c|}
\hline $\begin{array}{c}\text { MLQ 5x-Short } \\
\text { Scale }\end{array}$ & $\begin{array}{l}\text { \# of } \\
\text { Items }\end{array}$ & $\begin{array}{c}\text { Self } \\
\text { Norm } \\
\text { Mean } \\
n= \\
3,375\end{array}$ & $\begin{array}{c}\text { Self } \\
\text { Norm } \\
S D\end{array}$ & $\begin{array}{c}\text { Sample } \\
\text { Self } \\
\text { Mean } \\
n=33\end{array}$ & $\begin{array}{l}\text { Sample } \\
\text { Self } \\
\text { SD }\end{array}$ & $\begin{array}{c}\text { Peer } \\
\text { Level } \\
\text { Norm } \\
\text { Mean } \\
n= \\
5,185 \\
\end{array}$ & $\begin{array}{c}\text { Peer } \\
\text { Level } \\
\text { Norm } \\
\text { SD }\end{array}$ & $\begin{array}{c}\text { Sample } \\
\text { Peer } \\
\text { Level } \\
\text { Mean } \\
n=16\end{array}$ & $\begin{array}{c}\text { Sample } \\
\text { Peer } \\
\text { Level } \\
\text { SD }\end{array}$ & $\begin{array}{c}\text { Total } \\
\text { Sample } \\
\text { Norm } \\
\text { Mean } \\
N= \\
27,285 \\
\end{array}$ & $\begin{array}{c}\text { Total } \\
\text { Sample } \\
\text { Norm } \\
S D\end{array}$ & $\begin{array}{c}\text { Sample } \\
\text { Self }+ \\
\text { Peer } \\
\text { Level } \\
\text { Mean } \\
n=15 \\
\end{array}$ & $\begin{array}{c}\text { Sample } \\
\text { Self }+ \\
\text { Peer } \\
\text { Level } \\
\text { SD }\end{array}$ \\
\hline IIA & 4 & 2.95 & .53 & 3.77 & .62 & 2.93 & .75 & 4.07 & 86 & 2.94 & .64 & 3.94 & .62 \\
\hline IIB & 4 & 2.99 & .59 & 4.11 & .55 & 2.77 & .70 & 3.45 & .50 & 2.88 & .65 & 3.96 & 64 \\
\hline IM & 4 & 3.04 & .59 & 4.27 & 47 & 2.84 & .74 & 4.23 & .74 & 2.94 & .67 & 4.15 & .62 \\
\hline IS & 4 & 2.96 & .52 & 4.13 & 60 & 2.77 & .70 & 3.58 & 80 & 2.87 & .61 & 3.60 & 68 \\
\hline IC & 4 & 3.16 & .52 & 4.27 & .53 & 2.83 & .74 & 3.76 & 58 & 3.00 & .63 & 3.84 & .54 \\
\hline Transformational & 20 & 3.02 & .55 & 4.11 & .44 & 2.83 & .73 & 3.81 & 65 & 2.93 & .64 & 3.89 & .59 \\
\hline $\mathrm{CR}$ & 4 & 2.99 & .53 & 3.91 & .66 & 2.88 & .65 & 3.96 & .60 & 2.94 & .59 & 3.95 & .51 \\
\hline MBEA & 4 & 1.58 & .79 & 2.36 & .76 & 1.72 & .65 & 2.09 & .54 & 1.65 & .72 & 2.21 & 40 \\
\hline Transactional & 8 & 2.29 & .66 & 3.13 & .52 & 2.30 & .65 & 3.02 & 24 & 2.30 & .66 & 3.07 & 17 \\
\hline MBEP & 4 & 1.07 & .62 & 1.83 & .72 & 1.04 & .74 & 2.19 & .70 & 1.06 & .68 & 2.12 & .54 \\
\hline $\mathrm{LF}$ & 4 & .61 & .52 & 1.55 & 48 & .65 & .66 & 1.60 & .70 & .63 & .59 & 1.62 & .58 \\
\hline $\begin{array}{c}\text { Passive } \\
\text { Avoidant }\end{array}$ & 8 & .84 & .57 & 1.69 & .54 & .85 & .70 & 1.90 & .66 & .85 & .64 & 2.27 & .49 \\
\hline $\mathrm{EE}$ & 3 & 2.79 & .61 & 3.90 & .70 & 2.68 & .87 & 3.80 & .88 & 2.74 & .74 & 3.74 & .70 \\
\hline EFF & 4 & 3.14 & .51 & 4.34 & .44 & 3.02 & .73 & 4.02 & 91 & 3.08 & .62 & 4.07 & .75 \\
\hline SAT & 2 & 3.09 & .55 & 4.17 & 57 & 3.08 & .80 & 4.03 & 97 & 3.09 & .68 & 3.97 & .88 \\
\hline
\end{tabular}


displaying conduct that is consistent with leader ethics, principles and values.

As clearly demonstrated by Figure 5, social work leaders scored much higher on average on the idealized influence (attributed) subscale of the MLQ 5x-Short form no matter who was rating the leader. The difference between the average leadership scores of matched leaders and raters and the MLQ norm was statistically significant, $t(14)=6.244, p<.001$. The difference between leader self-ratings and the MLQ norm was also statistically significant, $t(32)=7.532, p$ $<.001$. Also significant was the difference between the rater scores and the MLQ norm, $t(15)=$ $5.330, p<.001$. The rater only and matched leader self-ratings were not significantly different, $t(14)=.795, p=.440$.

A second scale, idealized influence (behavior) measures the actual behavior the social work leader displays. There were differences on this subscale, as well (see Figure 6). The difference between the leadership style scores of matched leaders and raters and the MLQ norm was statistically significant, $t(14)=6.597, p<.001$. The difference between the mean of the leader self-ratings and the MLQ norm was also statistically significant, $t(32)=11.840, p<$

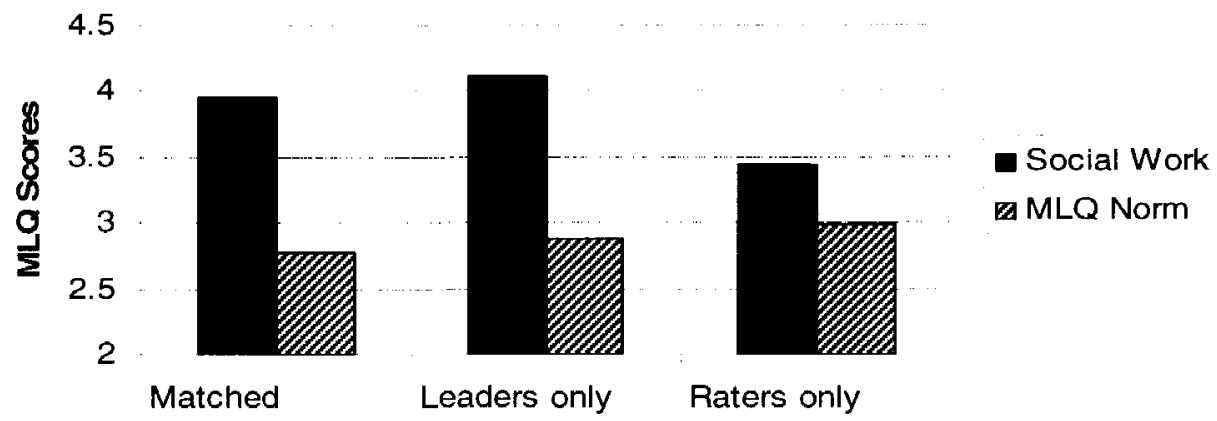

Figure 6.

Idealized influence (behavior) scale comparing social work leaders to national norms. .001. Also significant was the difference between the rater only scores and the MLQ norm, $t(15)=$ 5.436, $p<.001$. Additionally, there was a significant difference between the rater scores and 
matched leader self-ratings, $t(14)==2.959, p=.010$ with leaders rating themselves higher than their employees.

\section{Inspirational Motivation.}

This concept has to do with the ways the leader motivates those around them. Leaders high in inspirational motivation use optimistic and enthusiastic attitudes to assist their employees

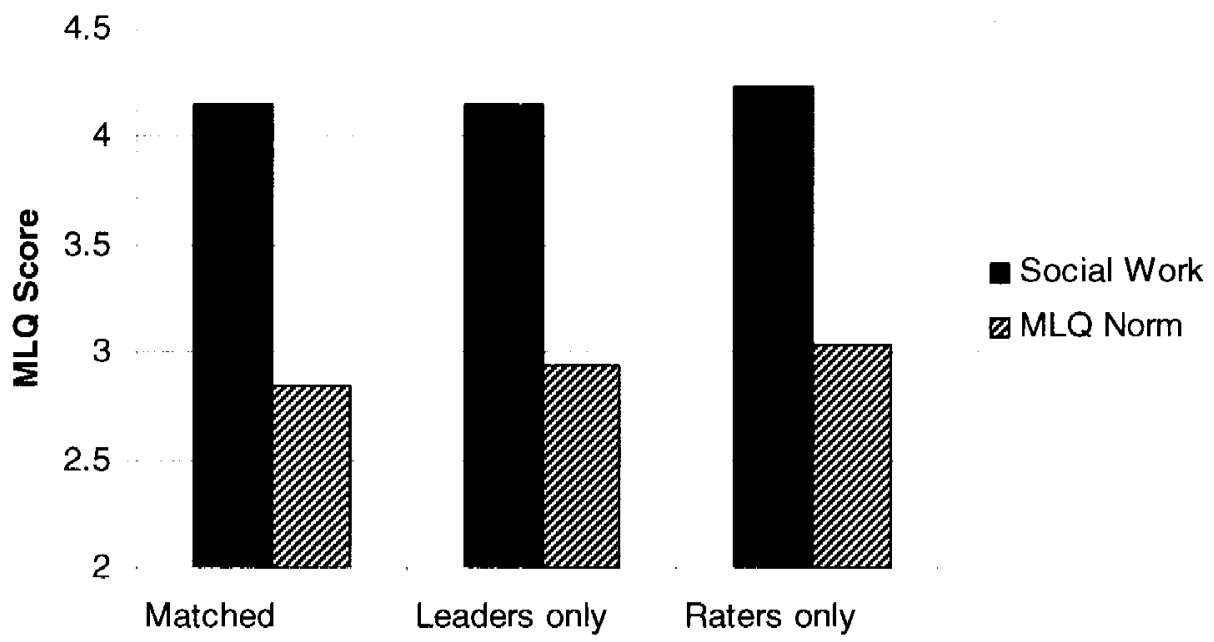

\section{Figure 7.}

Inspirational motivation scale comparing social work leader scores to national norms.

in seeing a bright future for themselves and others (Avolio \& Bass, 2004). The difference between social work leaders and MLQ norm scores are clearly shown in Figure 7. This difference between the mean leadership scores of matched leaders and raters and the MLQ norm was statistically significant, $t(14)=7.558, p<.001$. The difference between the leader self-ratings and the MLQ norm was statistically significant, $t(32)=15.228, p<.001$. Also significant was the difference between the rater MLQ scores and the MLQ norm, $t(15)=7.536, p<.001$. The difference between the rater scores and leader self-ratings was not significantly different, $t(14)=-.221, p$ $=.828$.

\section{Intellectual Stimulation.}

This concept relates to the leader's ability to foster innovative and creative problem solving in their employees through asking for new ideas and handling mistakes privately. Leaders 
high in this area stimulate their employees' thinking of problems in new ways (Avolio \& Bass, 2004). There were differences on this subscale (see Figure 8). The difference between the mean scores of matched leaders and raters and the MLQ norm was statistically significant, $t(14)=$ 4.148, $p=.001$. The difference between the mean of the leader self-ratings and the MLQ norm was statistically significant, $t(32)=11.193, p<.001$. Also significant was the difference between

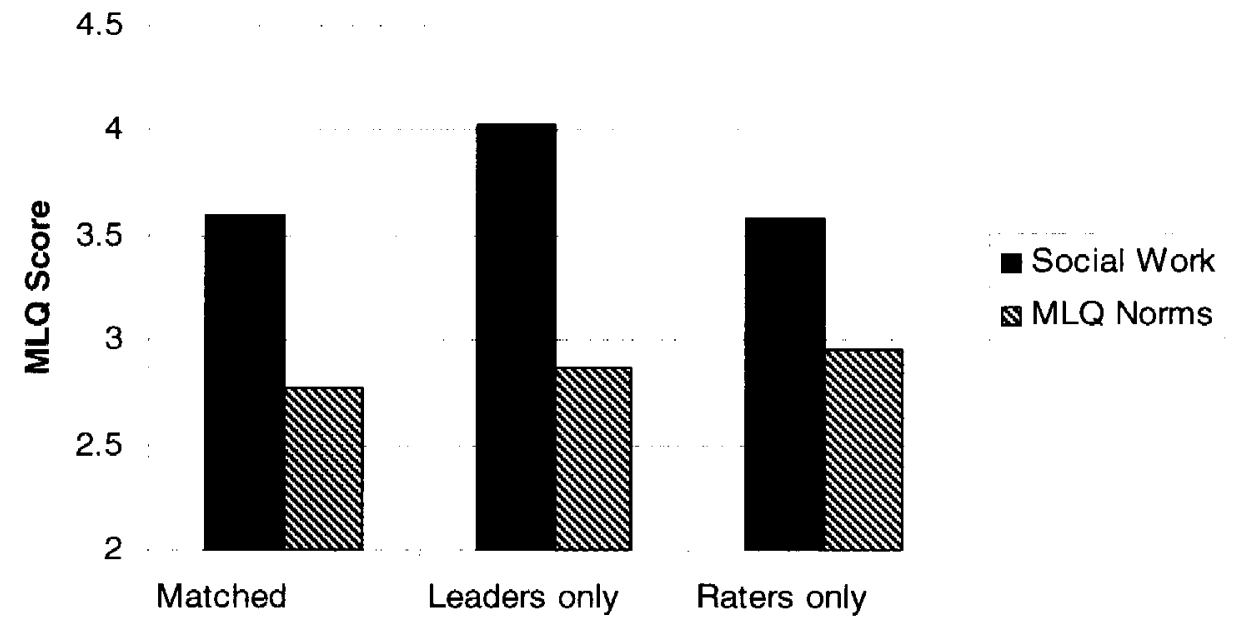

Figure 8.

Intellectual stimulation scale comparing social work leader scores with national norms. the rater only scores and the MLQ norm, $t(15)=4.093, p=.001$. Additionally, there was no significant difference between the raters and the leader self-ratings, $t(13)=-1.800, p=.095$ with leaders rating themselves higher than their employee raters, but this was a trend.

Individual Consideration.

Avolio and Bass (2004) identify mentoring and coaching employees in individualized ways as a hallmark of this leadership concept. Leaders who provide new growth and learning opportunities for employees on an individual basis are high in individual consideration. The difference between the mean leadership scores of matched leaders and raters and the MLQ norm was statistically significant, $t(14)=5.989, p<.001$. The difference between the mean of the leader self-ratings and the MLQ norm was also statistically significant, $t(32)=11.894, p<.001$. Also significant was the difference between the rater means and the MLQ norm, $t(15)=6.393, p$ 


$$
4.5
$$

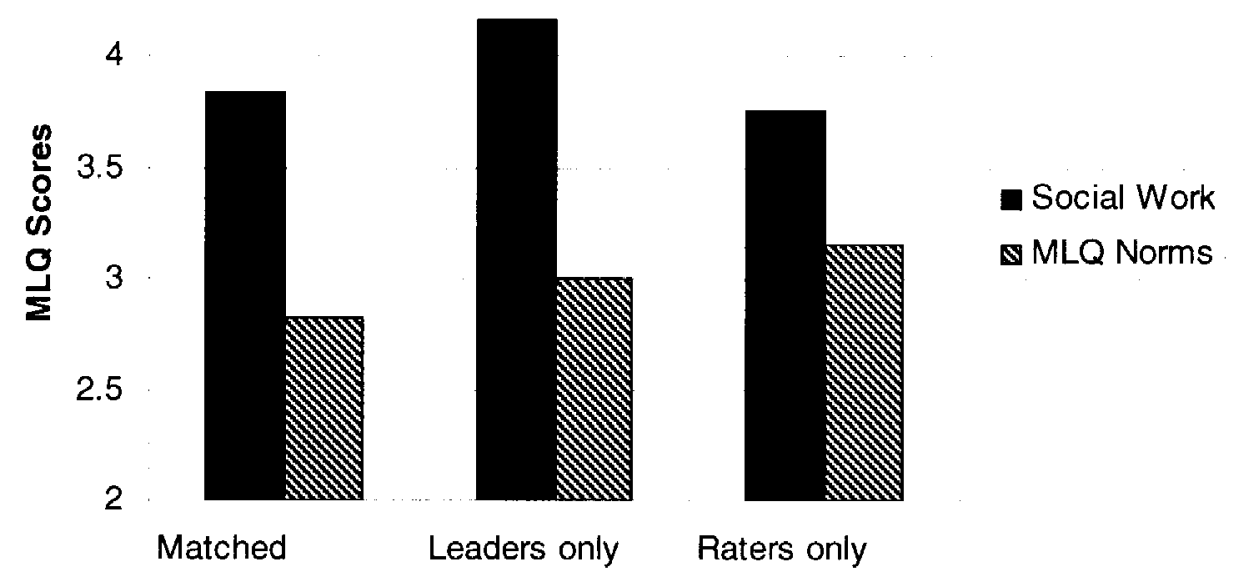

Figure 9.

Individual consideration scale comparing social work leaders to national norms.

$<.001$. Additionally, there was a significant difference between the raters only and the leader selfratings, $t(14)=-2.216, p=.044$ (see Figure 9) with leaders rating themselves higher on this scale than their employee raters.

\section{Transactional Leadership}

Two subscales are used by the MLQ $5 x-$ Short form to measure transactional leadership: the contingent reward and the management-by-exception scales. Transactional leadership is defined by both constructive (contingent reward) and corrective (management-by-exception) styles of management. Leaders reward employees for their effort and focus on mistakes, errors and failure to meet standards (Avolio \& Bass, 2004). Scores on the contingent reward and the management-by-exception (active) subscales were averaged to attain a general transactional leadership score (see Figure 10). The combination of the two subscales into one measure of transactional leadership demonstrates that as a group social work administrators are higher than the MLQ national norms. The difference between the leadership mean scores of matched leaders and raters and the MLQ norm was statistically significant, $t(13)=16.844, p<.001$. The difference between the mean of the leader self-ratings and the MLQ norm was also statistically significant, 


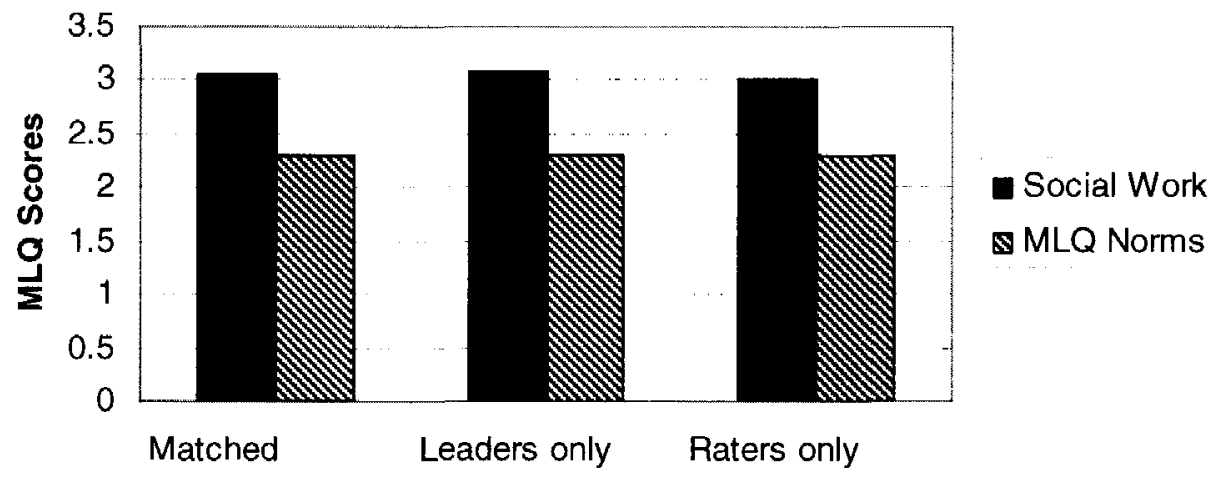

Figure 10.

Transactional leadership scale comparing social work leader scores to national norms.

$t(32)=9.224, p<.001$. Also significant was the difference between the rater scores and the MLQ norm, $t(15)=12.007, p<.001$. The difference between the raters only and the leader self-ratings was not significant, $t(13)=-.355, p=.728$.

\section{Contingent reward.}

This subscale measures leadership behaviors such as recognizing goal achievement and

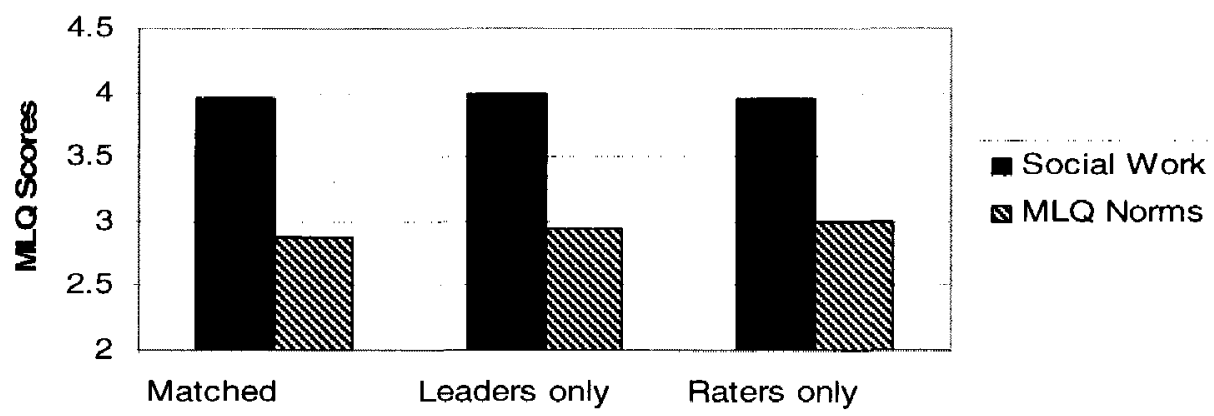

Figure 11.

Contingent reward scale comparing social work leader scores to national norms. 
clarifying expectations on the individual, group and organizational levels (Avolio \& Bass, 2004).This difference between the mean leadership scores of matched leaders and raters and the $M L Q$ norm was statistically significant, $t(14)=7.607, p<.001$. The difference between the mean of the leader self-ratings and the MLQ norm was also statistically significant, $t(32)=8.025, p$ $<.001$. Also significant was the difference between the employee ratings and the MLQ Norm, $t(14)=7.146, p<.001$. Additionally, there was no significant difference between rater and leader self-ratings, $t(14)=-.186, p=.855$ (see Figure 11) although leaders rated themselves slightly higher than their employee raters.

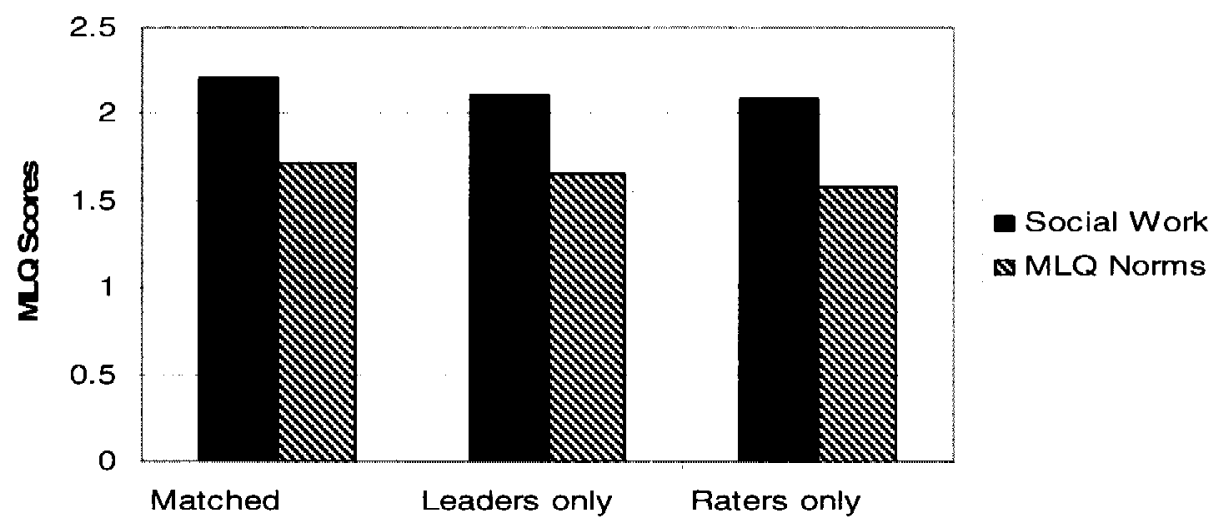

Figure 12.

Management by exception (active) comparing social work leader scores to national norms. Management-by-exception: Active

Leaders utilizing this type of management behavior are specific about expected behaviors, monitor employees closely for compliance with standards and are quick to take corrective action when mistakes or errors occur (Avolio \& Bass, 2004). Figure 12 depicts the relationship between social work administrator's leadership scores and MLQ norms. There were differences on this subscale (see Figure 12). This difference between the mean leadership scores of matched leaders and raters and the MLQ norm was statistically significant, $t(13)=5.399, p<$ .001 . The difference between the mean of the leader self-ratings and the MLQ norm was also statistically significant, $t(32)=5.843, p<.001$. There was a significant difference between the 
employee raters and the MLQ norm, $t(15)=2.724, p=.016$. The difference between the raters only and the leader self-ratings was not significant, $t(13)=-.270, p=.791$.

\section{Passive/Avoidant Leadership}

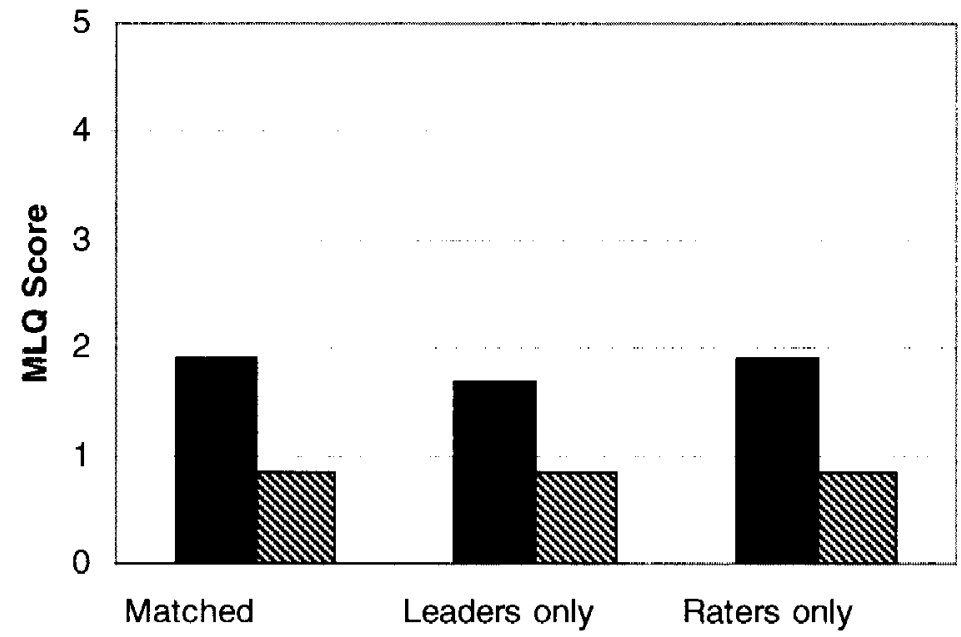

Social Work

MLQ Norms

Figure 13.

Passive/Avoidant leadership comparing social work leader scores to national norms.

Avolio and Bass (2004) describe this type of leader as both passive and reactive. This leader avoids clarifying expectations, doesn't respond when needed and fails to get involved when problems occur. In fact, these leaders only get involved when there is no other choice. Two subscales were used to measure passive/avoidant leadership: Management-by-Exception (Passive) and Laissez-Faire subscales.

The difference between the mean leadership scores of matched leaders and raters and the MLQ norm was statistically significant, $t(14)=11.302, p<.001$. The difference between the mean of the leader self-ratings and the MLQ norm was statistically significant, $t(32)=9.084, p<$ .001 . There was a significant difference between the rater scores and the MLQ norm, $t(15)=$ $6.363, p<.001$. There was a significant difference between employee ratings and leader selfratings, $t(14)=-3.984, p=.002$ with the leaders rating themselves lower on passive/avoidant leadership than their employee raters.

Management-by-exception (passive). 


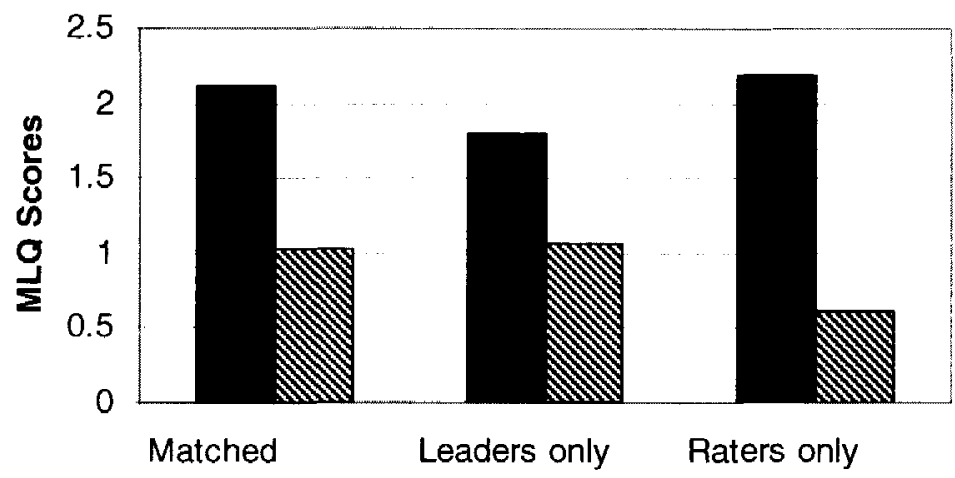

Social Work

MLQ Norms

Figure 14.

Management-by-exception (passive) scale comparing social work leader scores to national norms.

This type of leadership is characterized by failing to interfere until problems are severe or chronic (Avolio \& Bass, 2004). This difference between the mean leadership scores of matched leaders and raters and the MLQ norm was statistically significant, $t(14)=7.564, p<.001$. The difference between the mean of the leader self-ratings and the MLQ norm was also statistically significant, $t(32)=6.068, p<.001$. Also significant was the difference between the rater only scores and the MLQ norm, $t(15)=6.591, p<.001$. Additionally, there was no significant difference between the rater and the leader ratings, $t(14)=1.478, p=.162$ although employee raters gave higher scores than the leaders on this subscale.

\section{Laissez-faire.}

Avolio and Bass (2004) describe this type of leadership as passive and avoidant. A leader using this type of leadership style often feels that they are giving employees freedom when in fact they are avoiding giving the employees direction that would be helpful. This difference between mean leadership scores of matched leaders and raters and the MLQ norm was 
statistically significant, $t(14)=6.662, p<.001$. The difference between the mean leader selfratings and the MLQ norm was also statistically significant, $t(32)=11.213, p<.001$. Also

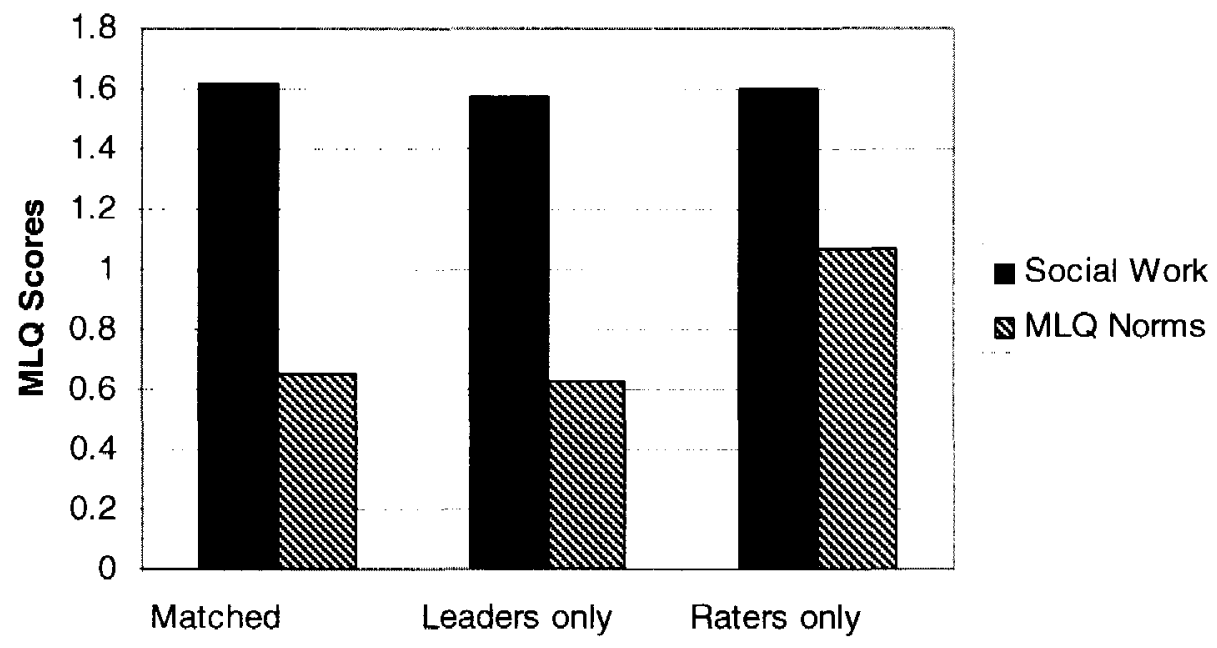

Figure 15.

\section{Laissez-faire scale comparing social work leader scores to national norms.}

significant was the difference between employee ratings and the MLQ norm, $t(15)=5.405, p<$ .001 . Additionally, there was no significant difference between mean rater and leader self-ratings $t(14)=.182, p=.858$ with lower leader self ratings (see Figure 15).

\section{Outcomes of Leadership Scales}

There are three additional subscales on the MLQ-5x Short: extra effort, effectiveness and satisfaction. These subscales measure the success of the group that is attributed to the leader's efforts (Avolio \& Bass, 2004). The results of social work administrator respondents are compared to $M L Q$ national norms in the following sections.

\section{Extra effort.}

This subscale reports on the leader's ability to increase the motivation of employees to meet individual, group and organizational objectives (Avolio \& Bass, 2004). The difference between mean leadership scores of matched leaders and raters and the MLQ norm was statistically significant, $t(13)=5.563, p<.001$. The difference between the mean leader selfratings and the MLQ norm was statistically significant, $t(32)=9.042, p<.001$. There was a 
significant difference between mean employee ratings and the MLQ norm, $t(15)=5.072, p<.001$. Additionally, there was not a significant difference between the rater and leader self-ratings,

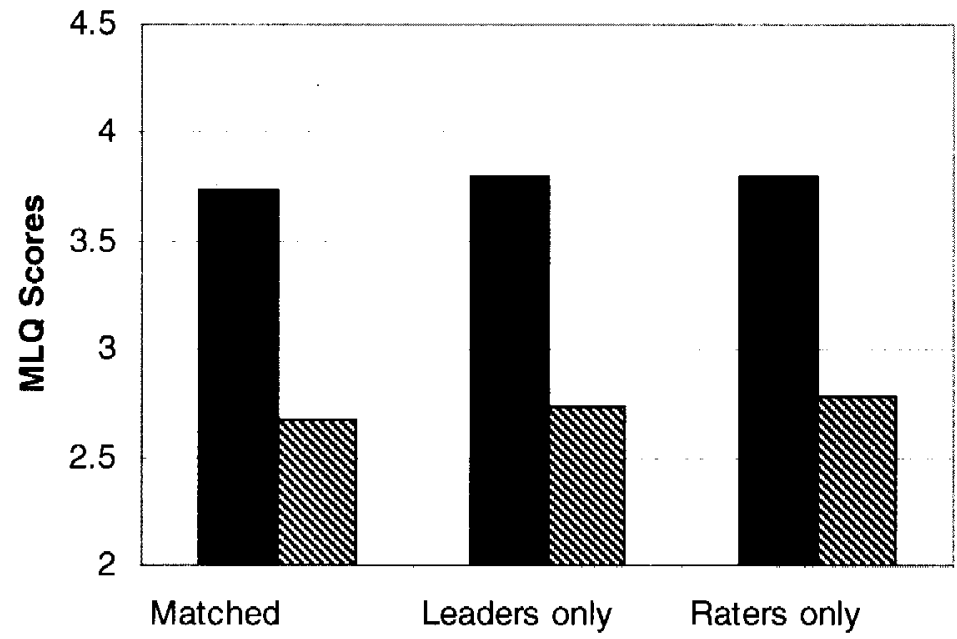

Social Work MLQ Norm

Figure 16.

Extra effort scale comparing social work leader scores to national norms.

$t(13)=-.063, p=.951$ with very little difference between rater and leader scores (See Figure 16).

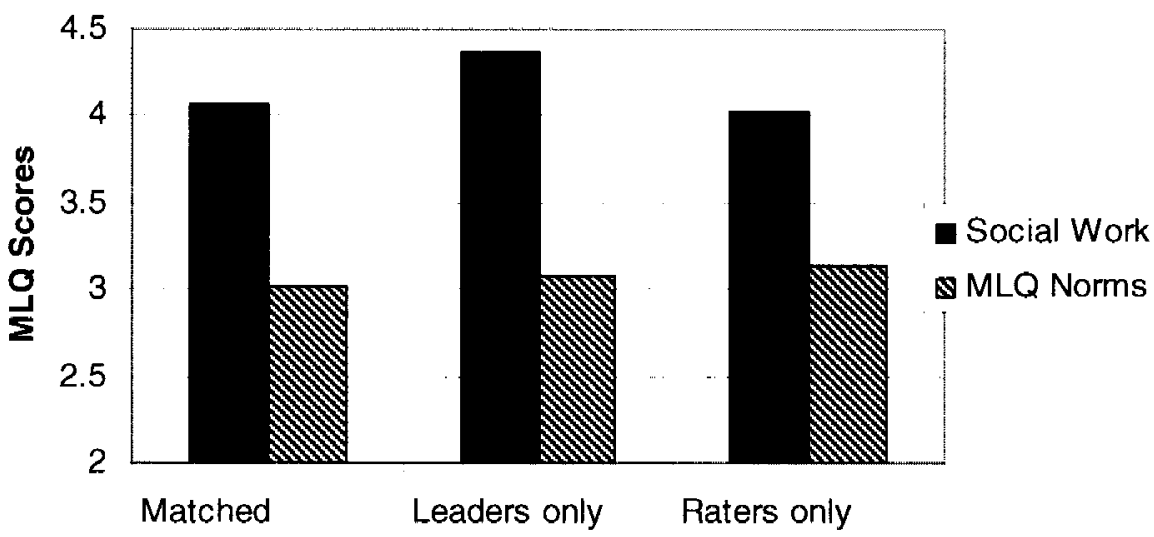

Figure 17.

Effectiveness scale comparing social work leader scores to national norms. Effectiveness. 
This scale measures the leader's effectiveness with meeting individual, group and

organizational needs. This difference between mean leadership scores of matched leaders and raters and the MLQ norm was statistically significant, $t(14)=5.105, p<.001$. The difference between the mean of the leader ratings only and the MLQ norm was also statistically significant, $t(31)=15.359, p<.001$. There was a significant difference between mean rater scores and the MLQ norm, $t(15)=4.402, p=.001$. Additionally, there was no significant difference between rater and leader self-ratings, $t(14)=-1.528, p=.149$, however, leaders rated themselves higher than their employee raters (see Figure 17).

\section{Satisfaction.}

This scale measures satisfaction with the leader's methods of leadership from their perspective as well as the employee's perspective. As displayed by Figure 18, there was a difference on this subscale, as well. This difference between mean leadership scores of matched leaders and raters and the MLQ norm was statistically significant, $t(14)=3.856, p=.002$.

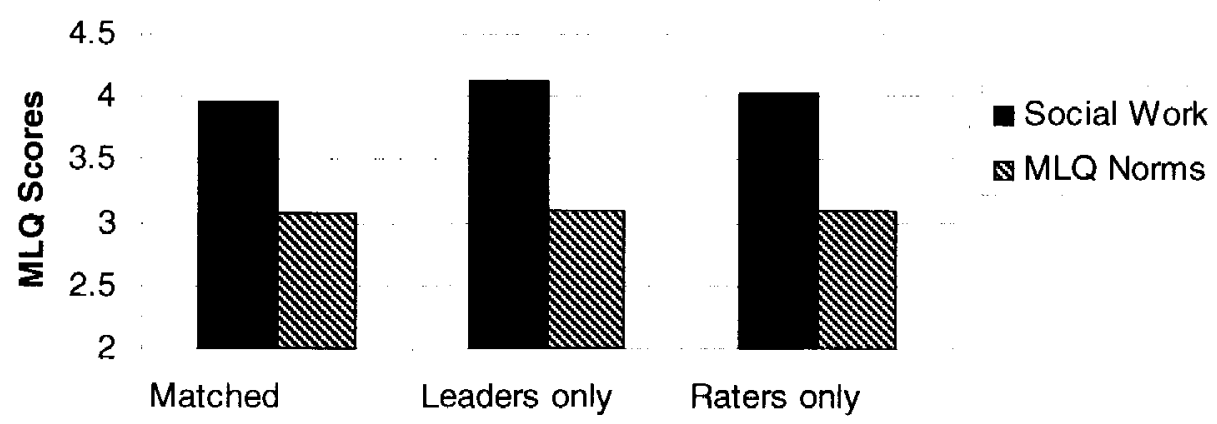

\section{Figure 18.}

\section{Satisfaction scale comparing social work leader scores to national norms.}

The difference between mean leader self-ratings and the MLQ norm was also statistically significant, $t(32)=10.884, p<.001$. There was a significant difference between employee ratings 
and the MLQ norm, $t(15)=3.893, p=.001$. Additionally, there was no significant difference between mean rater and leader self-ratings, $t(14)=-.401, p=.694$ with leaders giving themselves slightly higher ratings on satisfaction.

\section{Comparison of group views on leadership styles.}

In order to further explore the utilization of leadership styles by social work educational administrators, t-tests were completed comparing transformational to transactional leadership and transformational leadership to passive avoidant leadership in the matched group of leaders and raters $(n=15)$, the self-rated leader group $(n=33)$, and the employee peer rater group $(n=$ 16). Figure 19 depicts the comparison of three group views of leadership styles. There are differences among the three groups, and all groups agree that transformational leadership practices are used most frequently by social work educators with transactional leadership practices used next frequently and passive avoidant practices used the least.

\section{Comparison of matched group views by leadership style}

Significant differences in leadership style utilization were found in the matched group (see Figure 19). When comparing transformational to transactional leadership, leaders did utilize

5

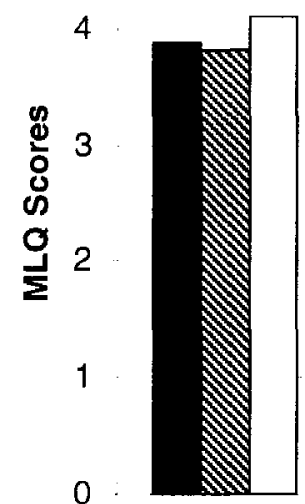

Transform

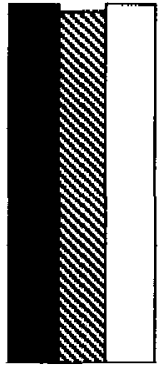

Transact

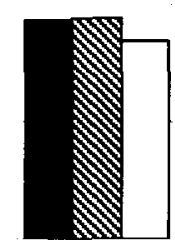

PA
- Matched Sample

s Peer Sample

$\square$ Self-rated Sample

Figure 19.

Comparison of group views on leadership styles. 
transformational leadership more frequently than transactional, $t(14)=5.363, p<.001$, and this difference was statistically significant. Transformational leadership was also utilized more frequently than passive avoidant leadership, $t(14)=10.604, p<.001$, a statistically significant differnce.

\section{Comparison of employee peer rater views by leadership style}

Significant differences in leadership style utilization were found in the employee peerrater group (see Figure 19). When comparing transformational to transactional leadership, leaders did utilize transformational leadership more frequently than transactional, $t(16)=4.836, p$

$<.001$ as observed by employee peer raters. This group also reported transformational leadership to be utilized more frequently than passive avoidant leadership, $t(16)=11.693, p<.001$.

\section{Comparison of self-rated views by leadership style}

Significant differences in leadership style utilization were found in the self-rated group (see Figure 19). When comparing transformational to transactional leadership, leaders did utilize transformational leadership more frequently than transactional, $t(32)=6.221, p<.001$, and this difference was statistically significant. Transformational leadership was also utilized more frequently than passive avoidant leadership, $t(32)=31.414, p<.001$, a statistically significant difference.

\section{Hypothesis 1}

As clearly seen by these figures, social work scores are significantly higher than the national MLQ-5x norm population on every subscale of the MLQ-5x Short form. There is a positive finding on hypothesis 1 . As hypothesized, social work educators utilize a transformational leadership style more often than a transactional or passive avoidant leadership style.

Interestingly, some MLQ-5x Short form scales were significantly different between leader and employee ratings. These three scales were idealized influence - behavior, intellectual stimulation, and passive-avoidant leadership scales. Social work educational administrators were also found to exhibit more passive avoidant leadership than national norms, an unexpected finding. Due to these unexpected finding additional analyses were completed to determine whether or not there were demographic differences within the sample based on these oddities. 
Age, years of total experience, and years of experience at current unit were explored, but no demographic differences were found. Gender was explored in other analyses described later.

The relationship between transformational and laissez faire leadership was examined with a Pearson's Chi Square. Of the 33 cases in self-rated leader group, there was a significant correlation between transformational and passive/avoidant leadership $X^{2}(1)=4.991, p=.025, r=$ .87. As seen in Table 7 there is a relationship between transformational and laissez faire leadership.

Table 7.

Passive Avoidant Groups by Transformational Groups Crosstabulation ( $\mathrm{n}=33$ ).

\begin{tabular}{llccc}
\hline & \multicolumn{5}{c}{ Transformational Groups } \\
\hline \multirow{2}{*}{ Laissez Faire Groups } & Low & Low & High & Total \\
\cline { 2 - 5 } & & 5 & 13 & 18 \\
\cline { 2 - 5 } & High & 10 & 5 & 15 \\
\cline { 2 - 5 } & Total & 15 & 18 & 33 \\
\hline
\end{tabular}

The group with the highest number is the low laissez faire leadership - high transformational leadership group with 13 members. Next largest at 10 members was the high laissez faire - low transformational leadership group, or groups that are opposite. The lowest group membership occurred in the low-low ( 5 members) and high-high ( 5 members) groups. This clearly demonstrates a correlation between transformational and passive/avoidant leadership with low and high groups sharing member leaders.

It is important to note that on self-rating percentiles reported by Avolio and Bass (2004) less than 60 percent of leaders had transformational leadership scores over 3.25 (the low transformational leadership category) and less than 5 percent had scores over 4.00 (the high transformational leadership category). Laissez faire leadership scores actually ranged from 1.00 to 1.79 . Low category scores were between 1.00 and 1.25 ; less than $20 \%$ or the national selfratings were that high. The high laissez faire category scales were between 1.26 and 2.25; less 
than $10 \%$ of leaders scored that high (Avolio \& Bass, 2004). This means the lowest scores in this group of leaders were high within national percentiles.

\section{Hypothesis 2}

Hypothesis 2 states that in social work educational administration female leaders utilize a transformational leadership style more often than males. In order to examine Hypothesis 2, data analysis was completed utilizing the matched database where ratings for both leaders and their peer employees were contained. 15 leaders ( 8 females, 7 males) were examined. Results of independent $t$-tests are found in Table 8 . Table 8 displays the results of $t$ tests, significance levels for each subscale, and the average transformational leadership scale as reported by the matched group of leaders and employees. Significant gender differences were found on four scales including idealized influence (attributed), idealized influence (behavior), inspirational motivation, and individualized consideration with females scored higher on all scales. There were differences between the leader and employee views on leadership. Tables 9 and 10 show these differences. The employees reported significant differences on almost all of the transformational subscales of the MLQ 5x Short when gender was taken into account while the leaders reported significant

\section{Table 8.}

\section{Gender and Transformational Leadership t tests from the Combined Group Perspective ( $n$}

$\equiv 15)$.

\begin{tabular}{l|c|c|c|c|c|c}
\hline $\begin{array}{c}\text { MLQ 5x-Short } \\
\text { Subscale }\end{array}$ & $\begin{array}{c}\text { Female } \\
M\end{array}$ & $\begin{array}{c}\text { Male } \\
M\end{array}$ & $\begin{array}{c}\text { Female } \\
S D\end{array}$ & $\begin{array}{c}\text { Male } \\
S D\end{array}$ & $t$ & $p$ \\
\hline $\begin{array}{l}\text { Idealized } \\
\text { Influence } \\
\text { (Attributed) }\end{array}$ & 4.09 & 3.76 & .12 & .31 & 7.334 & 0.018 \\
\hline $\begin{array}{l}\text { Idealized } \\
\text { Influence } \\
\text { (Behavior) }\end{array}$ & 4.05 & 3.87 & .29 & .91 & 7.882 & 0.015 \\
\hline $\begin{array}{l}\text { Inspirational } \\
\text { Motivation }\end{array}$ & 4.28 & 4.01 & .37 & .83 & 5.365 & 0.038 \\
\hline $\begin{array}{l}\text { Intellectual } \\
\text { Stimulation }\end{array}$ & 3.97 & 3.28 & .29 & .78 & 10.007 & 0.007 \\
\hline $\begin{array}{l}\text { Individualized } \\
\text { Consideration }\end{array}$ & 3.97 & 3.69 & .39 & .68 & 4.127 & 0.063 \\
\hline $\begin{array}{l}\text { Transformational } \\
\text { Leadership }\end{array}$ & 4.06 & 3.70 & .30 & .79 & 4.295 & 0.059 \\
\hline
\end{tabular}


differences on none of the subscales. The employee standard deviations were larger for male leaders. Employees rated males lower than females and lower than male self-ratings. While still significantly higher than national norms female social workers in educational administration demonstrated significantly less transformational leadership than their male counterparts in the

Table 9.

Gender and Transformational Leadership t tests from the Leader Only Perspective $(n=33)$.

\begin{tabular}{l|c|c|c|c|c|c}
\hline $\begin{array}{c}\text { MLQ 5x-Short } \\
\text { Subscale }\end{array}$ & $\begin{array}{c}\text { Female } \\
M\end{array}$ & $\begin{array}{c}\text { Male } \\
M\end{array}$ & $\begin{array}{c}\text { Female } \\
S D\end{array}$ & $\begin{array}{c}\text { Male } \\
S D\end{array}$ & $t$ & $p$ \\
\hline $\begin{array}{l}\text { Idealized } \\
\text { Influence } \\
\text { (Attributed) }\end{array}$ & 3.62 & 3.96 & .63 & .58 & 1.619 & 0.116 \\
\hline $\begin{array}{l}\text { Idealized } \\
\text { Influence } \\
\text { (Behavior) }\end{array}$ & 4.08 & 4.16 & .47 & .65 & .420 & 0.677 \\
\hline $\begin{array}{l}\text { Inspirational } \\
\text { Motivation }\end{array}$ & 4.20 & 4.38 & .45 & .48 & 1.088 & 0.285 \\
\hline $\begin{array}{l}\text { Intellectual } \\
\text { Stimulation }\end{array}$ & 4.07 & 4.21 & .62 & .58 & .697 & 0.491 \\
\hline $\begin{array}{l}\text { Individualized } \\
\text { Consideration }\end{array}$ & 4.29 & 4.23 & .49 & .60 & -.301 & 0.766 \\
\hline $\begin{array}{l}\text { Transformational } \\
\text { Leadership }\end{array}$ & 4.05 & 4.19 & .40 & .50 & .891 & 0.397 \\
\hline
\end{tabular}

Table 10.

Gender and Transformational Leadership $t$ tests from the Employee Only Perspective ( $n=$ 15).

\begin{tabular}{l|c|c|c|c|c|c}
\hline $\begin{array}{c}\text { MLQ 5x-Short } \\
\text { Subscale }\end{array}$ & $\begin{array}{c}\text { Female } \\
M\end{array}$ & $\begin{array}{c}\text { Male } \\
M\end{array}$ & $\begin{array}{c}\text { Female } \\
S D\end{array}$ & $\begin{array}{c}\text { Male } \\
S D\end{array}$ & $t$ & $p$ \\
\hline $\begin{array}{l}\text { Idealized } \\
\text { Influence } \\
\text { (Attributed) }\end{array}$ & 4.34 & 3.69 & .54 & 1.09 & 5.83 & 0.031 \\
\hline $\begin{array}{l}\text { Idealized } \\
\text { Influence } \\
\text { (Behavior) }\end{array}$ & 3.57 & 3.25 & .17 & .71 & 11.05 & 0.005 \\
\hline $\begin{array}{l}\text { Inspirational } \\
\text { Motivation }\end{array}$ & 4.39 & 3.99 & .45 & 1.00 & 3.53 & 0.083 \\
\hline $\begin{array}{l}\text { Intellectual } \\
\text { Stimulation }\end{array}$ & 3.93 & 3.18 & .45 & .99 & 5.79 & 0.032 \\
\hline $\begin{array}{l}\text { Individualized } \\
\text { Consideration }\end{array}$ & 3.91 & 3.56 & .31 & .81 & 14.45 & 0.002 \\
\hline $\begin{array}{l}\text { Transformational } \\
\text { Leadership }\end{array}$ & 4.03 & 3.52 & .32 & .88 & 7.27 & 0.018 \\
\hline
\end{tabular}

leader database only. On self-ratings males had a mean transformational leadership score of 4.19 while females had a mean of 3.89. Both the rater and combined databases placed females 
higher on transformational leadership (4.02 and 4.06) than males (3.52 and 3.70) (see Figure 20). Only employees reported significant gender differences on overall transformational leadership

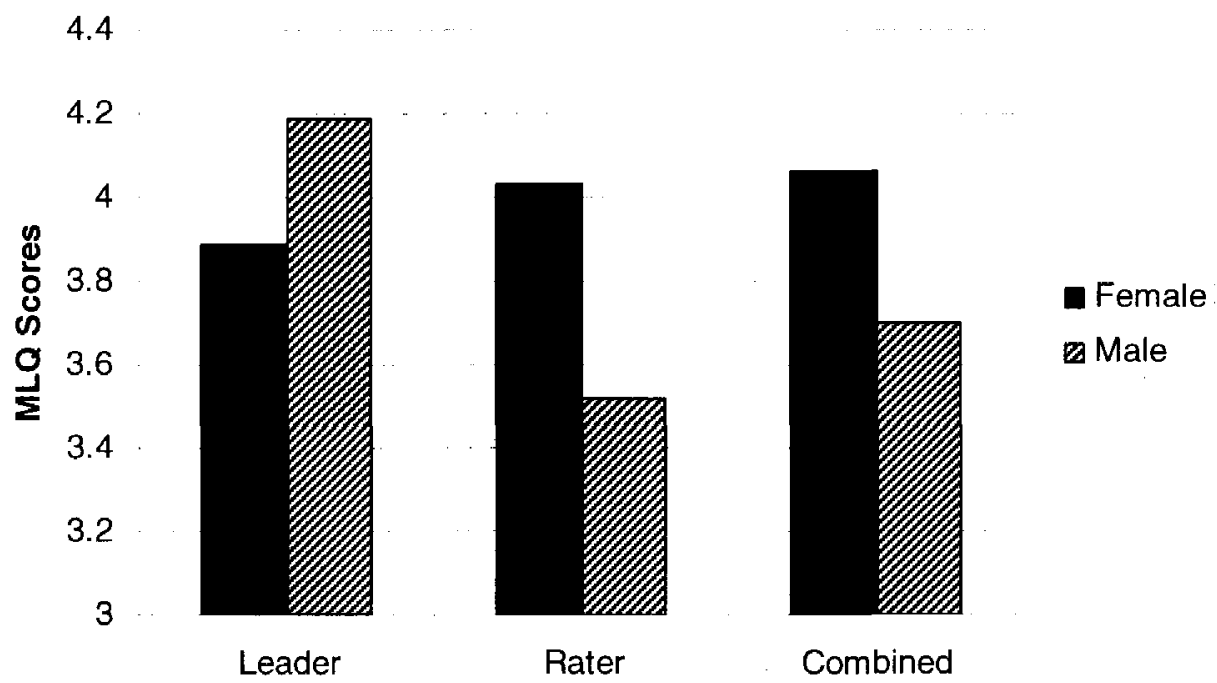

Figure 20.

Transformational leadership scores by gender differentiated by raters and leaders. practices.

With conflicting findings, Hypothesis 2 is not supported or refuted with this data. Female social work educational leaders utilize a transformational leadership style more often than male leaders according to their employee raters, however, according to the leaders only group the opposite is true with men utilizing this style more often.

\section{Context}

Contextual influence on leadership style was measured in several ways in this study. Only leaders were surveyed on these factors. The college/university size was taken into account as was social work program size. The Role instrument was utilized as an organizational measure of change climate. There were four scale questions separate from the Role that assessed impact of openness to change and context on leadership style. All of these measures were utilized as a way to increase understanding of contextual factors.

\section{College/University Factors}


These factors are divided into three sections: College/university size, college/university scale questions and ROLE scale instrument findings. Each section describes specifics of the schools from which these leaders in social work administration hail. The 33 leader database was utilized for these analyses.

\section{College/university size.}

Over $80 \%$ of the leaders in this study report a school type of combined undergraduate and graduate/professional and over $75 \%$ report a college/university size of over 10,000 students. The colleges and universities where these leaders work are predominantly located in cities with over 100,000 people (58\%) while the remaining city sizes are divided into two categories 50,001 to $99,999(21 \%)$ and 5,001 to $50,000(15 \%)$. As a reminder this distribution was inconsistent with the CSWE report with baccalaureate program leaders underrepresented. Only $6.1 \%$ of respondents were baccalaureate program leaders while among all social work programs they were a majority of program types at $63.1 \%$ (Lennon, 2004).

\section{College/university scale questions.}

Two scale questions were devised to determine the impact of the college/university context on leadership style. Question 1 assessed the school's openness to change. Most social work leaders reported that their school's openness to change has at least some impact on their leadership style. The most commonly given answer to the statement "Please place your perception of your college or university's openness to change on the following continuum" was "sometimes experiments with new approaches" at $59 \%$ of the sample. $22 \%$ of this group chose the answer "easily frustrated with change plans", and $13 \%$ chose "in a state of constant flux; embraces change." The remaining 2 responses were evenly divided between "frowns on change; completely traditional" and "neutral towards change." The responses are depicted in Table 11.

A second question was asked to assess the degree of impact the school/university setting has on leadership style. The question was stated as follows: "To what degree do you perceive that your college or university context impacts your leadership style?" There were five possible answers depicted in Table 12. On the college/university level there were three main categories of response. The largest percentage of respondents (40.6\%) chose "impacts my 
Table 11.

Openness to change response rates by frequency and percentage $(n=33)$.

\begin{tabular}{l|c|c|c|c}
\hline & \multicolumn{2}{|c|}{ College/University } & \multicolumn{2}{c}{ Social Work Unit } \\
\hline \multicolumn{1}{c|}{ Response Choice } & Frequency & Percent & Frequency & Percent \\
\hline Frowns on change; completely traditional & 1 & 3.1 & 0 & 0 \\
\hline Easily frustrated with change plans & 7 & 21.9 & 5 & 16.1 \\
\hline Neutral towards change & 1 & 3.1 & 2 & 6.5 \\
\hline Sometimes experiments with new approaches & 19 & 59.4 & 17 & 54.8 \\
\hline In a state of constant flux; embraces change & 4 & 12.5 & 7 & 22.6 \\
\hline
\end{tabular}

leadership style to a large degree". The next largest group (34.4\%) chose "regularly impacts my leadership style, while $18.8 \%$ chose the response "somewhat impacts my leadership style."

These responses were somewhat different than the responses to the first contextual question in that they were skewed more toward the middle in the social work unit's impact.

Table 12.

Impact on leadership style response rate by frequency and percentage $(n=33)$.

\begin{tabular}{l|c|c|c|c}
\hline \multicolumn{1}{c|}{ Response Choice } & \multicolumn{2}{c|}{ College/University } & \multicolumn{2}{c}{ Social Work Unit } \\
\hline No impact at all on my leadership style & Frequency & Percent & Frequency & Percent \\
\hline Somewhat impacts my leadership style & 2 & 6.3 & 2 & 6.3 \\
\hline Regularly impacts my leadership style & 6 & 18.8 & 6 & 18.8 \\
\hline Impacts my leadership style to a large degree & 13 & 34.4 & 12 & 37.5 \\
\hline Dictates my leadership style completely & 0 & 0 & 3 & 9.4 \\
\hline
\end{tabular}

\section{Individual Program Factors}

Individual program factors were divided into two sections. Both ways of assessing program factors will be explored in detail here beginning with program size.

Program descriptions. 
As previously noted, the programs described by their leaders include programs in 23 states and Puerto Rico with a mean of 400 students and 29 faculty members in the matched group. Programs ranged in student body size from 42 to 1,004 students with faculty member size ranging from 2 to 94 . Most of the programs in this study were joint programs (90.9\%) in varying combinations of baccalaureate, graduate and Ph.D. level programs. The most common type of joint program reported was a BSW/MSW program at $13(39.4 \%)$. When compared to the CSWE report of program types (which doesn't include Ph.D. programs) there was a difference. CSWE reported that joint programs make up $27 \%$ of the total CSWE accredited population of programs whereas this study included over $90 \%$ joint programs (Lennon, 2004).

\section{Program scale items.}

The question measuring the social work unit's openness to change was worded as follows: "To what degree do you perceive that your social work program context impacts your leadership style?" Table 11 depicts the social work unit's views as perceived by the social work leaders.

Table 11.

Openness to change response rates by frequency and percentage $(n=33)$.

\begin{tabular}{l|c|c|c|c}
\hline & \multicolumn{2}{|c|}{ College/University } & \multicolumn{2}{c}{ Social Work Unit } \\
\hline \multicolumn{1}{c|}{ Response Choice } & Frequency & Percent & Frequency & Percent \\
\hline Frowns on change; completely traditional & 1 & 3.1 & 0 & 0 \\
\hline Easily frustrated with change plans & 7 & 21.9 & 5 & 16.1 \\
\hline Neutral towards change & 1 & 3.1 & 2 & 6.5 \\
\hline Sometimes experiments with new approaches & 19 & 59.4 & 17 & 54.8 \\
\hline In a state of constant flux; embraces change & 4 & 12.5 & 7 & 22.6 \\
\hline
\end{tabular}

These views are very similar to the college/university openness to change with the social work units being slightly more change oriented than the colleges and universities in which they reside. None of the social work units were perceived as "frowns on change; completely traditional". The highest number of leaders ( 17 or $54.8 \%$ ) perceived their social work units as "sometimes 
experiments with new approaches" with the next highest number ( 7 or $22.6 \%$ ) of responses being given to the statement "in a state of constant flux; embraces change." Five leaders (16.1\%) felt that being "easily frustrated with change plans" best described their social work unit, and only two leaders $(6.5 \%)$ depicted their units as "neutral towards change."

Table 12.

Impact on leadership style response rate by frequency and percentage $(n=33)$.

\begin{tabular}{l|c|c|c|c}
\hline & \multicolumn{2}{|c|}{ College/University } & \multicolumn{2}{c}{ Social Work Unit } \\
\hline \multicolumn{1}{c|}{ Response Choice } & Frequency & Percent & Frequency & Percent \\
\hline No impact at all on my leadership style & 2 & 6.3 & 2 & 6.3 \\
\hline Somewhat impacts my leadership style & 6 & 18.8 & 6 & 18.8 \\
\hline Regularly impacts my leadership style & 11 & 34.4 & 12 & 37.5 \\
\hline Impacts my leadership style to a large degree & 13 & 40.6 & 9 & 28.1 \\
\hline Dictates my leadership style completely & 0 & 0 & 3 & 9.4 \\
\hline
\end{tabular}

The statement measuring the social work unit's impact on leadership style read as follows: "Please place your perception of your social work program's openness to change on the following continuum." The impact on leadership style was clearly stronger in the social work unit than within the college/university. There was little difference in the two categories as depicted in Table 12. When it comes to the social work unit, the largest percentage of respondents $(37.5 \%)$ chose "regularly impacts my leadership style" as their choice. $28.1 \%$ of respondents, the second largest group, chose "impacts my leadership to a large degree" as their response, and $18.8 \%$ chose "somewhat impacts my leadership style".

There were correlations between college/university and unit openness to change, $X^{2}(32)$ $=.619, p<.001, r=0.136$ and college/university and unit impact on leadership style, $X^{2}(32)=$ $.465, p=.006, r=.118$ This correlation was expected due to the placement of a unit within a college/university. The organizational context certainly impacted its subsystem. These two measures did not correlate in other ways such as unit to unit, $X^{2}(32)=.038, p=.836, r=.034$ or 
college/university impact on leadership style to unit openness to change, $X^{2}(32)=-.189, p=.292$, $r=.076$ demonstrating that these two constructs are different and unrelated.

\section{ROLE Instrument}

ROLE stands for "Rapid Organizational Learning Evaluation." The ROLE is a 20-item instrument designed to measure organizational learning (VanZyl, 2007), and this instrument sufficiently captures the transformational nature of leadership as it plays out in educational settings. Construct validity was determined through examination of the individual items where keywords common to the scale and the concepts within transformational leadership were determined to be adequate. A sample of terms common to both the scale and transformational leadership include "vision", "innovative", "means and ends" and "collectively." The ROLE was used in this study as a measure of organizational openness to change and creative expression encouraged at their particular learning institution.

Reliability assessment for the ROLE in this study included content analysis of items and determination of Cronbach's alpha (Carmines \& Zeller, 1979). This scale has been previously used to assess training success in facilitating agency change within statewide health departments (VanZyl, Sheils, \& Barbee, 2007). In the previous study, the reliability was slightly higher with Cronbach's alpha $=.90$ compared to a Cronbach's alpha $=.826$ in this study.

Reliability and validity results similar to those in the past study were found using the ROLE in this study. With a mean of 69.87 , a standard deviation of 8.44 , and a range of 53 to 88 out of a possible 100, it is obvious that most social work leaders in this study feel that their learning organization was fairly open to change and innovation. Contexts where learning is valued and encouraged, such as the colleges and universities under study here, are likely to allow great flexibility with its member leaders.

\section{Hypothesis 3}

Organizational culture was hypothesized to have an impact on transformational leadership styles with smaller size institutions allowing more utilization of transformational leadership style. In this study group there was minimal variability of institutional size. As 
previously mentioned, over $75 \%$ of the social work program leaders were situated in colleges/universities with over 10,000 students.

Several Pearson product-moment correlation coefficients were computed to assess the relationship between the contextual variables and transformational leadership variables in this study. There were no significant correlations found as reported in Table 13. As shown, no variable was correlated with transformational leadership at a significant level.

Table 13.

Correlations between orqanizational context variables and transformational leadership ( $n$ (33).

\begin{tabular}{l|c|c}
\hline \multicolumn{1}{c|}{ Variables } & Pearson's $r$ & $p$ \\
\hline Contextual impact of college/university & -0.039 & 0.828 \\
\hline Contextual impact of social work unit & -0.017 & 0.925 \\
\hline Number of students & -0.075 & 0.678 \\
\hline College/university openness to change & 0.132 & 0.463 \\
\hline Social Work Unit openness to change & 0.055 & 0.759 \\
\hline Type of college/university & 0.063 & 0.728 \\
\hline Total students in college/university & -0.030 & 0.870 \\
\hline Program Type & -.0198 & 0.270 \\
\hline Number of faculty & 0.182 & 0.345 \\
\hline Role score & 0.207 & 0.272 \\
\hline
\end{tabular}

The leaders in this study reported that context impacts the use of transformational leadership practices, however, no contextual variables in this study were correlated with transformational leadership. It is probable that due to the lack of college/university and program variability contextual variables were unable to be fully assessed.

\section{Hypothesis 4}

Organizational culture and gender were hypothesized to combine in predicting the utilization of transformational leadership. To eliminate outliers, subjects with transformational leadership scores less than or equal to 3.45 or greater than or equal to 4.65 were removed from the 33 leader database. This resulted in the removal of four outlying leaders. A Univariate ANOVA was conducted; a summary of results are presented in Table 14.

Main effect results revealed that transformational leadership was significantly different among leaders with different genders and types of schools, $F(1,2)=5.258, p=.031(r=.91)$. 
Table 14.

Two-way ANOVA summary table $(n=33)$.

\begin{tabular}{l|l|l|l|l|l|l}
\hline \multicolumn{1}{c|}{ Source } & \multicolumn{1}{|c|}{ SS } & \multicolumn{1}{|c|}{$d f$} & $M S$ & $F$ & $p$ & $\eta^{2}$ \\
\hline Between Treatments & 0.910 & 4 & 0.227 & 1.749 & 0.172 & 0.226 \\
Gender & 0.672 & 1 & 0.672 & 5.164 & 0.032 & 0.177 \\
School Type & 0.207 & 2 & 0.103 & 0.794 & 0.463 & 0.062 \\
Gender x School Type & 0.684 & 1 & 0.684 & 5.258 & 0.031 & 0.180 \\
Within Treatment & 3.122 & 24 & 0.130 & & & \\
Total & 4.032 & 28 & & & & \\
\hline Between Treatments & 1.421 & 7 & 0.203 & 1.632 & 0.181 & 0.352 \\
Gender & 0.155 & 1 & 0.155 & 1.248 & 0.277 & 0056 \\
Program Type & 0.481 & 4 & 0.120 & .968 & 0.446 & 0.156 \\
Gender x Program Type & 0.877 & 2 & 0.438 & 3.527 & 0.048 & 0.251 \\
Within Treatment & 2.611 & 21 & 0.124 & & & \\
Total & 4.032 & 28 & & & & \\
\hline
\end{tabular}

Males had a higher transformational leadership score $(M=4.14, \mathrm{SD}=.42)$ than females $(M=$ $4.00, \mathrm{SD}=.35$ ), and males led more frequently in exclusively graduate/professional schools ( 3 males versus 1 female) with no male leaders placed in the exclusively undergraduate university category where 2 females were leading. Interestingly, when leading in combined undergraduate and graduate professional type universities the female mean $(M=4.02, S D=.36)$ was identical to the male mean $(M=4.02, S D=.36)$ indicating there is a very strong connection with type of university context and leadership style.

Main effect results revealed that transformational leadership was significantly different among leaders with different genders and social work program types, $F(1,4)=3.527, p=.048(r$ $=.80)$. Women had a lower transformational leadership mean score $(M=4.00, S D=.35)$ than men $(M=4.14, S D=.42)$. The majority of women led in BSW, MSW joint (6) and BSW, MSW, Ph.D. joint (9) programs while the majority of men led in the BSW, MSW joint (4) and the MSW, Ph.D. joint (4) programs. Women had the highest transformational leadership scores when leading in the BSW only $(M=4.13, S D=.04)$ and the BSW, MSW joint programs $(M=4.13, S D=$ .38) while men had their highest in the MSW, Ph.D. joint program $(M=4.41, S D=.40)$.

Remember that there was a statistically significant gender difference between the employee rated group versus the leader self-rated and matched groups. This difference was not 
examined here due to the necessity of utilizing leader only scores with context which was assessed with the 33 self-rated leader group.

\section{Hypothesis 5}

A positive relationship between transformational leadership style and effectiveness among social work leaders was hypothesized. A Pearson Chi Square was computed to assess the relationship between the effectiveness and transformational leadership variables in this study. Due to six cells having a count of less than five a further test was run $(p=0.007$ by Fisher's exact test). Overall, there was a strong, positive correlation between transformational leadership and effectiveness, $X^{2}(4)=12.323, p=.05(r=.66)$. Increases in transformational leadership usage were correlated with increases in effectiveness ratings. 


\section{CHAPTER V}

\section{DISCUSSION}

There are assumptions and limitations with this study. It is assumed that the participants, both leaders and raters, were honest. A second assumption is that the web-based survey software, QuestionPro, was successful in accurately capturing the data provided by the participants. One limitation is a participant pool limited to social work educators who volunteered for the study. Another limitation is that as an ex post facto study, no causal inferences can be drawn. The sample is not representative of all social work leaders since the 33 leader respondents were provided a sample to small to generalize to the entire population, a third limitation. The small respondent group was most likely related to the sensitive nature of this topic. There was a high social cost for this research which was impossible to offset (Dillman, 2007). The leaders had to trust in the confidential nature of their survey responses, the appropriate use of their data, and the beneficial nature of the project. If handled improperly, results drawn from this data could be personally and professionally damaging as well as detrimental to the entire social work profession. Those assumptions and limitations notwithstanding, the pursuant discussion is presented.

This chapter is divided into a review of issues under study, implications for practice and future research suggestions. Each section is further divided as appropriate.

\section{Review of Issues Under Study}

Three issues were under study in this dissertation: style of leadership, gender and context. Each of these issues will be discussed separately now. Research questions will be examined in the appropriate sections.

\section{Research question 1: Styles of social work leadership}


Leadership styles of social workers in educational administration were the focus of the first of the research questions. To review, research question 1 queried "What types of leadership styles do social workers in educational administration typically practice?"

In this study the Multifactor Leadership Questionnaire (MLQ) 5X Short Form Scale was used to analyze leadership style. This instrument is based on the Full Range of Leadership Model initially developed by Bass and Avolio in 1990 (Bass \& Riggio, 2006). This leadership model includes three types of leadership including transformational, transactional, and passive avoidant leadership all of which are assessed with the MLQ-5X short.

According to Bass and Riggio (2006) transformational leadership is a type of leadership that increases the personal growth of the followers while simultaneously meeting the goals and objectives of the larger group whether that is a team, a unit, or an entire organization. It is important to clarify that transactional leadership style is conducive to transformational leadership. Transactional leadership has to do with those activities that sharpen the actual accomplishment of personal, group, and organizational goals through clearly defining expectations and outcome achievement. These two types of leadership style complement each other, and each is a necessary part of effective leadership. Passive/avoidant leadership, on the other hand, is an ineffective type of leadership whereby leaders avoid making decisions or doing the day to day activities necessary to make an organization effective (Bass \& Riggio, 2006).

As stated in the results section, the predominant style of leadership practiced by leaders in social work education was found to be transformational leadership style. When compared to national norms, social work administrators were found to have significantly higher levels of transformational leadership. This finding was expected. What was not expected was the finding that they also utilize higher levels of transactional and passive/avoidant leadership than leaders in the national norm group.

As fully discussed in Chapter IV no demographic variable was shown to correlate with transformational and passive avoidant leadership. It was determined using crosstabulation that the largest groups of leaders in this study were in the moderate transformational - low passive avoidant group with high transformational - low passive avoidant group in second place. Low 
passive avoidant leaders in this group were in the upper 50 to $80^{\text {th }}$ percentile of the national sample while moderate and high transformational leaders were in the $90^{\text {th }}$ percentile (Avolio \& Bass, 2004).

There are many ways to interpret these unexpected findings. One possible explanation is that social work administrators are very good at leading in certain situations (such as meeting organizational goals) but are substandard leaders or simply not instrumental in others (such as reducing employee conflict). Alternatively, these findings may suggest that as a group, social work leaders are excellent at transforming their employees into the highest form of themselves but are sometimes not doing enough leadership tending instead to avoid responsibility through lack of timely response to conflict or important items. Items such as "I avoid getting involved when important issues arise" and "I show that I am a firm believer in 'If it ain't broke, don't fix it." are examples of passive avoidant leadership style items (Avolio \& Bass, 2004) given high ratings by leaders and employees in this study.

It could be that employees at this level are seeking their own fulfillment through their work and are self motivated for personal transformation. One employee rater comment sums up this type of situation: "I am an exceptionally motivated person so the dean's input in motivating me is not necessary. This is not a reflection on her ability to motivate others since she does an excellent job of motivating some people in the organization. It is just an explanation of why I have not given her the highest ratings for her ability to motivate me." Individual views such as this may make rating these particular leaders difficult. It may be that the peer employees are more productive than typical employees; hence more laissez faire leadership is acceptable with this special group than with the typical groups led by the norming group leaders.

It is possible that there are inconsistencies with leader behaviors, making it difficult to give consistent ratings. One employee addressed leader inconsistencies in an open-ended comment. This employee stated "He [the leader] isn't consistent-I never know when he will make a thoughtful decision or a reactive decision. He has poor self awareness. He can be very generous at times (with giving assistance to faculty, etc.) but other times he is vindictive and manipulative." This statement highlights difficulties that can occur for faculty when leaders are 
inconsistent with behavior. Problems such as lack of respect for the leader, a perception of lack of fairness to employees and the perception of ineffective decision making processes will impact faculty to a large degree. Without knowing what to expect next faculty and staff may experience negative symptoms such as increased anxiety and stress that will ultimately make them less effective in their jobs.

A last possible explanation for high ratings on all three leadership subscales has to do with a possible response set. It is possible that without careful reading of the questions, high ratings were given on all items by both the leaders and the employees. It should be noted that this instrument does use reversal of the scale on several items as a safeguard against response set, so this is an unlikely explanation, but it is possible.

The results suggest that the hypothesized answer to research question 1 is correct; social work deans, directors and chairs in educational administration do utilize a transformational leadership style more often than the others in the full range of leadership model. Additionally, these deans, directors and chairs utilize a transactional and a passive avoidant leadership style more often than leaders in the national norm group.

An additional unexpected finding was that leaders and employees have significant differences of opinion on three of the fifteen scales. These three scales were idealized influence (behavior), intellectual stimulation, and passive-avoidant leadership scales. On the other scales, leaders and employee raters agreed with leader self ratings. Leader self ratings were higher on some scales (individualized influence (behavior), intellectual consideration) and lower on others (passive avoidant leadership scale) depending on which would portray them as better leaders.

Differences between leader self-ratings and employee ratings of leaders are typical; hence this particular instrument has different norms for each group. The typical differences are not statistically significant. While the leader self ratings and the employee ratings in this study were significantly different on three of the scales, there was agreement between leaders and employees that social workers leading in educational settings score higher than the national average on all subscales as previously discussed.

\section{Research question 2: Gender and social work leadership style}


Differences in leadership style based on gender have been found in the literature. Women tend to use a transformational leadership style that is closely aligned to their female gender role (vanEngen \& Willemson, 2004; Eagly et al., 2003; Bass et al., 1996; Eagly et al., 1995), and those differences are exacerbated when women are in gender incongruent roles (vanEngen \& Willemson, 2004). In exploration of research question 2, a series of analyses were completed to determine the leadership style differences between the genders.

Initially, a comparison of means was completed. Males and female social work leaders are both above national norms in the usage of transformational leadership practices, however, dependent upon the group doing the ratings, there were differences. Employees and the matched group (significantly impacted by the employee raters) found gender differences with females scoring higher on transformational leadership. The leader self-rated group reported that males demonstrated higher transformational leadership levels than females. These differences imply that females have a more negative view of their leadership than male leaders while employees have a more negative view of male leaders. This may be a function of female gender roles whereby women are typically expected to be modest. Importantly, both genders scored significantly above national norms.

In answer to research question 2, the hypothesis has limited support. There is a positive relationship between transformational leadership style and gender within the employee only group (females had higher transformational leadership ratings), however, males had higher transformational leadership style scores in the self-rated leader and the matched groups.

This finding has particular importance in light of the suggestion that a transformational leadership style is advantageous for women and minorities in educational leadership (Chliwniak, 1997). With an educational system in rapid flux due to funding inequalities among institutions (Thornton, 2007) and increasing diversity of new faculty (Benjamin, 1999) it would be prudent for these systems to encourage utilization of a leadership style that fits with the needs of all its members.

\section{Research question 3: Context and social work leadership style}


This study assessed the impact of context on social work leadership style through the use of four scale questions, demographic questions about school and community environment, the ROLE instrument and the MLQ. Openness to change was the specific facet of context explored. This facet was chosen due to the link in the research literature between transformational leadership style and context (Bommer et al., 2004; Pawar \& Eastman, 1997). In previous studies organizational context has been found to affect the utilization of transformational leadership (Bommer et al., 2004; Pawar \& Eastman, 1997), and in this study organizational culture did have an impact on transformational leadership utilization.

In this study the majority of leaders reported that their university was open to change. In other words, their school would "sometimes experiment with new approaches", however, the next most commonly given answer for college/universities was "easily frustrated with change plans". This openness to change was carried over to their social work unit, as well, with almost identical answers given regarding their units. Interestingly, the social work units were slightly more likely to "embrace change" than their colleges/universities.

When leaders were asked how much their leadership style is impacted by their college/university the majority gave the answer "to a large degree" with a close second being "regularly impacts" leadership style. These answers were similar in degree and percentages to the same question asked about social work units. One notable difference is that no leaders felt their college/university "completely dictated" their leadership style while three leaders felt that their social work unit context "completely dictated" their leadership style.

These findings lead to the conclusion that social work units while more likely to be open to change also have more impact on the leadership style used by their leaders. Researchers have found that if peer leaders were using transformational leader behaviors, then the leader was more likely to use a transformational style (Bommer et al., 2004). It is probable that social workers in general use more transformational leadership than the typical manager leading to an increase in a transformational style.

A second analysis revealed a relationship between leadership style, gender and social work program type. This analysis relied on leader data only, which was different from the 
combined group data. In the leader only data females were found to utilize transformational leadership style less than males no matter what the context. Transformational leadership was impacted by social work program type and type of college/university, as well, with larger programs and colleges/universities leading to increased use of a transformational leadership style.

There are several possible explanations for these findings. It is possible that larger social work programs have more freedom within the college/university to lead in whatever manner that they choose. Transformational leadership that fits so well with social work values is likely to be the choice (Rank \& Hutchison, 2000). It is also possible that males are more likely to lead in larger colleges/universities and social work units as this is consistent with the situation in colleges and universities in general where males are more likely to be in leadership positions in larger, more prestigious settings (Glazer-Raymo, 1999). Possibly, females are less likely than males to utilize a transformational leadership style in larger colleges/universities due to factors such as sexual harassment, unavailability of effective mentors and training, and tokenism (Bass, 1990). These factors may have a negative impact leading females to make different leadership choices. It is important to note that both male and female leaders in social work education were above the national norm in transformational leadership.

In answer to research question 3 , a relationship between leadership style, gender and type of learning organization was found. A second analysis revealed a relationship between leadership style, gender and social work program type, as well. As hypothesized, organizational culture and gender did combine to predict the utilization of transformational leadership style by social work educational leaders.

\section{Research question 4: Effectiveness of social work educational leadership}

Research Question 4 asked "Is the predominant type of leadership practiced by social workers in educational administration effective?" Lowe, Kroeck, and Sivasubramaniam (1996) found that effectiveness and transformational leadership style were correlated in their metaanalysis. In accordance with research question 4 , it is important to note that the predominant type of leadership style practiced by social work educators is effective, satisfying to employees, and 
encourages employees to provide extra effort. The findings on the MLQ-5x short outcomes of leadership subscales demonstrate this to be the case. As hypothesized, in this study a positive relationship between transformational leadership style and effectiveness was found.

\section{Implications for Social Work Practice}

Moses Newsome, Jr., (1995) president of the Council on Social Work Education (CSWE) at the time, noted that the development of effective leaders within the profession was a top priority. Without effective social work leaders coming to the "bargaining table where research and training priorities are identified and social policies are developed", social work outcomes would likely be absent (Newsome, 1995). The present study findings have many implications for social work leadership practice and training. Recommendations for leadership practice and training follow.

\section{Practice recommendations}

Rank and Hutchinson (2000) point to a future where strong leadership in social work would include roles such as proactively using collaborative skills to engage social workers and policy makers from diverse backgrounds to advance social work values. These views on leadership are very consistent with the transformational leadership style predominant among social workers.

Currently, social work practice often includes a leadership component. Social workers lead and manage within a variety of settings including human services organizations, higher education, and governmental programs and organizations (Austin, 1995). Often times leadership roles are given to social workers by default in these settings because others are unwilling or lack the training or the confidence to undertake these roles. Developed in the late 1940 s as a secondary practice method for social work, administration (in addition to research) has been viewed as supplemental to the basic skills of caseworker, group facilitator, or community organizer (Morales \& Sheafor, 1998). This practice method is increasingly important as the need for social service leaders is increasing (Perlmutter \& Crook, 2004).

Educational leadership is a specialty area within social work administration, and as such it requires special skills and competencies that are often not provided until the leader is in the role 
(Keys, 2008). Social work programs are situated within university settings that are dealing with multiple complex issues such as increasing student and faculty diversity, accountability for use of public funding, expectations to increase community engagement, and enrollment management (Keys, 2008). In addition, changes such as organizational restructuring will have a significant impact on the social work profession as its stature within the university dwindles and resources are diverted to other higher-status professions such as medicine and law (Videka-Sherman et al., 1995). This leads to the conclusion that a strong focus on social work values through specific leadership activities designed to increase the influence of social work programs in the university setting is needed to maintain and improve the situation of social work programs.

The National Network for Social Work Managers (NNSWM) has developed a set of management standards including fourteen categories of competencies (NNSWM, 2004). Standards such as these can be used as a basis for developing best practice guidelines for social work educational leaders.

Leadership is one of the NNSWM categories (NNSWM, 1997; revised 2004). Based on the results of this study transformational leadership is the most commonly practiced type of leadership among social work leaders, and this type of leadership is consistent with social work values. It follows that an appropriate type of leadership to influence growth and change in school and university settings would be transformational leadership. Social work administrative practices in educational settings should and do often include transformational leadership practices.

It is important to provide student social workers with effective leadership practice guidelines, as well. Educational Policy and Accreditation Standards (EPAS) state that "social workers provide leadership in promoting sustainable changes in service delivery and practice to improve the quality of social services" (CSWE, 2008, p. 6). This mandate clearly demonstrates the recognition of leadership skills in multiple settings as important for all social workers, and the present study suggests transformational leadership is a comfortable fit with social work practice in education. The principles of transformational leadership would be well used in both coursework and field as best practice for social workers. 
This study found a reliance on laissez faire leadership practices by social workers in educational administration that is important to address in both education and practice. Laissez faire leadership is ineffective and inconsistent with social work values, yet social workers in educational administration are using laissez faire leadership practices at a higher rate than national norms. It is important to educate and to provide practice experiences to students, upcoming leaders, and current leaders that assist them in identifying not only effective leadership, but also ineffective leadership practices. Utilizing a full range of leadership model to assist in this regard is necessary (Bass \& Riggio, 2006).

According to Bass and Riggio (2006) it is very easy to confuse empowerment practices with laissez faire leadership practices. Empowerment of employees or clients means that leaders delegate tasks and allow others to work independently. This can easily lead to laissez faire leadership practices such as avoiding decision making or refraining from intervening when needed. Whereas empowerment practices of transformational leaders include follow up, clear descriptions of missions and goals, and a dedication to the group, these practices are absent with laissez faire leaders (Bass \& Riggio, 2006). With an emphasis on empowerment in social work education and practice a clear understanding of the difference between empowerment and laissez faire leadership practices is necessary. With a greater awareness of this difference a corresponding reduction in the use of ineffective laissez faire leadership is likely to occur.

If increased use of laissez faire leadership practices is related to inconsistent leadership, this will need to be addressed. Assisting leaders in understanding the negative effects of inconsistent leadership as well as clarifying inconsistencies for each particular leader may be beneficial.

\section{Training recommendations}

Social work leadership practice is an important facet of any social work program curriculum. Brilliant (1986) advocated for increased leadership training in social work programs and curriculum and fieldwork changes that would assist students to learn and practice social work leadership. Newsome (1995) proposed increased training and increased professional leadership development with students through mentoring and professional socialization as one way to 
achieve this aim. Leadership training for students is only the beginning of the process; leaders should be developed from within the various fields. Deans require specialized continuing education opportunities to achieve their best leadership practices, as well.

The lack of leadership preparation and the lack of opportunity for external professional activities (which could have been satisfying enough to make up for a lack of personal fulfillment derived from their post as a dean) were cited as definite downsides to the deanship (Gandy et al., 1979). Brilliant's (1986) suggested changes for deans and social work programs including reducing conflict regarding program differences and developing programs and policies that work alongside significant human service agencies leading them towards positive change. Nesoff (2007) states that the issues of lack of administrative training and increasing the strength of administration components within social work programs are still primary concerns in the social work profession.

There has been an upsurge of interest in social work leadership. The Council on Social Work Education (CSWE) implemented the Leadership Development Council in 2006 to respond effectively to leadership development needs in the social work profession as a whole instead of the current fragmented training system (Sheafor, 2005). CSWE in their Educational Policy and Accreditation Standards (2008) require that curriculums include leadership components for student development, fieldwork guidelines encouraging evidence based practice and conflict resolution, and specific program specializations based specifically on program missions generated by contextual needs.

In 2008 the Social Work Leadership Institute in collaboration with the New York Medical Academy launched the Leadership Academy on Aging with the aim of addressing the needs of an aging population in the U.S. through providing specific training to deans and directors of social work programs. NASW has taken leadership through the Social Work Reinvestment Initiative (SWR) to increase the social work workforce through passage of legislation in the form of the "The Dorothy I. Height and Whitney M. Young, Jr. Social Work Reinvestment Act" (NASW, 2008). These types of initiatives only take place within a profession that values leadership. 
Increased leadership training availability and increased interest in social work leadership within educational and legal domains are important steps towards improving the quality of social work leadership, and these types of changes need to continue. In addition, it is important that young inexperienced social work leaders are nurtured through appropriate level trainings with some financial commitment to their development (Sheafor, 2005). Particularly new leaders may not have the funds to attend the kind of trainings that are necessary to develop their leadership skills, and our profession should foster developing leaders as well as established ones.

One specific finding in this study is that social work leaders and their employees have different views of their leadership practices. These particular differences are important to explore because accurate evaluation is important for leaders and employees. One specific way to encourage accurate assessment in training and education is to encourage and assist social work leaders and employees in seeking feedback from others in assessing the utility of their own and others' leadership styles and practices. There are instruments available that do just that; One example is the MLQ instrument utilized in this study which takes a 360 degree view of leadership. Munson (2002) reports that self-observation of supervisory style through audiovisual recordings is the most effective method of helping leaders see the reality of their behaviors. This tool could be easily utilized in staff meetings, individual employee consultations, and university wide meetings to provide effective feedback to leaders and managers in educational administration.

Developing leadership trainings and curriculums based on leadership models that are research based and effective for social work is important to the profession. An example of a successful empirically based leadership model is the Leaders in Action program utilized in California to make sure that collaboration between social work programs and human services community organizations is ongoing and effective (Packard \& Tucker-Tatlow, 2006). Whether the recommendations are being made for practice or training, research based best practice models and information needs to be included in the recommendations. Leadership models such as the Leaders in Action program are available and need to be utilized as often as possible for social work leadership training and evaluation at all levels of the profession. 
Changing oppressive environments is well within the purview of social workers. This study found that perceptions of college/university settings or social work units as more oppressive led to less transformational leadership practices. Therefore, it is important that change processes effective within various organizational settings are presented and practiced by students and established leaders alike. These skills are transferable; this training is extremely valuable for social workers.

This is one of the few leadership studies specifically about social work leadership style in higher education. Much more research is needed; recommendations for future research follow.

\section{Recommendations for Future Research}

Additional research is needed to increase knowledge about social work leadership best practice. Research exploring the relationship between successful organizational outcomes of gender equity in social work departments and leadership style is needed. Limitations with the current study due to lack of study sample diversity can be overcome with future research specifically targeting BSW level social work programs specifically and social work programs from learning institutions of varying sizes.

\section{Increase knowledge about social work leadership best practices}

It is imperative that leadership best practices be established in social work educational administration. Currently, there is an assumption in social work education that social work practice skills carry over to effective leadership practice (Takamura, 2008). There is little evidence to back up this assumption. In fact, many other disciplines (such as business administration, educational administration, public administration) spend more credit hours focused exclusively on management skills and practice than the discipline of social work (Nesoff, 2007). Nesoff (2007) reports that social workers in educational administration often struggle with ineffectiveness or leadership failures related to lack of knowledge and training.

This study utilized the MLQ 5x-Short which has the Outcomes of Leadership Subscales which consist of three scales: satisfaction, extra effort, and effectiveness (Avolio \& Bass, 2004). This study found that leaders in social work administration scored significantly higher than the national norms on all three scales, however, few studies have tied the leadership styles of social 
work administrators directly to outcomes (Gellis, 2003; Mary, 2005; Mizrahi \& Berger, 2001). None were found linking social work leadership practices to measurable departmental outcomes. There is much work to be done in this area.

Measurable outcomes related to social work leadership practices are available. An example would be to explore the correlation between social work unit goal achievement (ie. program expansion, grant funding, faculty retention, or research productivity goals) and leadership practices. In fact, university organizations such as faculty governance boards may influence social work program productivity in variable ways, and these sorts of impacts should also be reviewed. This sort of exploration done on a large scale could effectively demonstrate what types of leadership practices encourage specific outcomes.

It is important to consider that there is little agreement on the national level as to which outcomes are most significant for social work programs to achieve. Successful outcome measurement will include the individualized goal achievement based on specific social work program objectives, and these will necessarily differ from program to program dependent upon regional needs.

It is possible that social work leaders are adaptive with their leadership styles demonstrating different types of leadership based on context of the university and specific departmental needs. Studies clarifying what styles of leadership would be used in response to differing departmental, university wide, and national contexts would be beneficial here as would longitudinal studies following social work leaders over time.

\section{Explore how social work equalizes gender}

Austin (1995) points out that an analysis of texts in organizational social work practice uncovered that more than half did not mention barriers for access for women or people from diverse ethnic backgrounds to managerial positions. Edwards describes a context where these barriers were discussed openly at social work conferences, journals and in popular culture but were absent from social work texts. Despite this lack of curricular cohesiveness with the rest of the social work profession, social work is one of the few professions that have drastically improved gender equity within the professorate (DiPalma, 2005). 
This transformation to a more equitable social work educational system warrants further exploration. Is it the use of transformational leadership practices that has led to this change or is some other factor responsible? There are several possible alternative explanations for this gender equity. Maybe the social work value of social justice is responsible. It is possible that college/university policies and procedures are responsible. Maybe it is the extraordinary numbers of females in this profession that makes the difference.

This study did not explore how social work has achieved this gender equity, although it is safe to conclude that transformational leadership practices have something to do with it.

Qualitative research exploring power structures of the administrative branch of the educational system might be enlightening. Experienced social work administrators would most likely have some ideas of how power structures have been challenged over time leading to change (Blackmore, 1999). Awareness of how gender equity has been furthered in social work would be a definite positive addition to the research.

\section{Need BSW level research}

The lack of contextual diversity in this study is a limitation here with the majority of the programs, over $80 \%$, being joint programs. This is different from the composition of CSWE schools where over $63 \%$ of programs are strictly bachelor level. In this study bachelor level programs were a minority at a little over $6 \%$ of the leader sample (Lennon, 2004). Over $72 \%$ of these joint programs include BSW components; however, the respondent leaders were leading joint programs as opposed to solely directing BSW programs.

In order to fully assess leadership style of social work educational administrators, a larger group of BSW program directors is needed. It is difficult to understand the totality of the social work educational leadership when a majority of the leaders are left out of the analysis. In this study the use of the National Association of Deans and Directors (NADD) mailing list did not capture this group effectively. Use of the Association of Baccalaureate Social Work Program Directors (BPD) mailing list would be useful in a study attempting to capture data from this population.

\section{Need for contextual exploration}


As a limitation, in this study group there was minimal variability of institutional size. As previously mentioned, over $75 \%$ of the social work program leaders in this study were situated in colleges/universities with over 10,000 students. When the size of the study colleges/universities was compared to the CSWE report of baccalaureate only, graduate only and joint programs, the distribution is consistent (Lennon, 2004). However, it is important that all contexts are sufficiently explored to accurately assess the impact of context on social work leadership practices.

Capturing social work units situated within educational institutions of varying sizes should be a focus of future research.

Organizations can be viewed as cultures which impact how administrators "frame meaning for subordinates" and develop performance outcomes (Oggawa \& Bossert, 1997). Leadership itself is an organizing factor that runs throughout the organizational context, and as such should be tracked not only within individuals, but as it flows throughout the organization (Oggawa \& Bossert, 1997). This study examined more than one level of organization (college/university and social work unit), but only through the eyes of the leader. It would be worthwhile to assess the organizational context through the eyes of their employees, their supervisors, and their peer leaders.

Contextual factors such as financial constraints during times of economic crisis, the current place of the learning organization within a developmental framework, and the influence of faculty governance boards are important to consider, as well, when assessing contextual impacts on leadership style. Context will influence the leadership style chosen by any leader if they are in tune with the political climate, their coworker mores, and employee needs, so assessing the context from other vantage points may provide further insight into leadership. Varying views of context may explain some of the differences in leader self ratings and employee leadership ratings, but without more data that factor cannot be explored.

\section{Summary}

These particular leaders, due to their placement at large colleges/universities with large social work programs, have a more far reaching effect than if they chose to lead in smaller colleges/universities. The social work leaders responding to this study directly influence 569 
social work faculty members and 12,732 social work students yearly which constitute $7 \%$ of the faculty and $30 \%$ of the students in CSWE accredited social work programs in 2006 (CSWE, 2007). These results have importance based on these numbers alone despite the lack of generalizability to the entire group of social work educational administration leaders.

Findings that social work educational administrators are naturally utilizing a transformational leadership style are not surprising. This leadership style dovetails nicely with social work values. Values such as social justice, dignity and worth of the person, and the importance of human relationships (NASW, 2008) are consistent with transformational leadership components such as empowerment and development of follower capacities and values as a basis for mission and goal development (Bass \& Riggio, 2006).

This is the first study to explore gender difference in the utilization of social work educational leadership. Gender differences in utilization of transformational leadership are in line with past research on the subject. Females have been found to utilize transformational leadership at a higher rate than males across professions (Eagly, Johannesen-Schmidt, \& vanEngen, 2003), and this holds true for social work educational leaders when both leader and employee ratings are combined. (In this study, male self-ratings were significantly higher than female self-ratings.)

It is important to note the effect of context on social work educational leadership style. There is an effect with social work units having slightly more influence than the larger college or university context on the leadership style of their leader and being more open to change. Again, based on past research this finding is not unexpected (Bommer et al., 2004; Pawar \& Eastman, 1997).

In this study gender and context combine to have an effect on transformational leadership style is social work education as it has in other college/university departments (vanEngen \& Willemson, 2004; Yoder, 2001). Females in larger colleges/universities and units utilized more transformational leadership than males or females in smaller colleges/universities and units, another expected finding.

There was one unexpected finding: social work educational leaders utilize passive/avoidant leadership at a higher rate than national norms. Typically, leaders who are high 
in transformational leadership are low in passive/avoidant leadership style. This group was different in that they were higher than national norms on both styles, and demographic variables were unable to explain these differences. Possible reasons for this were explored.

In short, social work is a profession dedicated to empowerment and growth.

Transformational leadership style is the perfect fit for social work values, and as expected social work leaders utilize this style frequently. While more research, training and support for social work leadership is needed at all levels, social work is well on its way in development of leadership initiatives to increase the knowledge base of the profession and its individual members. 


\section{REFERENCES}

Alpert, D. (1987). Gender inequality in academia: An empirical analysis. Initiatives, 52, 9-14. Antonakis, J., Avilio, B.J., \& Sivasubramaniam, N. (2003). Context and leadership: An examination of the nine factor full-range leadership theory using the multifactor leadership questionnaire. The Leadership Quarterly, 14(3), 261-295.

Austin, D.M. (1997). The profession of social work in the second century. In Reisch, M. \& Gambrill, E. (Eds.). Social Work in the $21^{\text {st }}$ Century. Pp. 396-407.

Austin, D.M. (1995). Management overview. In R.L.Edwards (Ed.), Encyclopedia of Social Work (19 ${ }^{\text {th }}$ ed., pp. 1642-1658).

Avolio, B.J. \& Bass, B.M. (2004). Mutlitactor leadership questionnairre ( $3^{\text {rd }}$ ed.): Manual and sampler set. MindGarden, Inc.

Barker, R.A. (1994). The rethinking of leadership. The Journal of Leadership Studies, 1(2), 46-54.

Bass, B.M. (1997). Does the transactional-transformational leadership paradigm transcend organizational and national boundaries? American Psychologist, 52(2), 130-139.

Bass, B.M. (1995). Comment: Transformational leadership, looking at other possible antecedents and consequences. Journal of Management Inquiry, 4(3), 293-297.

Bass, B. M. (1990). Bass \& Stogdill's handbook of leadership: Theory, research, and managerial application, $3^{\text {rd }}$ ed. New York: The Free Press.

Bass, B.M. \& Avolio, B.J. (1989). Manual: The multifactor leadership questionnaire. Palo Alto, CA: Consulting Psychologists Press.

Bass, B.M. \& Avolio, B.J. (1994). Shatter the glass ceiling: women may make better managers than men. Human Resource Management, 33(4), 549-560.

Bass, B.M., Avolio, B.J., \& Atwater, L. (1996). The transformational and transactional leadership of men and women. Applied Psychology: An International Review, 45(1), 5-34. 
Bass, B.M. \& Riggio, R.E. (2006). Transformational leadership ( $2^{\text {nd }}$ ed.). Mahwah, New Jersey: Lawrence Eribaum Associates, Publishers.

Beare, H., Caldwell, B., \& Millikan, R. (1997). Dimensions of leadership. In M. Crawford, L. Kydd, \& C. Riches (Eds.). Leadership and teams in educational management (pp. 24-39).

Benjamin, E. (1999). The new academic generation: A profession in transformation. Academe, 85(5), 86-89.

Bentley, K.J., Hutchison, E.D., \& Green, R.G. (1994). Women as social work scholars: An empirical analysis. Affilia, 9(2), 171-189.

Blackmore, J. (1996). Chapter 28: 'Breaking the silence': Feminist contributions to educational administration policy. In K. Leithwood, J. Chapman, D. Corson, P. Hallinger, \& A. Hart, (Eds.). International handbook of educational leadership and administration (pp. 997 1034). Netherlands: Kluwer Academic Publishers.

Bommer, W.H., Rubin, R.S., \& Baldwin, T.T. (2004). Setting the stage for effective leadership: Antecedents of transformational leadership behavior. The Leadership Quarterly, 15(2), 195-210.

Brilliant, E. L. (1986). Social work leadership: A missing ingredient? Social Work, 31, 325-330.

Burns, J.M. (2003). Transforming leadership. New York: Grove Press.

Burns, J.M. (1978). Leadership. New York: Harper \& Row, Publishers.

Caplan, P.J. (1995). Lifting a ton of feathers: $A$ woman's guide to surviving in the academic world. Toronto, Canada: University of Toronto Press.

Carless, S.A. (1998). Gender differences in transformational leadership: An examination of superior, leader, and subordinate perspectives. Sex Roles, 39(11/12), 887-902.

Carli, L.L. \& Eagley, A.H. (2001). Gender, hierarchy, and leadership: An introduction. Journal of Social Issues, 57(4), 629-636.

Carmines, E.G. \& Zeller, R.A. (1979). Reliability and validity assessment. Newbury Park: Sage Publications. 
Chliwniak, L. (1997). Higher education leadership: Analyzing the gender gap. (Report No. RR-93002008). Washington, DC: The George Washington University: ASHE-ERIC Higher Education Reports. (ERIC Document Reproduction Services No. ED410846 1997-00-00).

Chin, J.L. (2004). 2003 Division 35 presidential address: Feminist leadership: Feminist visions and diverse voices. Psychology of Women Quarterly, 28(1), 1-8.

Colarossi, L. (2006, February). Historical overview of feminist and transformational leadership theories. In L. Colarossi (Chair), Who will start the revolution?: Anti-oppressive leadership for social work education. Symposium conducted at the meeting of the Council on Social Work Education Women's Council Symposium, Chicago, IL.

Conger, J. (1999). Charismatic and transformational leadership in organizations: An insider's perspective on these developing streams of research. Leadership Quarterly, 10(2), 145179.

Cook, C., Heath, F., \& Thompson, R.L. (2000). A meta analysis of response rates in the web or internet based survey. Educational \& Psychological Measurements, 60, 821-836.

Council on Social Work Education (2008). Educational policy and accreditation standards.. Council on Social Work Education: Alexandria, VA.

Council on Social Work Education (2007). 2006 annual survey of social work programs. Council on Social Work Education: Alexandria, VA.

Dillman, D.A. (2007). Mail and internet surveys: The tailored design method ( $2^{\text {nd }}$ ed.). Hoboken, New Jersey: John Wiley \& Sons, Inc.

DiNitto, D., Martin, P.Y., \& Harrison, D.F. (1984). Sexual inequality among social work faculty: An international comparison. International Social Work, 27, 27-36.

DiPalma, S. (2005). Progress for Women Faculty in Social Work Academia. Affilia, 20(1), 71-86.

DiPalma, S.L. \& Topper, G.G. (2001). Social work Academia: Is the glass ceiling beginning to crack? Affilia, 16(1), 31-45.

Druskat, V. U. (1994). Gender and leadership style: Transformational and transactional leadership in the roman catholic church. Leadership Quarterly, 5(2), 99-119. 
Eagly, A.H. (2003). Few women at the top: How role incongruity produces prejudice and the glass ceiling. In D. van Knippenberg \& M.A. Hogg (Eds.). Leadership and power: Identity processes in groups and organizations (pp. 79-93). London: Sage Publications.

Eagly, A.H., Karau, S.J., \& Makhijani, M.G. (1995). Gender and effectiveness of leaders: A metaanalysis. Psychological Bulletin, 117(1), 125-145.

Eagly, A.H., Johannesen-Schmidt, M.C., \& vanEngen, M.L. (2003). Transformational, transactional, and laissez-faire leadership styles: A meta-analysis comparing men and women. Psychological Bulletin, 129(4), 569-591.

Fagin, C.M. (1997). The leadership role of a dean. In M.J. Austin, F.L. Ahearn, \& R.A. English, (Eds.). The professional school dean: Meeting the leadership challenges (pp. 95-99). San Francisco: Jossey-Bass Publishers.

Fiedler, F.E., Chemers, M.M., \& Mahar, L. (1976). Improving leader effectiveness: The LEADER MATCH concept. New York: Wiley.

Fanshel, D. (1976). Status differential: Men and women in social work. Social Work, 21(6), 448454.

Fletcher, J.K. (1994). Castrating the female advantage: Feminist standpoint research and management science. Journal of Management Inquiry, 3(1), 74-82.

Gandy, J.T., Randolph, J.L., \& Raymond, F.B. (1979). On minding the store: Research on the social work deanship. College of Social Work: University of South Carolina.

Gellis, Z.D. (2001). Social work perceptions of transformational and transactional leadership in health care. Social Work Research, 25(1), 17-25.

Gilligan, C. (1982). In a different voice: Psychological theory and women's development. Cambridge, MA: Harvard University Press.

Glazer-Raymo, J. (1999). Shattering the myths: Women in academe. Baltimore: The Johns Hopkins University Press.

Graen, G. (1976). Role making processes within complex organizations. In M.D. Dunnette (Ed.), Handbook of Industrial and Organizational Psychology. Chicago: Rand McNally. 
Graham, J.W. (1991). Servant-leadership in organizations: inspirational and moral. Leadership Quarterly, 2(2), 105-119.

Gunter, H.M. (2001). Leaders and leadership in education. Thousand Oaks, CA: Sage Publications.

Hall, V. (1999). Gender and education management: Duel or dialogue? In T. Bush, L. Bell, R. Bolam, R. Glatter, \& P. Ribbins (Eds.). Educational management: Redefining theory, policy and practice (pp. 155-165). Thousand Oaks, CA: P. Chapman Publishing.

Hargens, L. L., \& Long, J. S. (2002). Demographic inertia and women's representation among faculty in higher education. The Journal of Higher Education, 73(4), 494-506.

Hartman, M.S. (1999). Talking leadership: Conversations with powerful women. New Brunswick, NJ: Rutgers University Press.

Havens, C.M. \& Healy, L.M. (1991). Do women make a difference? The Journal of State Government, 64(2), 63-67.

Helgensen, S. (1990). The female advantage: Women's ways of leadership. New York: Doubleday Currency.

Heilman, M.E. (2001). Description and prescription: How gender stereotypes prevent women's ascent up the organizational ladder. Journal of Social Issues, 57(4), 657-674.

Hersey, P., \& Blanchard, K.H. (1982). Management of organization behavior: Utilizing human resources $\left(4^{\text {th }}\right.$ ed.). Englewood Cliffs, NJ: Prentice-Hall.

Hubbard, S. \& Robinson, J. (1998). Mentoring: a catalyst for advancement in administration. Journal of career development, 24(4), 289-299.

IRB, http://www.hhs.gov/ohrp/irb/irb chapter6ii.htm\#g10

Jung, D.I. \& Sosik, J.J. (2002). Transformational leadership in work groups: The role of empowerment, cohesiveness, and collective-efficacy on perceived group performance. Small Group Research, 33(3), 313-336.

Kanter, R. M. (1977). Men and women of the corporation. New York: Basic Books.

Kark, R., Shamir, B., \& Chen, G. (2003). The two faces of transformational leadership: Empowerment and dependency. Journal of Applied Psychology, 88(2), 246-255. 
Katz, D., \& Kahn, R.L. (1978). The social psychology of organizations. New York: Wiley.

Keys, P.R. (2008). The social work educator potential in higher education administration. In L. H. Ginsberg (Ed.), Management and Leadership in Social Work Practice and Education. Alexandria, VA: Council on Social Work Education.

Kezar, A.J., Carducci, R., \& Contreras-McGavin, M. (2006). Rethinking the "L" word in higher education: The revolution of research on leadership. ASHE Higher Education Report, 31(6).

Kjeldal, S., Rindfleish, J., \& Sheridan, A. (2005). Deal-making and rule-breaking: behind the façade of equity in academia. Gender and Education, 17(4), 431-447.

Kimball, C.N., Watson, T., Canning, S.S., \& Brady, J.L. (2001). Missing voices: Professional challenges for academic women. Journal of Psychology and Christianity, 20(2), 132-144.

Kouzes, J.M. \& Posner, B.Z. (2007). The Leadership Challenge $\left(4^{\text {th }}\right.$ ed.). SanFrancisco: John Wiley \& Sons, Inc.

Kravetz, D. \& Austin, C.D. (1984). Women's issues in social service administration: The views and experiences of women administrators. Administration in Social Work, 8(4), 25-38.

Lennon, T. M. (2004). Statistics on social work education in the United States: 2002. Alexandria, VA: Council on Social Work Education.

Lowe, K.B., Kroeck, K.G., \& Sivasubramaniam, N. (1996). Effectiveness correlates of transformational and transactional leadership: A meta-analytic review of the MLQ literature. The Leadership Quarterly, 7(3), 385-425.

Madden, M.E. (2005). 2004 Division 35 presidential address: gender and leadership in higher education. Psychology of Women Quarterly, 29(1), 3-14.

Maher, K.J. (1997). Gender-related stereotypes of transformational and transactional leadership. Sex Roles, 37(3-4), 209-225.

Marshall, C. (1993). The politics of denial: gender and race issues in administration. In C. Marshall (Ed.), The new politics of race and gender: the 1992 yearbook of the politics of education association (pp. 168-175). Washington, D.C.: Falmer Press. 
Mary, N.L. (2005). Transformational leadership in human service organizations. Administration in Social Work, 29(2), 105-118.

Mertler, C.A. \& Vannatta, R. A. (2002). Advanced and Multivariate Statistical Methods: Practical Application and Interpretation ( $2^{\text {nd }}$ ed.). Los Angeles: Pyrczak Publishing.

Mizrahi, T. \& Berger, C.H. (2001). A longitudinal look at social work in hospitals: the impact of a changing health care system. Health and Social Work, 30(2), 155-165.

Morales, A.T. \& Sheafor, B.W. (1998). Social work: A profession of many faces ( $8^{\text {th }}$ ed.). Needham Heights, MA: Allyn and Bacon.

Munson, C. E. (2002). Handbook of clinical social work supervision ( $3^{\text {rd }}$ ed.). Binghamton, New York: The Haworth Press.

National Association of Social Workers. (n.d.). A mandate for action: Social work reinvestment initiative. Retrieved January 21, 2008, from http://www.socialworkreinvestment.org/GOALS.aspx

National Association of Social Workers. (2008). Code of Ethics. Silver Springs, MD: Author. National Network for Social Work Managers. (2004). Leadership and management practice standards [Electronic Version]. Retrieved 9/17/09 from http://www.socialworkmanagers.org/pdfs/Standards_new\%20logo.doc.

Nesoff, I. (2007). The importance of revitalizing management education for social workers. Social Work, 52(3).

Newsome, M. (1995). Vision manifested in leadership. Social Work Education Reporter, 43(3), 12.

Ogawa, R.T. \& Bossert, S.T. (1997). Leadership as an organizational quality. In M. Crawford, L. Kidd, \& C. Riches (Eds.), Leadership and teams in educational management (pp. 9-23). Open University Press: Philadelphia, PA.

Osborn, R.N., Hunt, J.G., \& Jauch, L.R. (2002). Toward a contextual theory of leadership. The Leadership Quarterly, 13(6), 797-837.

Packard, T. \& Tucker-Tatlow, J. (2006, February). Leaders in action. Paper presented at the meeting of the Council on Social Work Education, Annual Program Meeting, Chicago, IL. 
Pawar, B.S. \& Eastman, K.K. (1997). The nature and implications of contextual influences on transformational leadership: A conceptual examination. Academy of Management Review, 22(1), 80-109.

Perlmutter, F.D. \& Crook, W.P. (2004). Changing hats while managing change: From social work practice to administration ( $2^{\text {nd }}$ ed.). Washington, D.C.: National Association of Social Workers.

Petchers, M.K. (1996). Debunking the myth of progress for women social work educators. Affilia, 11(1), 11-38.

Rank, M. G., \& Hutchinson, W. S. (2000). An analysis of leadership within the social work profession. Journal of Social Work Education, 36(3), 487-502.

Reay, D. \& Ball, S.J. (2000). Essentials of female management: Women's ways of working in the education market place? Educational Management \& Administration, 28(2), 145-159.

Roa, A. \& Kelleher, D. (2000). Leadership for social transformation: some ideas and questions on institutions and feminist leadership. Gender and Development, 8(3), 74-79.

Rosener, J.B. (1990). Ways women lead. Harvard Business Review, 119-125.

Rosser, V.J. (2003). Faculty and staff members' perceptions of effective leadership: Are there differences between women and men leaders? Equity and Excellence in Education, $36(1), 71-81$.

Rost, J.C. (1993). Leadership development in the new millennium. The Journal of Leadership Studies, 1(1), 92-110.

Rubin, A. \& Babbie, E. (2001). Research Methods for Social Work $\left(4^{\text {th }}\right.$ ed.). Belmont, CA: Wadsworth/Thomson Learning.

Rutherford, S. (2001). Any difference? An analysis of gender and divisional management styles in a large airline. Gender, Work, and Organization, 8(3), 326-345.

Scanlon, K.C. (1997). Mentoring women administrators: Breaking through the glass ceiling. Initiatives, 58(2), 29-59.

Schaefer, D. \& Dillman, D.A. (1998). Development of a standard e-mail methodology: Results of an experiment. Public Opinion Quarterly, 62(3), 378-397. 
Schnieder, A. (2000). Female scientists turn their backs on jobs at research universities. Chronicle of Higher Education, 46(50), A12-A16.

Shakeshaft, C. (1999). Chapter 5: The struggle to create a more gender-inclusive profession. In Murphy, J. \& Lewis, C.S. (Eds.). Handbook of research on educational administration (pp. 99-118).

Shakeshaft, C. (1989). The gender gap in research in educational administration. Educational Administration Quarterly, 25(3), 324-337.

Sheafor, B.W. (2005). CSWE leadership initiative update. Social Work Education Reporter, 54(1), 21-22.

Singleton, R.A. \& Straits, B.C. (1999). Approaches to social research ( $3^{\text {rd }}$ ed.). New York: Oxford University Press.

Skrla, L. (2003). Normalized femininity. In M.D.Young \& L. Skrla (Eds.), Reconsidering feminist research in educational leadership (pp. 247-263). Albany, NY: State University of New York Press.

Slater, R.O. (1995). The sociology of leadership and educational administration. Educational Administration Quarterly, 31(3), 449-472.

Sowers-Hoag, K.M. \& Harrison, D.F. (1991). Women in social work education: Progress or promise? Journal of Social Work Education, 27(3), 320-329.

Starratt, R.J. (1999). Moral dimensions of leadership. In P.T. Begley \& P.E. Leonard (Eds.). The Values of Educational Administration (pp. 22-35).

Stogdill, R.M. (1974). Handbook of leadership: A survey of the literature. New York: Free Press. Stratham, A. (1987). The gender model revisited: Differences in the management styles of men and women. Sex Roles, 16(7/8), 409-430.

Sue, V.M. \& Ritter, L.A. (2007). Conducting online surveys. Los Angeles: Sage Publications. Takamura, J.C. (2008). The graduate social work dean: Roles and reflections. In L. H. Ginsberg (Ed.), Management and leadership in social work practice and education. Alexandria, VA: Council on Social Work Education.

Thornton, S. (2007). Financial inequality in higher education. Academe, 93(2), 21-34. 
Valian, V. (2004).Beyond gender schemas: Improving the advancement of women in academia. NWSA Journal, 16(1), 207-220.

Van Engen, M.L. \& Willemson, T.M. (2004). Sex and leadership styles: A meta-analysis of research published in the 1990s. Psychological Reports, 94(1), 3-18.

vanZyl, M.A. (2007). Rapid Organizational Learning Evaluation (ROLE). Unpublished scale.

Videki-Sherman, L., Allen-Meares, P., Yeggedis, B., \& Yu, Y. (1995). Social work deans in the 1990's: Survey findings. In F. Raymond (Ed.), The administration of social work education programs: The role of deans and directors. Columbia, SC: National Association of Deans and Directors of Schools of Social Work.

Yammarino, F.J., Spangler, W.D., \& Bass, B.M. (1993). Transformational leadership and performance: a longitudinal investigation. Leadership quarterly, 4(1), 81-102.

Yoder, J.D. (2001). Making leadership work more effectively for women. Journal of Social Issues, $57(4), 815-828$.

York, R.O., Henley, H.C., \& Gamble, D.N. (1988). The power of positive mentors: Variables associated with women's interest in social work administration. Journal of Social Work Education, 24(3), 242-250.

Young, I.P. \& Brown, J. (1996). Sex bias in compensation: an examination of compensation differentials for female and male educational administrators. Educational Administration Quarterly, 32(1), 142-159.

Young, P. (2004). Leadership and gender in higher education: a case study. Journal of Further and Higher Education, 28(1), 95-106. 


\section{APPENDIX A}

\section{Introductory Leader Subject Recruitment Letter \#1}

Dear Dean, Director, or Chair:

A few days from now you will receive an email request to complete a brief web-based survey being conducted by Kent School of Social Work at the University of Louisville.

It concerns leadership practices among social work educators, and it is one of very few studies addressing this topic. This study is endorsed by Terry Singer, Dean of the Kent School of Social Work at the University of Louisville, and by Alberto Godenzi, president of the National Association of Directors and Deans (Council on Social Work Education), and their letters of support are attached.

I am emailing in advance because we have found that many people like to know ahead of time that they will be contacted. The study is an important one that will help social work educators know what type of leadership practices are currently being utilized and also the effectiveness of the current practices.

Please enter my email address (pldesr01@louisville.edu) into your computer so that future correspondence will make it through your university filter.

Thank you for your time and consideration. It's only with the generous help of people like you that our research can be successful.

Sincerely,

Patricia L. Desrosiers, LCSW

Ph.D. Candidate

LL\# 1 


\section{APPENDIX B}

\section{Leader Subject Recruitment Letter \#2}

Dear Director, Dean, or Chair:

I am writing to ask your help in a study of leadership being conducted for social work educators in the United States. This study is an effort to learn about leadership practices in social work education.

It is my understanding that you are a social work leader in education. We are contacting all deans, directors, and chairs of social work educational programs in the United States in order to determine what their leadership practices are as well as the effectiveness of their leadership. With an awareness of the limitations of studying only formal leaders, in order to keep the study of a manageable size we are limiting the sample to deans, directors, and chairs of accredited social work programs in the United States.

Results from the survey will be used to partially fulfill dissertation requirements of a doctoral student, and more importantly the results will be submitted for publication in journals and social work conferences in order to increase knowledge about leadership practices in the social work profession. It concerns leadership practices among social work educators, and it is one of very few studies addressing this topic. This study is endorsed by Terry Singer, Dean of the Kent School of Social Work at the University of Louisville, and by Alberto Godenzi, president of the National Association of Directors and Deans (NADD), and their letters of support are attached.

Your answers will be completely confidential and will be released only in summaries where no individual answers can be identified. The survey is voluntary; however, you can help us a great deal by taking thirty to forty minutes to provide your views on leadership and your individual leadership practices.

In order to get the most accurate view of your leadership practices, at least two employees must rate your leadership practices in addition to yourself. Once your completed survey is received, an invitational email will be sent to appropriate employees and direct reports at your college or university social work department via your preselected contact person. Telephone, email, and regular mail follow up invitations may be sent requesting employee surveys be completed if needed. The link to the anonymous employee survey on social work leadership is as follows: http://www.questionpro.com/akira/TakeSurvey?id=893194. The password is SOCIAL. This survey is slightly different from yours.

The link to the online survey for deans, directors, and chairs is as follows: http://www.questionpro.com/akira/TakeSurvey?id=859737. The password is JUSTICE. You may also complete the attached Word survey on your computer and email a saved copy with your name in the title to pldesr01@louisville.edu.

Sincerely,

Patricia Desrosiers, Ph.D. candidate

University of Louisville 


\section{APPENDIX C}

\section{Leader Subject Recruitment Letter \#3}

Dear Director, Dean, or Chair:

Two weeks ago an email was sent to you requesting your participation in a web-based survey about leadership practices in social work education.

If you have already completed the survey, please accept our sincere thanks. If not, please do so today. We are especially grateful for your help because it is only by asking social workers like you to share their experiences that we can understand leadership in our profession.

The link to the leader survey is as follows: http://www.questionpro.com/akira/TakeSurvey?id=859737. The password is JUSTICE. You may also complete the attached Word survey on your computer and email a saved copy with your name in the title to pldesr01@louisville.edu. You may print out and fax your completed survey to the Kent School of Social Work, Attention: Dr. Thomas Lawson (502-852-0422) or regular mail return it to Dr. Thomas Lawson, Kent School of Social Work, University of Louisville, Louisville, KY 40292.

Please pass this information along to the other social work directors, deans, and chairs, as well, and contact pldesr01@louisville.edu with any questions.

Sincerely,

Patricia L. Desrosiers, Ph.D. Candidate

University of Louisville

LL\#3 


\section{APPENDIX D}

\section{Leader Subject Recruitment Letter \#4}

Dear Dean, Director, or Chair:

About three weeks ago I sent a survey to you that asked about your experiences with leadership in social work education. The comments about people who have already responded include a wide variety of leadership experiences in social work education. We think that these responses will be very useful to social work educators.

We are writing again because of the importance that your survey has for helping to get accurate results. Although we sent surveys to all deans, directors, and chairs listed in the CSWE NADD mailing list, we have not received completed surveys representing all. It is only by hearing from nearly everyone in the sample that we can be sure the results are truly representative.

A few people have responded saying they are no longer a leader in their department or program. If this is the case for you, then please pass the web survey information on to the appropriate person and consider completing a rater form about the new leader.

As you know, protecting the confidentiality of people's answers is very important to us, as well as the university. No information will be shared except in the aggregate, and no codes will be kept after surveys are matched for averaging.

We hope that you will complete this voluntary web-based survey soon. The link to the leader survey is as follows: http://www.questionpro.com/akira/TakeSurvey?id=859737. The password is JUSTICE. You may also complete the attached Word survey on your computer and email a saved copy with your name in the title to pldesr01@louisville.edu. You may print out and fax your completed survey to the Kent School of Social Work, Attention: Dr. Thomas Lawson (502-852-0422) or return it regular mail to Dr. Thomas Lawson, Kent School of Social Work, University of Louisville, Louisville, KY 40292.

Sincerely,

Patricia Desrosiers, Ph.D. Candidate

University of Louisville

LL\#4 


\section{APPENDIX E}

\section{Leader Subject Recruitment Letter \#5}

Dear Dean, Director, or Chair:

During the past four weeks we have contacted you several times about an important research study we are conducting for the social work profession.

Its purpose is to increase the understanding of leadership in social work education and to partially complete the degree requirements for Patricia Desrosiers' Ph.D. in social work.

This study is drawing to a close, and this is the last contact that will be made with the initial group of social work deans and directors. The last day to complete the survey will be September 19, 2008.

In addition to this email, there may be a follow up call to all the schools in the states that have had low or no response. Hearing from everyone in the population helps assure that the survey results are as accurate as possible.

We also want to remind you that your response to this study is voluntary, and if you prefer not to respond that's fine. If you are not a current leader in social work education, it would be helpful for you to pass this survey information along to other social work deans and directors.

The link to the leader survey is as follows:

http://www.questionpro.com/akira/TakeSurvey?id=859737. The password is JUSTICE. You may also complete the attached Word survey on your computer and email a saved copy with your name in the title to pldesr01@louisville.edu. You may print out and fax your completed survey to the Kent School of Social Work, Attention: Dr. Thomas Lawson (502-852-0422) or regular mail return it to Dr. Thomas Lawson, Kent School of Social Work, University of Louisville, Louisville, KY 40292.

Finally, we appreciate your willingness to consider our request as we conclude this effort to better understand leadership in social work education.

Sincerely,

Patricia Desrosiers, Ph.D. Candidate

University of Louisville

\section{LL\#5}




\section{APPENDIX F}

\section{President Alberto Godenzi Support Letter}

\section{$\theta_{1+2}^{+\infty+2}$ \\ boston college}

office of the dean

graduate school of social work

July 2,2008

RE: Social Work Educational Leadership Survey

The mission of the National Association of Deans and Directors of Schools of Social Work (NADD) is to promote excellence in social work education. NADD supports Deans, Directors, and Chairs in their professional development and effectiveness as acadernic administrators through training and support of best practices models, research into effective social work leadership, and nurturance and development of social work leaders.

Ms. Desrosiers is a Kent School of Social Work (University of Louisville) doctoral student. Her important and timely research will increase the knowledge base of educational leadership in the social work profession. Through examination of the effectiveness of current leadership styles in use in social work education, this research will serve as baseline measurements of leadership style and effectiveness. Based on these measurements, social work educators can decide on future leadership training needs to further enhance the development of social work leaders.

NADD will assist Ms. Desrosiers by providing access to NADD distribution list through Dean Terry Singer in order that Ms. Desrosiers may contact all deans, directors, and chairs inviting participation in this study. We encourage deans, directors, and chairs to complete this twenty to thirty minute long survey. We are especially grateful for your help because it is only by asking social workers like you to share their experiences that we can understand leadership in our profession.

We at NADD look forward to the results of this study. Dissemination of information gathered from our social work leaders will take the form of journal articles and conference presentations.

Sincerely,

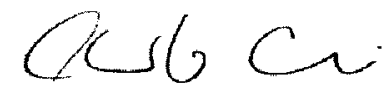

Alberto Godenzi, Ph.D.

President of the National Association of Deans and Directors of Schools of Social Work

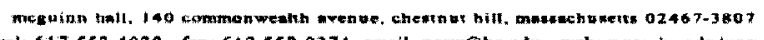

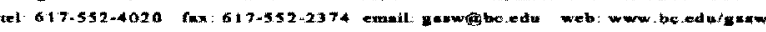




\section{APPENDIX G}

\section{Dean Terry Singer Support Letter}

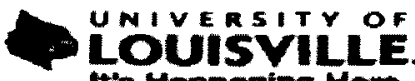 \\ t's Happonimg Mons.}

July 1,2008

RE: Social Work Educational Leadership Survey

One of the most pressing contemporary challenges in the social work profession is the development of effective leaders in a variety of contexts. However, at the current time there is little researeh on the current nuture of social work leadership. In order to build the leadership capacity of the profession, it is imperative that research on best practice takes place.

1 am writing to express my strong support for the research study being conducted at the Kent School of Social Work, University of Louisville, by doctoral candidate, Patricia Desrosiers, under the guidance of her dissertation committee chaired by Dr. Tom Lawson. The Kent School has committed to in-kind support for this research in the form of utilization of fax machines, telephone communications, and email accoumt usage as well as computer and software access.

The Kent School has a strong interest in furthering social work knowledge about the styles of educational leadership currently being practiced in the United States. Increased knowledge about the effectiveness of various leadership practices as well as the effect of contextual influences on social work leadership style will be achieved through this study.

With an awareness of the importance of effective social work leadership development, I respectfully request that you assist the $\mathrm{Ms}$. Desrosiers in her efforts to ascertain the current nature of social work educational leadership practices. Completion of a short survey will greatly benefit the social work profession.

Sincerely,

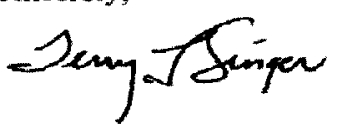

Terry L. Singer, $\mathbf{P h} . \mathrm{D}$.

Dean

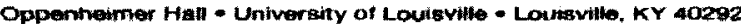

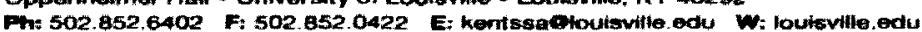




\section{APPENDIX H}

\section{Rater Subject Recruitment Letter \#1}

Dear Social Work Educator:

A few days from now you will receive an email request to complete a brief web-based survey being conducted by Kent School of Social Work at the University of Louisville.

It concerns leadership practices among social work educators, and it is one of very few studies addressing this topic. This study is endorsed by Terry Singer, Dean of the Kent School of Social Work at the University of Louisville, and by Alberto Godenzi, president of the National Association of Directors and Deans (Council on Social Work Education), and their letters of support are attached. It has also been approved by the University of Louisville Institutional Review Board.

I am emailing in advance because we have found that many people like to know ahead of time that they will be contacted. The study is an important one that will help social work educators know what type of leadership practices are currently being utilized and also the effectiveness of the current practices.

Please enter my email address (pldesr01@ louisville.edu) into your computer so that future emails will make it through your university filter.

Thank you for your time and consideration. It's only with the generous help of people like you that our research can be successful.

Sincerely,

Patricia Desrosiers, LCSW

Ph.D. Candidate

RL \#1 


\section{APPENDIX I}

\section{Rater Subject Recruitment Letter \#2}

Dear Social Work Educator:

I am writing to ask your help in a study of leadership being conducted for social work educators in the United States. This study is an effort to learn about leadership practices in social work education.

It is my understanding that you are a social work educator. With an awareness of the limitations of studying only formal leaders, in order to keep the study of a manageable size we are requesting that you rate the person in the regards line of your email. The dean, director, or chair of your social work school has returned a leadership survey. Your ratings will be combined with the self-ratings of the leaders for an average leadership score. This will insure the most accurate portrayal of the leadership style and practices of this particular leader.

Your answers will be completely anonymous if completed on the web survey and completely confidential if completed via the email survey attached. Results will be released only in summaries where no individual answers can be identified. The survey is voluntary; however, you can help us a great deal by taking fifteen to twenty minutes to provide your views on your dean, director, or chair's leadership practices.

This invitational email has been sent to all the coworkers and direct reports at your school. Telephone, email, and regular mail follow up invitations may be sent requesting rater surveys be completed if needed.

Results from the survey will be used to partially fulfill dissertation requirements, and more importantly the results will be submitted for publication in journals and social work conferences in order to increase knowledge about leadership practices in the social work profession.

The link to the anonymous leader survey is as follows:

http://www.questionpro.com/akira/TakeSurvey?id=893194. The password is SOCIAL. You may also complete the attached confidential Word survey on your computer, save it with your leader's name in the title, and email pldesr01@louisville.edu. You may print the completed survey and fax to the Kent School of Social Work, Attention: Dr. Thomas Lawson (502-852-0422), or print and regular mail return it to Dr. Thomas Lawson, Kent School of Social Work, University of Louisville, Louisville, KY 40292.

Sincerely,

Patricia Desrosiers, Ph.D. candidate

University of Louisville 


\section{APPENDIX J}

\section{Rater Subject Recruitment Letter \#3}

Dear Social Work Educator:

One week ago an email was sent to you requesting your participation in a web-based survey about leadership practices in social work education.

If you have already completed the survey about your dean, director or chair please accept our sincere thanks. If not, please do so today. We are especially grateful for your help because it is only by asking social workers like you to share their experiences that we can understand leadership in our profession.

My email address is pldesr01 @ louisville.edu. The link to the anonymous leader survey is as follows: http://www.questionpro.com/akira/TakeSurvey?id=1134143. The password is social. You may also complete the attached confidential Word survey on your computer, save it with your leader's name in the title, and email pldesr01@louisville.edu. You may print the completed survey and regular mail return it to Dr. Thomas Lawson, Kent School of Social Work, University of Louisville, Louisville, KY 40292. Please pass this information along to the other social work educators in your school, as well, and contact pldesr01@louisville.edu with any questions.

Sincerely,

Patricia Desrosiers, Ph.D. Candidate

University of Louisville

RL\#3 


\section{APPENDIX K}

\section{Rater Subject Recruitment Letter \#4}

\section{Dear Social Work Educator:}

About two weeks ago I sent a survey to you that asked about your experiences with leadership in social work education. The comments about people who have already responded include a wide variety of leadership experiences in social work education. We think that these responses will be very useful to social work educators.

We are writing again because of the importance that your survey has for helping to get accurate results. Although we sent surveys to all deans, directors, and chairs listed in the CSWE NADD mailing list, we have not received completed rater surveys representing all. It is only by hearing from nearly everyone in the sample that we can be sure the results are truly representative.

As you know, protecting the anonymity of people's answers is very important to us, as well as the university. No information will be shared except in the aggregate, and all rater surveys will be combined with the leader survey for an average score.

We hope that you will complete this voluntary web-based survey soon. The link to the anonymous rater survey on social work leadership is as follows:

http://www.questionpro.com/akira/TakeSurvey?id=1134143. The password is social. You may also complete the attached confidential Word survey on your computer, save it with your leader's name in the title, and email pldesr01@louisville.edu. You may print the completed survey and regular mail return it to Dr. Thomas Lawson, Kent School of Social Work, University of Louisville, Louisville, KY 40292.

Sincerely,

Patricia Desrosiers, Ph.D. Candidate

University of Louisville

RL\#4 


\section{APPENDIX L}

\section{Rater Subject Recruitment Letter \#5}

Dear Social Work Educator:

During the past four weeks we have contacted you several times about an important research study we are conducting for the social work profession.

Its purpose is to increase the understanding of leadership in social work education and to partially complete the degree requirements for Patricia Desrosiers' Ph.D. in social work.

This study is drawing to a close, and this is the last contact that will be made with the initial group of peers and direct reports of leaders. The last day to complete the survey will be June 1, 2009.

In addition to this email, there may be a follow up call to all the schools in the states that have had low or no response. Hearing from everyone in the population helps assure that the survey results are as accurate as possible.

We also want to remind you that your response to this study is voluntary, and if you prefer not to respond that's fine.

My email address is pldesr01@louisville.edu. The link to the anonymous leader survey is as follows: http://www.questionpro.com/akira/TakeSurvey?id=1134143. The password is social. You may also complete the attached confidential Word survey on your computer, save it with your leader's name in the title, and email pldesr01@louisville.edu. You may print the completed survey and regular mail return it to Dr. Thomas Lawson, Kent School of Social Work, University of Louisville, Louisville, KY 40292.

Finally, we appreciate your willingness to consider our request as we conclude this effort to better understand leadership in social work education.

Sincerely,

Patricia Desrosiers, Ph.D. Candidate

University of Louisville

RL\#5 


\section{APPENDIX M}

\section{Leader Preamble}

\section{LEADERSHIP STYLES OF SOCIAL WORK EDUCATORS}

September 11, 2008

\section{Dear Social Work Leader:}

You are being invited to participate in a research study by answering the attached survey about social work leadership practices in educational settings. There are no known risks for your participation in this research study. The information collected may not benefit you directly. The information learned in this study may be helpful to others. The information you provide will be used to advance the knowledge of the way social workers lead in educational settings. Your completed survey will be stored at in the co Pls' locked office on password protected computers not accessible to the general employees. The survey will take approximately 45 minutes to complete.

Individuals from the Department of Social Work, the Institutional Review Board (IRB), the Human Subjects Protection Program Office (HSPPO), and other regulatory agencies may inspect these records. In all other respects, however, the data will be held in confidence to the extent permitted by law. Should the data be published, your identity will not be disclosed. Neither you nor your employees will have access to completed survey results on an individual basis. In fact, once the surveys are matched by name and prior to data analysis, the survey data will be deidentified by assignment of matched numbers in place of the names. The two endorsers (Terry Singer, Dean of the Kent School of Social Work and Alberto Godenzi, President of the National Association of Directors and Deans) are not members of the research staff and will not have access to any individualized or aggregate raw data; they will only receive data analysis results in the aggregate form.

Taking part in this study is voluntary. By completing this survey you agree to take part in this research study. You do not have to answer any questions that make you uncomfortable. You may choose not to take part at all. If you decide to be in this study you may stop taking part at any time. If you decide not to be in this study or if you stop taking part at any time, you will not lose any benefits for which you may qualify. Employees or "Raters" are defined as direct reports of the deans and directors and may include administrative assistants, instructors, lecturers, part-time faculty, and full-time faculty who have worked with the leader for at least 6 months. Your survey will not be included in the research unless at least two rater surveys are received prior to the completion of the data collection period. You will be asked in the survey to provide a contact email for someone in your department who may forward the employee survey to the appropriate departmental employees as listed above. Please give careful thought as to who the most appropriate contact will be.

If you have any questions, concerns, or complaints about the research study, please contact: Dr. Thomas Lawson at (502) 852-6922 or trlaws01@louisville.edu.

If you have any questions about your rights as a research subject, you may call the Human Subjects Protection Program Office at (502) 852-5188. You can discuss any questions about your rights as a research subject, in private, with a member of the Institutional Review Board (IRB). You may also call this number if you have other questions about the research, and you cannot reach the research staff, or want to talk to someone else. The IRB is an independent committee made up of people from the 
University community, staff of the institutions, as well as people from the community not connected with these institutions. The IRB has reviewed this research study.

If you have concerns or complaints about the research or research staff and you do not wish to give your name, you may call 1-877-852-1167. This is a 24 hour hot line answered by people who do not work at the University of Louisville.

Sincerely,

Dr. Thomas Lawson

Patricia Desrosiers, MSW, Ph.D. Candidate

\section{Rater Preamble}

\section{September 11, 2008}

\section{LEADERSHIP STYLES OF SOCIAL WORK EDUCATORS}

Dear Social Work Educator:

You are being invited to participate in a research study by answering the attached survey that asks questions about social work leadership practices in educational settings with one particular leader, your dean, director, or chair. There are no known risks for your participation in this research study. The information collected may not benefit you directly. The information learned in this study may be helpful to others. The information you provide will allow the researchers a more comprehensive view of social work leadership practices than could be achieved through the self-reports of the leaders only. Your completed survey will be stored at in the co Pls' locked office on password protected computers not accessible to general employees. The survey will take approximately 20 to 30 minutes to complete.

Individuals from the Department of Social Work, the Institutional Review Board (IRB), the Human Subjects Protection Program Office (HSPPO), and other regulatory agencies may inspect these records. In all other respects, however, the data will be held in confidence to the extent permitted by law. Should the data be published, your identity will not be disclosed. Neither you nor the raters will have access to completed survey results on an individual basis. In fact, once the surveys are matched by name and prior to data analysis, the survey data will be deidentified by assignment of matched numbers in place of the names. The two endorsers (Terry Singer, Dean of the Kent School of Social Work and Alberto Godenzi, President of the National Association of Directors and Deans) are not members of the research staff and will not have access to any individualized or aggregate raw data; they will only receive data analysis results in the aggregate form.

Taking part in this study is voluntary. By completing this survey you agree to take part in this research study. You do not have to answer any questions that make you uncomfortable. You may choose not to take part at all. If you decide to be in this study you may stop taking part at any time. If you decide not to be in this study or if you stop taking part at any time, you will not lose any benefits for which you may qualify. Employees or "Raters" are defined as direct reports of the deans and directors and may include administrative assistants, instructors, lecturers, part-time faculty, and full-time faculty who have worked with the leader for at least 6 months. If you do not meet these criteria, please do not answer this survey.

If you have any questions, concerns, or complaints about the research study, please contact: Dr. Thomas Lawson at (502) 852-6922. 
If you have any questions about your rights as a research subject, you may call the Human Subjects Protection Program Office at (502) 852-5188. You can discuss any questions about your rights as a research subject, in private, with a member of the Institutional Review Board (IRB). You may also call this number if you have other questions about the research, and you cannot reach the research staff, or want to talk to someone else. The IRB is an independent committee made up of people from the University community, staff of the institutions, as well as people from the community not connected with these institutions. The IRB has reviewed this research study.

If you have concerns or complaints about the research or research staff and you do not wish to give your name, you may call 1-877-852-1167. This is a 24 hour hot line answered by people who do not work at the University of Louisville.

Sincerely,

Dr. Thomas Lawson

Patricia Desrosiers, MSW, Doctoral Candidate 


\section{APPENDIX N}

\section{Demographic and Open-ended Questions for Leaders}

\section{Demographic Questions}

Please mark your age.

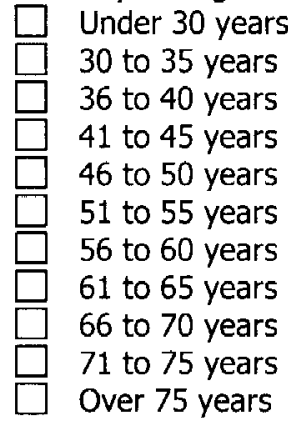

What is your gender?

Male

Female
What is the highest college degree you have earned?
Bachelors
Masters
Ph.D./DSW
Other

What discipline is your highest college degree?

\section{College or University Setting}

Please enter the number of years at your current college or university setting.

To what degree do you perceive that your college or university context impacts your leadership style?

$\square$ No impact at all on my leadership style

$\square$ Somewhat impacts my leadership style

$\square$ Regularly impacts my leadership style

Impacts my leadership style to a large degree

$\square$ Dictates my leadership style completely What size is the city in which your college or university is located? You may add a specific number in the other box of you choose.

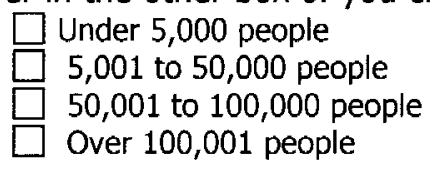

What is the total student enrollment of your college or university?

\footnotetext{
$\square$ Under 1,000 students 1,001 to 2,999 students 3,000 to 9,999 students Over 10,000 students
}

Please enter the total number of years you have worked in any college or university setting.

Please place your perception of your college or university's openness to change on the following continuum.

$\square$ Frowns on change; Completely traditional

$\square$ Easily frustrated with change plans

$\square$ Neutral towards change

$\square$ Sometimes experiments with new approaches

In a state of constant flux; Embraces change

Describe the type of college or university in which you work.

$\square$ Exclusively undergraduate

Combined undergraduate and graduate/professional $\square$ Exclusively graduate/professional Other

Please enter the name and email address of a contact person in your social work school or unit who will forward the employee survey to all appropriate employees. 
Please enter the state in which your college or university is located.

Please enter the total number of years you have served in your current administrative role in any college or university.

\section{Social Work School or Unit Setting}

Check the program level for all programs offered in your school.

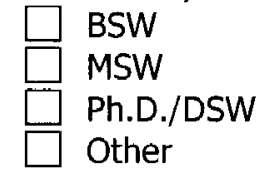

Please give the approximate number of faculty assigned to primary appointment in each part of your social work school/unit. Baccalaureate level faculty

Masters level faculty Ph.D./DSW level faculty Other

To what degree do you perceive that your social work school/unit context impacts your

leadership style?
$\square$ Reg degree
Please give your name.
Remember that your ratings are
confidential, and data will be
reported only in an aggregate
format. Also, your name will be
deleted from my database once
it is matched with two direct
reports evaluation of your
leadership style.

Somewhat impacts my leadership style

arly impacts my leadership style

$\square$ Impacts my leadership style to a large

$\square$ Dictates my leadership style completely
Please choose your job title.

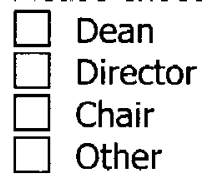

Please give the approximate number of students in each part of your social work school/unit.

Baccalaureate students

Masters students

Ph.D./DSW students

Other

Please enter the number of years at your current social work school/unit position.

Please enter the total number of years you have worked in any social work program setting.

Please place your perception of your social work school/unit's openness to change on the following continuum.

$\square$ Frowns on change; Completely traditional

$\square$ Easily frustrated with change plans

$\square$ Neutral towards change

$\square$ Sometimes experiments with new approaches

$\square$ In a state of constant flux; Embraces change 


\section{APPENDIX 0}

\section{MLQ 5X - Short Leader Form Sample Items}

1. I provide others with assistance in exchange for their efforts.

7. I am absent when needed.

14. I specify the importance of having a strong sense of purpose.

32. I suggest new ways of looking at how to complete assignments.

40. I am effective in representing others to higher authority. 


\section{APPENDIX P \\ MLQ 5X - Short Rater Form Sample Items}

1. Provides me with assistance in exchange for my efforts.

7. Is absent when needed:

14. Specifies the importance of having a strong sense of purpose.

32. Suggests new ways of looking at how to complete assignments.

40. Is effective in representing me to higher authority. 


\section{APPENDIX Q}

\section{Demographic and Open-ended Questions for Raters}

\section{Demographic Questions}

Please mark your age.

$\square$ Under 30 years

30 to 35 years

36 to 40 years

41 to 45 years

46 to 50 years

51 to 55 years

56 to 60 years

61 to 65 years

66 to 70 years

71 to 75 years

Over 75 years

What is your gender?

Male

Female
What is the highest college degree you have earned?

$$
\begin{aligned}
& \square \text { Bachelors } \\
& \square \text { Masters } \\
& \square \text { Ph.D./DSW } \\
& \square \text { Other }
\end{aligned}
$$

What discipline is your highest college degree?

\section{College or University Setting}

Please enter the number of years at your current position.

Please enter the state in which your college or university is located.

Please enter the number of months you have known the leader you are rating. You must have known them for at least 6 months to rate this leader.

Name the Leader you are rating. Remember that your ratings are confidential, and data will be reported in an aggregate format only. If you prefer anonymity, please complete the online survey at the above address.
Please enter the total number of years you have worked in any college or university setting.

Please enter the number of years at your current university or college setting. 


\section{APPENDIX R}

\section{ROLE Scale Sample Items}

1. We continually expand our capacity to create the results we truly desire.

4. We continually learn how to learn together.

11. Team learning IS NOT important.

14. We often experiment with new approaches.

19. We are tired of change. 


\section{APPENDIX $\$$}

IRB APPROVAL EMAIL

Print View

Page 1 of 1

From: <InstitutionalReviewBoard@louisville.edu>

To: <trlawso1@gwise.louisville.edu>, <pldesro1 @gwise.louisville.edu>

CC: <pldesro1@gwise.louisville.edu>

Date: Wednesday - October 1, 2008 2:26 PM

Subject: BRAAN2: New IRB Protocol Approved

The following new IRB Protocol has been approved.

Tracking \#: 08.0427

PI: Lawson, Thomas

Title: The Leadership Styles of Social Work Educators

Approval Date: 10/1/2008 12:00:00 AM

Expiration Date: 9/30/2009 12:00:00 AM

Link to BRAAN2 Login <https://braanprod.louisville.edu/> Help is available at the BRAAN2 Help Site

<http://louisville.edu/research/braan2>

For additional assistance please call the Human Subjects Protection

Program at 502-852-5188. 


\section{Permission to Use MLQ 5x-Short}

For use by Patricia Desrosiers only. Received from Mind Garden, Inc. on Iune 11,2008

\section{mind garden}

\section{wWw.mindgarden.com}

To whom it may concerm,

This letter is to grant permission for the above named person to use the following copyright material:

Instrument: Multifactor Leadership Questionnaire

Authors: Bruce Avolio and Bernard Bass

Copyright: 1995 by Bruce Avolio and Bernard Bass

for his/her thesis research.

Five sample items from this instrument may be reproduced for inclusion in a proposal, thesis, or dissertation.

The entire instrument may not be included or reproduced at any time in any other published material.

Sincerely,

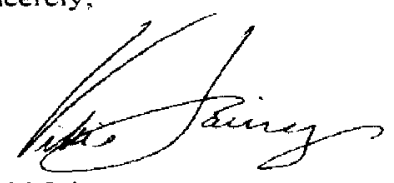

Vicki Jaimez

Mind Garden, Inc.

www.mindgarden.com

MLQ. 1995 Bruce Avolio and Bernard Bass. Alt Rights Reserved.

Published by Mind Garden, Inc., whw. Mindqarden.com 


\section{CURRICULUM VITA}

NAME:

Patricia Louise Desrosiers

ADDRESS:

5225 Jack Hinton Road

Philpot, KY 42366

DOB:

Charleston, West Virginia - July 11, 1969

EDUCATION

\& TRAINING:

B.A., Counseling Psychology

Kentucky Wesleyan College

1990-92

M.S.W.

University of Southern Indiana

1999-2001

Licensed Clinical Social Worker in KY

8/15/04-present

AWARDS: $\quad$ Stand for Children Case Management Award 1997

PROFESSIONAL SOCIETIES:

Council on Social Work Education Society for Social Work Research National Association of Social Workers American Association of University Women

NATIONAL MEETING

PRESENTATIONS:

Desrosiers, P. (2008, October). Leadership in social work educational administration. Paper presented at the Annual Program Meeting of the Council on Social Work Education, Philadelphia, PA.

Desrosiers, P. (2009, November). Leadership in social work. Paper presented at the Annual Program Meeting of the Council on Social Work Education, SanAntonio, TX.

REFEREED JOURNALS: None

BOOKS AND SYMPOSIA: None

INVITED PRESENTATIONS: None

PUBLICATIONS: None 